\title{
CHARACTERIZATION OF SECONDARY METABOLITES PRODUCED BY FOLIAR ENDOPHYTES OF RED AND BLACK SPRUCE
}

by

Blake Donald Green

A thesis submitted to the Faculty of Graduate and Postdoctoral Affairs in partial fulfillment of the requirements for a degree of

Master of Science

in

Chemistry with a Specialization in Chemical and Environmental Toxicology

Carleton University

Ottawa, Ontario

(C) 2016

Blake Donald Green 


\begin{abstract}
Eastern spruce budworm (Choristoneura fumiferana) is a cyclic pest responsible for widespread defoliation of conifer trees in the Acadian forest. During epidemics, affected forestry areas are vast, making insecticidal protection impractical. Research has shown endophytes produce toxins in planta at effective concentrations that deter spruce budworm herbivory. Red and black spruce endophytes were studied here. Five isocoumarins (1-5) were isolated from Phaeocryptopus cf. gaeumannii, where compound (1) is a new structure. Two new pyrones $(\mathbf{6}, \mathbf{7})$, two phthalides $(\mathbf{8}$, 9), two isocoumarins $(\mathbf{1 0}, \mathbf{1 1})$ and tyrosol $(\mathbf{1 2})$ were isolated from an undescribed Rhytismatales species. Phomopsolides A-C (13-15) were isolated from a newly described fungal endophyte, Diaporthe maritima. Cryptosporiopsin (16), 5-hydroxy cryptosporiopsin (17), cryptosporiopsinol (18) and mellein (19) were produced by Pezicula sporulosa. A majority of these compounds possessed antibacterial (Bacillus subtilis, Escherichia coli) and/or antifungal activity (Saccharomyces cerevisiae, Microbotryum violaceum).
\end{abstract}




\section{Acknowledgements}

I would like to give primary thanks to Dr. David Miller for all the years of learning and support. It seems strange now to think back to the summer of 2010 when I was becoming an "expert" at making polyacrylamide gels. Although I said it in my undergraduate thesis it still remains true: thank you for encouraging me to work on my weaknesses. On a serious note, a saying I really admire and know that I will hold with me is that "there is always more hours in the day".

Thank you Dr. David McMullin for all the tough love. I feel I got to experience a phase where we both were forced to mature in our own way, which brings a smile to my face. With that said, we should probably stop getting pizza for lunch.

I would also like to thank Joey Tanney for quickly and thoroughly answering all of the phylogenetic questions I had along the way.

Final thanks to Monica Gill for the emotional support, Elisa Mantil for the walks around campus, Grace Daly and Trinda Crippin for the fun times gardening, Kimberlynn MacDonald for all the help with rugulosin, Natasha Prince for nominating me as lab DJ and Emma Groulx for confirming that I am not the only person who talks to themselves. 


\section{Table of Contents}

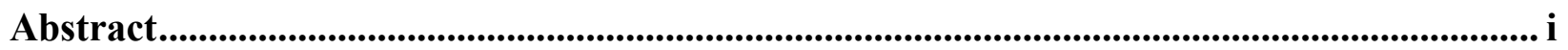

Acknowledgements ............................................................................................................................. ii

List of Figures.......................................................................................................................... iv

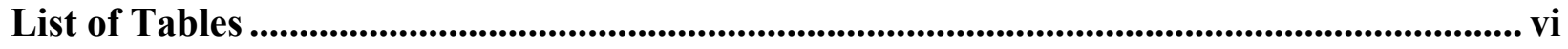

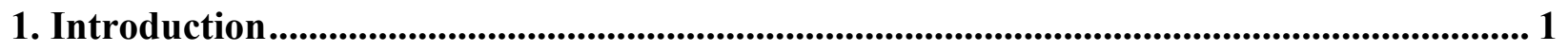

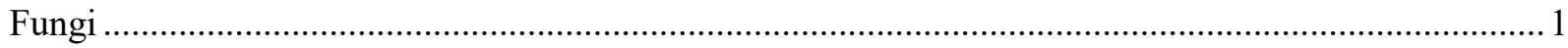

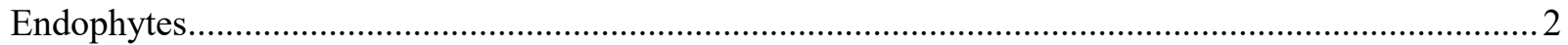

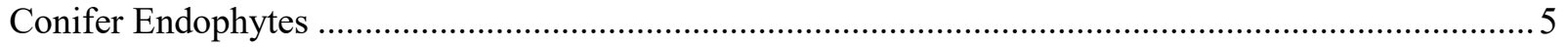

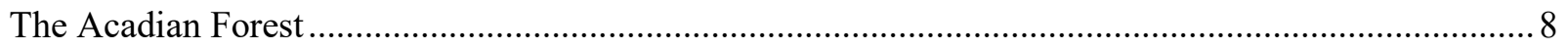

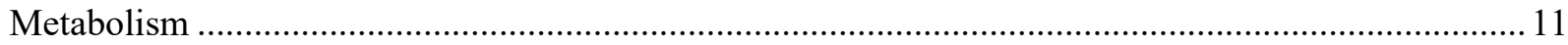

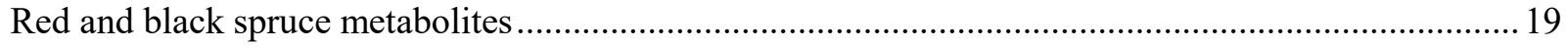

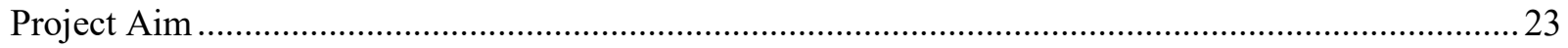

2. Materials and Methods.............................................................................................................. 24

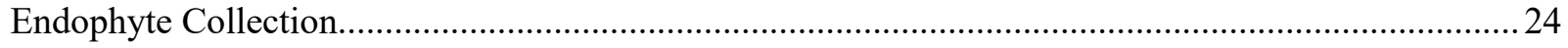

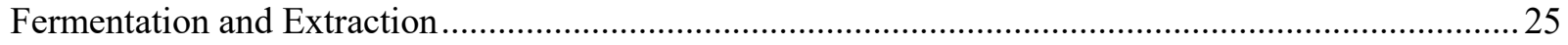

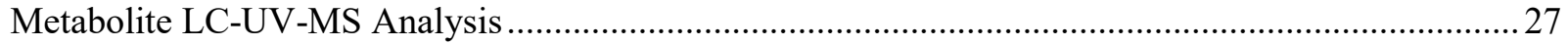

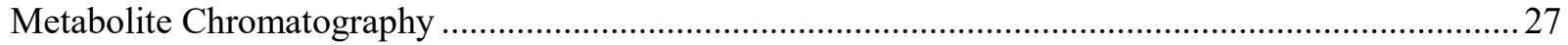

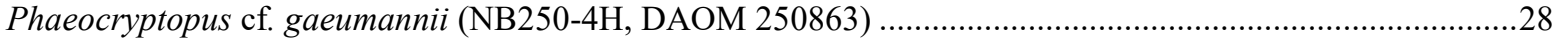

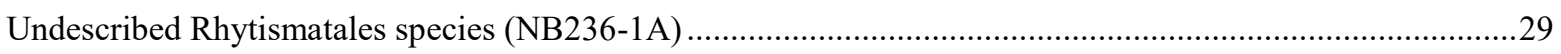

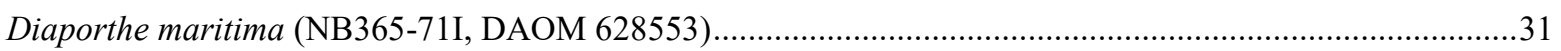

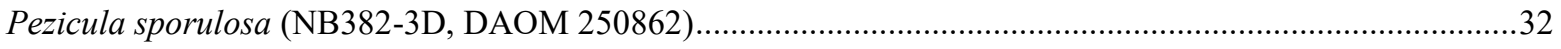

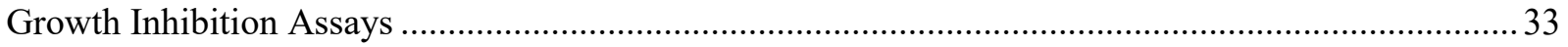

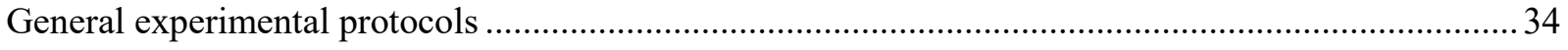

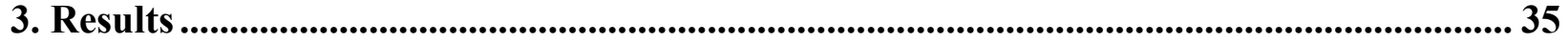

Metabolites of an Undescribed Rhytismatales species (NB236-1A) .................................................. 41

Metabolites of Diaporthe maritima (NB365-71I, DAOM 628553) ……...........................................53

Metabolites of Pezicula sporulosa (NB382-3D, DAOM 250862) ……............................................57

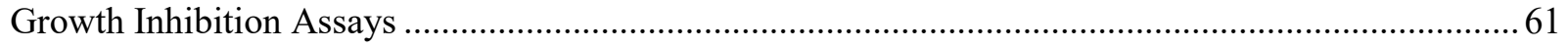

4. Discussion........................................................................................................................................6 67

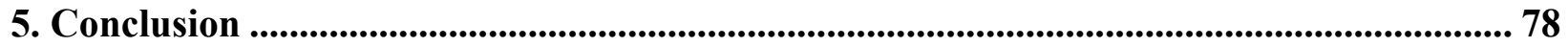

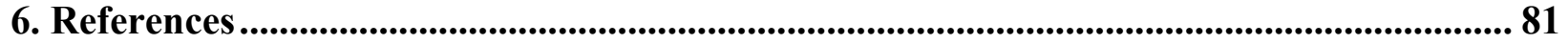

Appendix I $-{ }^{1} \mathrm{H}$ and ${ }^{13} \mathrm{C}$ NMR spectra of isolated endophyte metabolites ............................ 90

Appendix II - Strain, host, collection site and preliminary antifungal screening results .. 108 


\section{List of Figures}

Figure 1.1: Image of an endophyte growing out of a surface-sterilized needle. 2

$\begin{array}{ll}\text { Figure 1.2: Chemical structure of rugulosin produced by P. scopiformis. } & 7\end{array}$

Figure 1.3: Spruce budworm (C. fumiferana) larvae defoliating conifer needles. 9

Figure 1.4: The primary metabolite origins of the secondary metabolite classes (adapted from Dewick, 1997).

Figure 1.5: Acetate pathway illustrating polyketide biosynthesis (adapted from Deacon, 2005). 15

Figure 1.6: Chemical structures of the macrolides pyrenophorol and vermiculine.

Figure 1.7: Overview of acetyl-CoA being converted into terpene core by the mevalonate pathway (adapted from Keller et al., 2005).

Figure 1.8: Chemical structures of heptelidic acid (HA), HA chlorohydrins and hydro-HA, and two diterpenoids toxic to spruce budworm larvae from balsam fir.

Figure 1.9: Shikimic pathway showing biosynthesis of aromatic amino acids and subsequent secondary metabolite families (adapted from Herrmann, 1995).

Figure 1.10: Structures of ergonovine and peramine alkaloids produced by grass endophytes. 21

Figure 1.11: Structures secondary metabolites characterized from three red spruce endophyte strains of the Acadian forest.

Figure 1.12: Chemical structures isocoumarins produced by a foliar endophyte of black spruce.

Figure 2.1: Flow chart illustrating the screening process used to select four endophyte species for secondary metabolites investigations.

Figure 2.2: Phaeocryptopus cf. gaeumannii (DAOM 250863) growing on a 2\% MEA.

Figure 2.3: HPLC separation outlining major metabolites produced by DAOM $250863(254 \mathrm{~nm})$.

Figure 2.4: Undescribed Rhytismatales species growing on a 2\% MEA.

Figure 2.5: Diaporthe maritima (DAOM 628553) growing on a red spruce twig (A), magnified to show pycnidia protruding through the plant tissue (B) and the conidiophores producing conidia $(\mathbf{C})$. 
Figure 3.1: Structures of isocoumarins (1-5) isolated from Phaeocryptopus

cf. gaeumannii (DAOM 250863).

Figure 3.2: Key HMBC and COSY correlations observed for compound 1.

Figure 3.3: Structures of rhytismatones A (6) and B (7) isolated from the unidentified Rhytismatales sp.

Figure 3.4: Key HMBC and COSY correlations observed for compound 7. 44

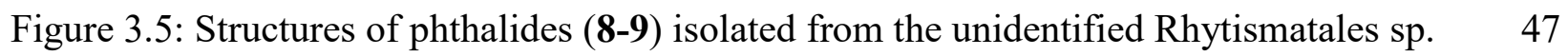

Figure 3.6: Structures of isocoumarins (10-11) isolated from Rhytismatales sp. 49

Figure 3.7: Structure of tyrosol (12) isolated from an undescribed Rhytismatales sp. 53

Figure 3.8: Structure of phomopsolides A-C (13-15) isolated from D. maritima

DAOM 628553.

Figure 3.9: Structure of cryptosporiopsin related metabolites (16-18) and

(R)-mellein (19) isolated from DAOM 250862.

Figure 3.10: Secondary metabolites (1-19) characterized from foliar endophytes as part of this thesis. 


\section{List of Tables}

Table 3.1: ${ }^{1} \mathrm{H}$ and ${ }^{13} \mathrm{C}$ NMR data of isocoumarins 1-5 in $\mathrm{CD}_{3} \mathrm{OD}$. 40

Table 3.2: Physicochemical data for isocoumarin compounds 1-5. 41

Table 3.3: ${ }^{1} \mathrm{H}$ and ${ }^{13} \mathrm{C}$ NMR data of compounds 6-7 in $\mathrm{CD}_{3} \mathrm{OD}$. 45

Table 3.4: Physicochemical data for rhytismatones A and B (6-7). 46

Table 3.5: ${ }^{1} \mathrm{H}$ and ${ }^{13} \mathrm{C}$ NMR data for phthalides 8 and 9 in $\mathrm{CD}_{3} \mathrm{OD}$. 48

Table 3.6: Physicochemical data for phthalide metabolites (8-9). 48

Table 3.7: ${ }^{1} \mathrm{H}$ and ${ }^{13} \mathrm{C}$ NMR data for isocoumarins 10-11 in $\mathrm{CD}_{3} \mathrm{OD}$. 51

Table 3.8: Physicochemical properties of isocoumarins (10-11). 52

Table 3.9: ${ }^{1} \mathrm{H}$ and ${ }^{13} \mathrm{C}$ NMR data for phomopsolides A-C (13-15) in $\mathrm{CD}_{3} \mathrm{OD}$. 56

Table 3.10: Physicochemical properties of phomopsolides A-C (13-15). 57

Table 3.11: ${ }^{1} \mathrm{H}$ and ${ }^{13} \mathrm{C}$ NMR data for cryptosporiopsin related metabolites 16-18 in $\mathrm{CD}_{3} \mathrm{OD} . \quad 60$

Table 3.12: Physicochemical properties of compounds 16-18. 61

Table 3.13: Antibacterial activity of isolated metabolites towards E. coli $(p \leq 0.05)$. 63

Table 3.14: Antibacterial activity of isolated metabolites towards B. subtilis $(p \leq 0.05)$.

Table 3.15: Antifungal activity of isolated metabolites towards $S$. cerevisiae $(p \leq 0.05) . \quad 65$

Table 3.16: Antifungal activity of isolated metabolites towards M. violaceum $(p \leq 0.05) . \quad 66$ 


\section{Introduction}

\section{Fungi}

The fungal kingdom is comprised of a highly diverse group of unicellular and multicellular eukaryotic organisms. Fungi are heterotrophic and present in all inhabitable environmental niches worldwide as they can metabolize many forms of organic matter (Ferreira et al., 2006). Some fungi are saprophytes that live on decaying organic matter and in doing so provide the essential ecological function of nutrient recycling. Other fungi are parasitic or pathogenic and are responsible for many diseases observed in plants and animals. The last group of fungi are known as endophytes as they colonize the inside of plants without causing apparent damage (Figure 1.1). Endophytes are not limited to fungi as plants also associate with algae and bacteria, but the term endophyte used hereafter will refer to fungal endophytes. Endophytes have been found within all plants studied to date, but their existence and ecological importance have largely been overlooked until recently (Petrini, 1991; Arnold \& Lutzoni, 2007). To date, only ca. 35,000 endophytes have been studied and an estimated 465,000 remain undescribed (Schmit \& Mueller, 2007; Sieber, 2007).

The identification of fungi is often difficult meaning multiple approaches are necessary. Taxonomists typically combine the use of traditional and molecular methods. Traditional methods involve varying culturing conditions (e.g. $\mathrm{pH}$, water activity, nutrient sources) to elicit distinguishable morphological features (Schmidt \& Lodge, 2004). With molecular methods, the internal transcribed spacer (ITS) region between the small and large ribosomal RNA subunit genes is sequenced and compared to available databases. In fungi, this ITS sequence is commonly 
referred to as the universal barcode and customary for fungal identifications at the species level (Scholch et al., 2012). The main limitation with molecular methods is the need for alpha taxonomy and a reliable reference sequences. With the vast number of undescribed endophytes, it is often difficult to find meaningful matches in currently available databases. Another interesting approach that can be a helpful addition to traditional and molecular methods is to compare and contrast the metabolite and lipid profiles of fungi (Boysen et al., 2000; Dörge et al., 2000). This approach is most useful when trying to distinguish between similar fungi as the presence of diverse metabolites or lipids profiles corresponds to different genes or gene expressions.

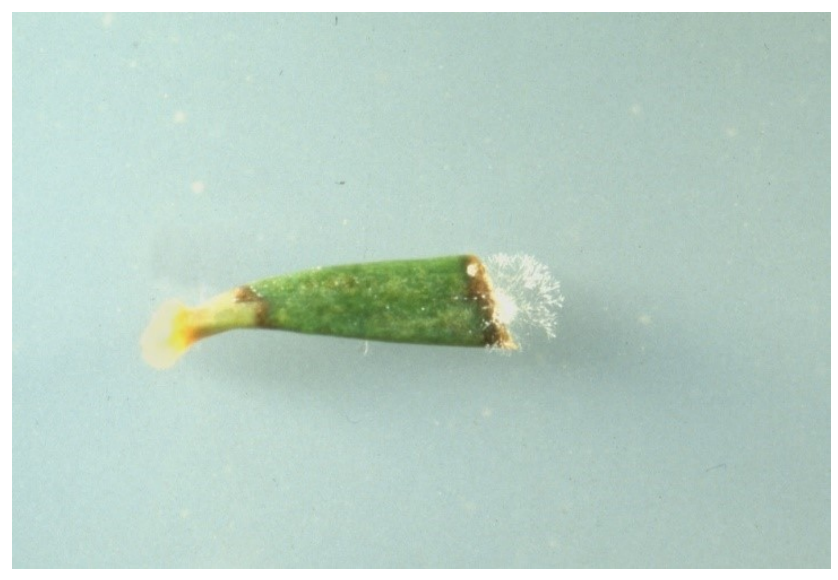

Figure 1.1: Image of an endophyte growing out of a surface-sterilized needle.

\section{Endophytes}

There have been two major driving forces behind the extensive research into these cryptic fungal species. Since the discovery of penicillin, fungi have been extensively investigated as a source of bioactive compounds as their diverse nature translates to the production of metabolites with an array of chemical complexity and diversity. For example, a review article from 2005 illustrated the antibacterial, antifungal or antitumor activity of 1,500 compounds that have been isolated 
between 1993 and 2001 (Pelaez, 2005).

The other important driver is understanding plant-endophyte interactions and the influence of this interaction on ecosystems. Endophytes are classified into three groups: mycorrhizal endophytes associated with plant roots, clavicipitaceous endophytes that colonize grasses and nonclavicipitaceous endophytes. The current plant-endophyte interaction model is based on grass endophytes since they have been the most extensively studied due to their agricultural impact (Rodriguez et al., 2009). Multiple studies have shown grass endophytes conferring various benefits to their grass host in exchange for protection and dispersion. Observations of decreased food intake, weight loss and gangrenous extremities in cattle grazing on cool season fescues have been linked to neurotoxic ergot alkaloids and indole diterpenes produced by grass endophytes (Bacon et al., 1977; Mortimer et al., 1982). Reduced insect herbivory in agronomically-relevant fescues have been linked to grass endophytes producing pyrrolopyrazine and pyrroizidine alkaloids (Bush et al., 1997; Clay \& Schardl, 2002). Clay (1997) demonstrated that grass endophytes produce metabolites that stimulate germination and increase biomass production of field fescues by $30 \%$. The seaweed endophyte, Mycosphaerella ascophylli, has been shown to increase the drought tolerance of the intertidal species Ascophyllum nodosum (Garbary \& London, 1995; Garbary, 2009). Overall, grass endophytes have been widely shown to increase host tolerance to abiotic and biotic stresses. In return, grass endophytes infect all above-ground tissues of their host to propagate the next generation via the host seed (vertical transmission). The production of fungal metabolites that deter herbivory, promote growth and increase host tolerance of the plant host, in exchange for dispersal represents a plant-endophyte mutualistic relationship. 
The relationship (mutualism, commensalism or parasitism) of endophytes in non-clavicipitaceous plants is not as clearly defined. For instance, a meta-analysis of 157 primary publications was able to statistically show the defensive mutualistic role grass endophytes play in deterring herbivory, but was unable to show this association with non-claviceptaceous endophytes (Saikkonen et al., 2010). In the late Carboniferous period 300 million years ago, angiosperms came into existence by diverging from gymnosperms (Sieber, 2007). This divergence coincided with the divergence of the Helotialean and Diaporthalean taxonomic orders of fungi. Presently, the leaf tissues of angiosperms and gymnosperms is dominantly colonized by Diaporthalean and Helotialean endophyte species, respectively. This suggests that plant-endophyte interactions co-evolved over millions of years, in which the lack of associated disease suggests this relationship to be either mutualism, commensalism or low-virulence parasitism (Sieber, 2007). However, the number of scientific studies is still too limited to clearly detail the symbiosis between endophytes and nonclavicipitaceous plants or why the relationship started.

The current theory is centralized around the lifespan of plants being longer compared to common pests and pathogens that attack them (Miller, 1986). This concept is highlighted in woody plants, such as conifers, as their long lifespans result in slower gene mutations/evolutionary adaptations. Additionally, woody plants are attacked by a variety of animal and insect herbivores as well as fungal pathogens due to their long lifespan. As such, woody plants tend to produce a high abundance of generalized secondary metabolites to ward off a variety of pests and pathogens (Miller, 1986). As expected, this results in weaknesses in their natural defenses. For instance, balsam fir (Abies balsamea) produce an array of terpene metabolites predominately in their needles, in which the abundance of these terpenes increases with age (Hunt $\&$ Rudloff, 1977). 
These terpenes have been shown to mitigate fungal pathogens but are ineffective towards insects such as the Eastern spruce budworm (Choristoneura fumiferana), which prefer feeding on young needles (Miller, 1986). It is believed that non-clavicipitaceous plants have overcome this evolutionary limitation by developing mechanisms that allow endophytes to live within their foliage while preventing endophyte biomass from increasing. As the life span of endophytes is much shorter than woody trees, they are able to mutate at a much faster rate. This means faster evolution to selective pressures, such as insects that have been shown to have fungal endophytes in their digestive systems. Taken together, endophytes will develop the genes to produce secondary metabolites targeting their natural predators faster than plants and trees take advantage of this feature by allowing endophytes to live within their foliage (Miller, 1986).

\section{Conifer Endophytes}

Research into the foliar endophytes of coniferous trees was initially pursued following the suggestion by Carroll \& Carroll (1978) that the needle endophyte Rhabdocline parkeri was improving the tolerance of Douglas fir (Pseudotsuga menziesii) towards the gall forming needle pest called gall midges (family Cecidomyidae). Douglas-fir trees showing infection of the needle endophyte $R$. parkeri were able to increase the mortality of gall midge larvae (Sherwood-Pike et al., 1986; Carroll, 1986). Miller (1986) showed that fungal extracts of R. parkeri slowed the growth rate and increased the mortality rate of spruce budworm larvae when introduced into a synthetic diet. This discovery lead to the postulation that conifer endophytes improve the fitness of their host by producing an array of anti-feedants to deter insect herbivory. This possibility was highlighted in the monograph published on the population dynamics of spruce budworm in New Brunswick (NB) between 1945 and 1983 (Royama, 1984). Eastern spruce budworm is a cyclical 
pest responsible for large scale mortalities in the Acadian forests of Eastern Canada and Maine. While modeling the population dynamics of the spruce budworm, Royama described five mortality factors: parasitism, predation, food shortage, weather and an unknown fifth agent. His prediction of an unknown factor arose from unclear population oscillations occurring in late stage larvae that could not be completely explained by parasitism. Extensive research has been performed under the hypothesis that toxigenic endophytes are the fifth agent.

Over the past 25 years, endophytes have been collected from various conifers in the Acadian forest in order to better define the number of toxigenic endophyte genotypes present in the region (Miller, 2011). During the initial sampling of balsam fir (Abies balsamea), red spruce (Picea rubens), white spruce ( $P$. glauca) and black spruce (P. mariana), it was observed that the proportion of endophytes with toxigenic properties was extremely low ( $\sim 5 \%$; Johnson and Whitney, 1989; Wilson et al., 1994; Miller et al., 2002). Another observation was that approximately $20 \%$ of the toxigenic strains originating from NB in the first collections produced rugulosin (Figure 1.2), which was known to have broad spectrum biological activity (Miller et al., 2002). Growth chamber tests showed spruce budworm larvae feeding on detached white spruce needles colonized by the rugulosin producing endophyte Phialocephala scopiformis had significantly reduced growth in comparison to the un-inoculated control needles. In growth chambers and in field tests white spruce saplings inoculated with P. scopiformis continued to produce rugulosin above the effective toxin level of $0.5 \mu \mathrm{g} \mathrm{g}^{-1}$, which was shown by the reduction in spruce budworm growth (Miller et al., 2002, 2008). 


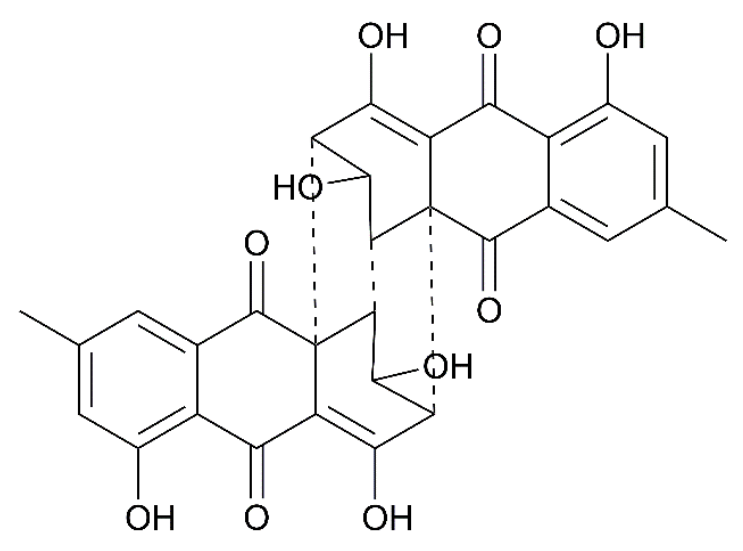

Figure 1.2: Chemical structure of rugulosin produced by $P$. scopiformis.

During these studies, nursery seedlings intended for reforestation were observed to lack diverse endophyte communities (Miller et al., 2002; Sumarah et al., 2008a). In a field test, un-inoculated woody plants (balsam fir and red, black and white spruce) were placed two meters around a white spruce tree that had been inoculated with the endophyte $P$. scopiformis. After 3 years, $P$. scopiformis was detectable by enzyme linked immunosorbent assay (ELISA) in only the white spruce saplings that surrounded the test tree (Miller et al., 2009). Contrasting to grass endophytes, this discovery contributed to the sparse data suggesting non-clavicipitaceous endophytes transmit horizontally rather than vertically (Miller et al., 2009; Miller, 2011). It also demonstrated that $P$. scopiformis had host specificity towards white spruce (Miller et al., 2009). This discovery of horizontal transmission helped explain the reduced endophyte diversity observed in tree stands that have been reforested/afforested artificially or naturally following a deforestation event (fire, forestry; Petrini, 1991; Miller, 2011). This work emphasizes the importance of understanding endophyte diversity and ecological function in relation to maintaining endophyte diversity during reforestation efforts and improving the fitness of tree plantations to common pests and pathogens. 


\section{The Acadian Forest}

The Acadian forest region covers the majority of Maine and the three Maritime Provinces as well as parts of eastern Quebec and New England. This forest region is uniquely high in biological diversity as it is located where the warm and humid Southern Gulf Stream hits the cold Labrador Current (Loo \& Ives, 2003). The forest region is comprised primarily of red, black and white spruce, balsam fir, yellow birch and sugar maple but also contains red pine, Eastern white pine, eastern hemlock and beech (Miller, 2011). Analyses of the forest structure over long time scales have identified small changes due to tree diseases and forest fires but attributes most of the alterations to early European settlers and the cyclical pest C. fumiferana (Figure 1.3; Loo \& Ives, 2003). In the 1600 s, early settler's extensively harvested pine to build establishments to the point where pine stands today are estimated to span half the area they previously covered (Lorimer, 2008).

Spruce budworm outbreaks have been document since as early as 8240 before present (BP) through macrofossil analysis of spruce tree cores obtained from an 8,600 year old bog in Eastern Quebec (Miller, 2011). Since 1760, there has been six documented outbreaks of spruce budworm in New Brunswick (Forbes et al., 1998). Since the 1900s, these outbreaks have increased in intensity and frequency (Loo \& Ives, 2003). For context, it is believed that prior to the 1900s spruce budworm outbreaks occurred every 42 to 72 years, yet the documented outbreaks since the 1900 s have occurred every 19 to 34 years (Blais, 1983). At the peak of the last outbreak, 50 million hectares of coniferous forests were defoliated (Natural Resources Canada, 2016). To mitigate this widespread damage, chemical pesticides were sprayed over 4 million hectares, totaling a cost of ca. 200 million dollars (Irland, 1980; Sumarah \& Miller, 2009). Since then, these chemical 
pesticides have been deregistered due to environmental and safety concerns (MacLean et al., 2002).

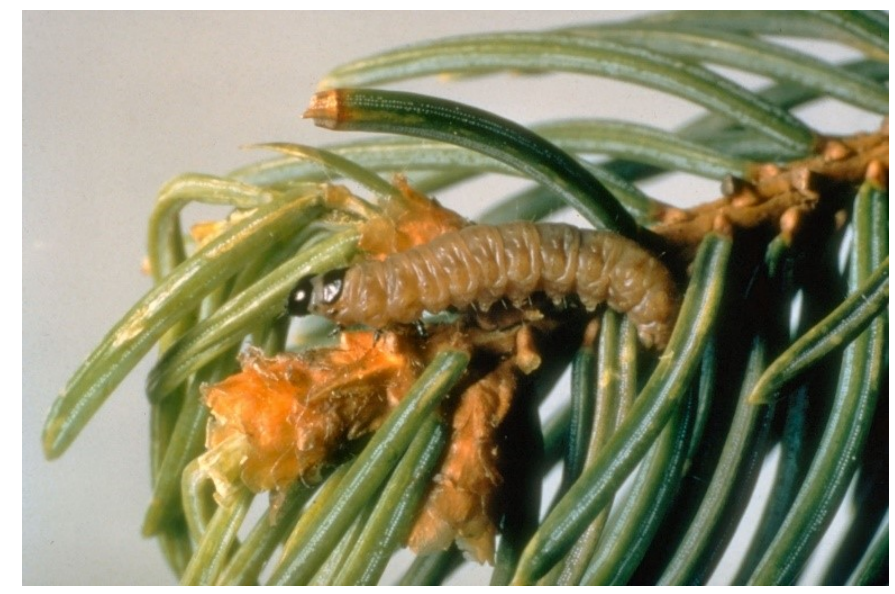

Figure 1.3: Spruce budworm (C. fumiferana) larvae defoliating conifer needles.

Through this extensive damage, spruce budworm has changed the populations of coniferous tree species of the Acadian forest. A study by Hennigar et al. (2008) analyzed the differences in spruce budworm defoliation in balsam fir and red, white and black spruce. Between 1984 and 1992, they measured defoliation in 136 tree stands that possessed a range of the following variables: species composition, stand maturity, foliage protection and net defoliation change from the previous year's measurement. Doing so ensured their results accounted for external factors. For instance, insecticides used for foliage protection work more efficiently on balsam fir than on spruce trees (Lysyk, 1990). This is because spruce foliage is denser, which prevents the insecticide droplets from penetrating into the inner foliage layers (Lysyk, 1990). As such, protected stands will overstate the amount of spruce defoliation in comparison to balsam fir defoliation. At the end of this long term study Hennigar et al. (2008) found that balsam fir was most susceptible to budworm defoliation and that white, red and black spruce had $c a .70,40$ and $30 \%$ as much defoliation, 
respectively, in comparison. They attributed these differences to when these tree types begin to grow new leaves (budburst) and how this coincides with budworm larvae development (Hennigar et al., 2008). In red and black spruce, budburst occurs 13 days later compared to balsam fir. This is too late for spruce budworm larvae that are in early instar stages and looking for foliage to consume. This results in higher larval mortality and reduced defoliation of red and black spruce. In white spruce, budburst occurs only 4 days after balsam fir budburst, which is not long enough to cause extensive larvae mortality. Instead the difference in defoliation were attributed to white spruce ability to grow larger shoots at a faster rate and having more overall foliage per unit area than balsam fir (Hennigar et al., 2008). This translates to there being less defoliation on white spruce as they are combating the damage by growing faster than balsam fir. These findings are crucial to mitigating future spruce budworm deforestation events as they highlight that the damage will be more severe in stands with higher percentages of balsam fir and white spruce. This will permit more directed insecticidal foliage protection approaches.

In an effort to combat the extensive budworm deforestation, over 900 million conifers have been planted over the past 60 years (Miller, 2011). However, analyses have shown no major change in the percentage of hardwood in the Acadian forest during this period (Etheridge et al., 2005, 2006; Amos-Binks et al., 2010). The cyclical damage caused by spruce budworm indicates there is a pressing need to improve the fitness of our coniferous forests as the affected area is too expansive to utilize pesticides and pruning techniques. As exemplified by the antifeedant properties of the rugulosin producing endophyte ( $P$. scopiformis) of white spruce, endophytes may be a viable option in mitigating forest damage. However, inoculating trees intended for reforestation with only one toxigenic endophyte is insufficient as it limits forest endophyte diversity, and spruce budworm 
could develop tolerance. This project is an example of a continuing effort to discover more endophytes producing biologically active secondary metabolites that serve an important ecological function.

\section{Metabolism}

Primary metabolism is essential for the survival and reproduction of all organisms involving the breakdown of nutrients from the environment into energy. Organisms use primary metabolic machinery and pathways (glycolysis, Krebs cycle, fatty and nucleic acid metabolism) to convert the stored potential energy present in complex macromolecules into useable chemical potential energy in the form of adenosine triphosphate (ATP). Organisms subsequently utilize ATP to fuel unfavorable cellular processes that are necessary for growth and proliferation. The intermediary and end products generated during these catabolic processes are known as primary metabolites. Although there is an extensive chemical diversity of secondary metabolites, most originate from the primary metabolites acetyl-CoA, mevalonate and shikimic acid (Figure 1.4; Manitto, 1981). Acetyl-CoA is the starting material for oxidative respiration via the Kreb cycle. Due to its importance it can be generated by multiple resource pathways. For instance, simple sugars are catabolized into pyruvate by glycolysis, which can be oxidatively decarboxylated into acetyl-CoA. Acetyl-CoA can also be generated by the beta-hydroxylation of fatty acids or through the deamination and oxidation of amino acids.

In secondary metabolism, acetyl-CoA is utilized by the acetate pathway to generate a diverse family of secondary metabolites known as polyketides (Manitto, 1981). Alternatively, three acetylCoAs can be condensed together and subsequently reduced to generate mevalonate. Mevalonate 
is used by the mevalonate pathway to produce a diverse family of secondary metabolites known as terpenes (Manitto, 1981). The last major primary metabolite used in secondary metabolism is shikimic acid. It is formed from combining the phosphoenolpruvate intermediate of glycolysis with the erythrose-4-phosphate intermediate of the pentose phosphate cycle (Haslam, 1974). Shikimic acid is then used in the shikimate pathway to generate the aromatic amino acids (tyrosine, tryptophan and phenylalanine). Subsequent modifications then convert these aromatic amino acids into various families of secondary metabolites such as alkaloids, lignans and cinnamic acid derivatives (Haslam, 1974; Dewick, 1997).

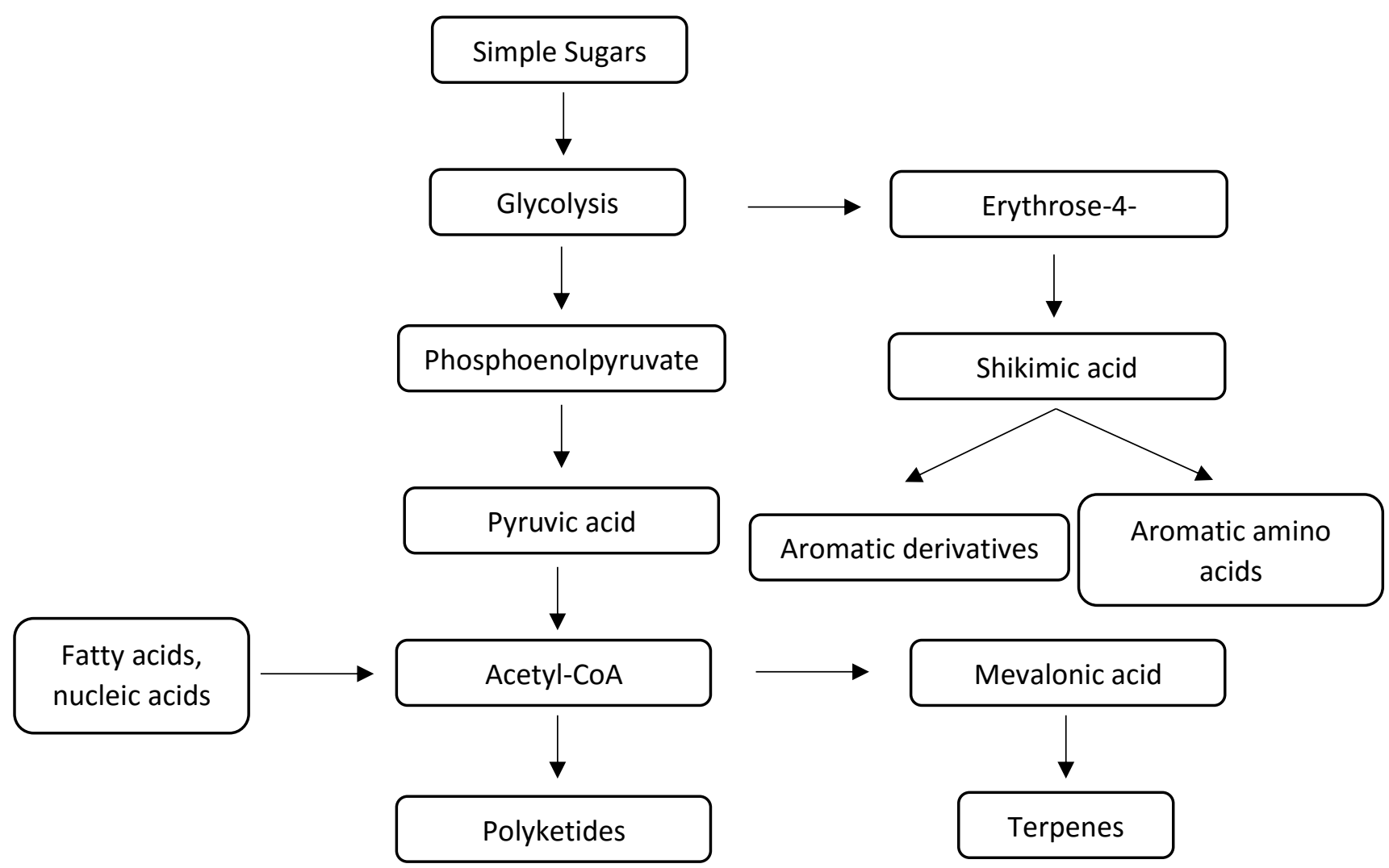

Figure 1.4: The primary metabolite origins of the secondary metabolite classes (adapted from Dewick, 1997). 
Secondary metabolism is not essential for the growth or survival of the Ascomycete fungi previously discussed here since it yields no usable energy. Producing secondary metabolites is energetically demanding. When essential nutrients are abundant, organisms produce minimal amounts of secondary metabolites (Wicklow, 1981). Instead, all available resources are used for growth and proliferation in order to colonize nutrient sources. This is considered a type of competition as colonizing the available space prevents other organism from getting a foothold. A classic example of this is shown in barnacles in the intertidal regions of Scotland. With Chthamalus barnacles growing up on in the rocky areas and Balanus barnacles down by the shore. Connell (1961) removed the Balanus barnacles and observed Chthamalus barnacles were able to grow down by the shore. Yet, when Connell (1961) reintroduced the Balanus barnacles, the Chthamalus barnacles were overcrowded and eventually receded back up to the rocks where Balanus barnacles could not grow due to desiccation.

Similar to excluding an organism by occupying the available space, secondary metabolites are believed to ward off competition as many have been found to be biologically potent (e.g. antibacterial, antifungal, antiinsectan; Pelaez, 2005). Organisms capable of producing secondary metabolites increase their production when essential nutrients such as carbon, nitrogen and phosphorous become scarce in the environment (Wicklow, 1981). It is believed that by forgoing some energy to create secondary metabolites, organisms are able to monopolize the remaining nutrient source by warding off competitors.

Although secondary metabolites arise from few primary metabolites, there is enormous chemical diversity due to the range of modifications that are performed. As these modifications are catalyzed 
by numerous enzymes, organisms will produce unique profiles of secondary metabolites as they possess different sets of biosynthetic genes, often organized into clusters (Hoffmeister \& Keller, 2007). This is why genetically diverse tree-endophytes are a potential untapped trove of novel, biologically active secondary metabolites (Miller, 1986).

Polyketides are a major class of secondary metabolites that originate from the acetate pathway mentioned above. This pathway has a high degree of similarity to fatty acid biosynthesis as both operate by sequential additions of $\mathrm{C}_{2}$ units (Manitto, 1981). However, rather than adding $\mathrm{CH}_{2}$ subunits, the acetate pathway sequentially adds acetyl subunits $\left(\mathrm{CO}-\mathrm{CH}_{2}\right)$ to form a polyketide chain (Figure 1.5). In fungi, this addition is limited to one module as fungi elongate the polyketide chain using type I polyketide synthases (PKSs; Manitto, 1981). These PKSs elongate the polyketide chain by exchanging the chain between two thiol groups. Starting out, PKSs will bind acetyl-CoA to one of the thiol groups. Then, sequential malonyl-CoA groups are bound to the other thiol group as they are used to elongate this bound acetyl group. This is done by a Claisen condensation, which results in an acetyl group addition to the growing chain as well as the evolution of carbon dioxide (Keller et al., 2005). After a variable number of elongation steps the PKSs will release the polyketide chain by hydrolysis or cyclization (Hoffmeister \& Keller, 2007). The resulting polyketide core is then modified (e.g. oxidations, reductions, methylations) to form an array of polyketide structures. 

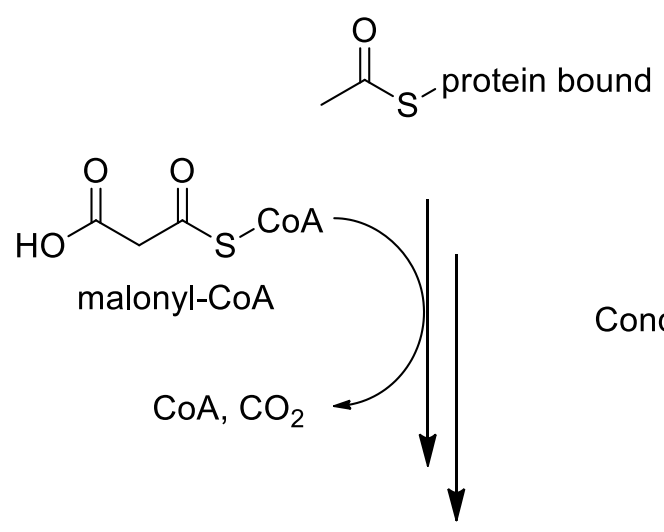

\section{Condensation}<smiles></smiles>

ketide chain

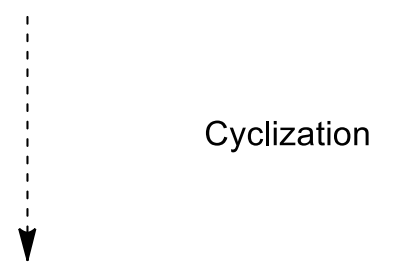<smiles>Cc1cc(O)ccc1C(=O)O</smiles><smiles>Cc1cccc(O)c1C(=O)O</smiles>

Various cyclization possibilities

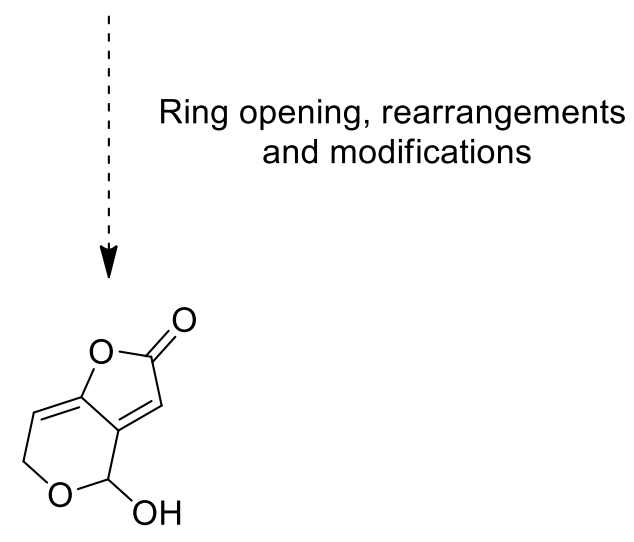

Figure 1.5: Acetate pathway illustrating polyketide biosynthesis (adapted from Deacon, 2005). 
In conifers, two potent polyketide metabolites isolated from foliar endophytes are pyrenophorol and vermiculine (Figure 1.6). Both natural products are 16 membered homomeric macrolides. Pyrenophorol was produced with other macrolides and sesquiterpenoids from several Lophodermium nitens strains originating from Eastern white pine (Pinus strobus; Sumarah et al., 2011). Pyrenophorol inhibited the growth of the biotrophic pathogen Microbotryum violaceum, which serves as a proxy for Cronartium ribicola, the fungus that the causes the disases white pine blister at concentrations as low as $5 \mu \mathrm{M}$ (Sumarah et al., 2011). Vermiculine was obtained from a white spruce endophyte and showed toxicity to spruce budworm cells at $2 \mu \mathrm{g} \mathrm{mL}^{-1}$ (Findlay et al., 2003).

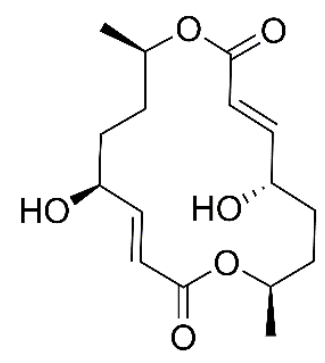

Pyrenophorol

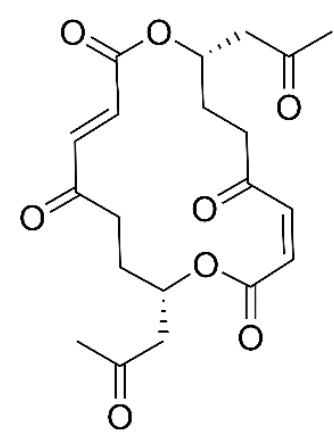

Vermiculine

Figure 1.6: Chemical structures of the macrolides pyrenophorol and vermiculine.

Terpenes are another major class of fungal secondary metabolites. They are assembled through sequential additions of $\mathrm{C}_{5}$ subunits through the mevalonate pathway (Figure 1.7; Manitto, 1981). This pathway starts with two phosphorylations to convert mevalonate into 5-pyrophosphate. After a trans elimination reaction, the tertiary hydroxyl group and the carboxyl group are removed to generate isopentenyl pyrophosphate (IPP; Manitto, 1981). Isopentenyl pyrophosphate then isomerizes to form the reactive dimethylallyl pyrophosphate (DMAPP; Manitto, 1981). When an IPP condenses with DMAPP in a head-to-tail manner it isomerizes to conserve the reactive tail 
(Manitto, 1981). This allows for continual $\mathrm{C}_{5}$ additions, which is why terpenes are classified by the number of $\mathrm{C}_{5}$ subunits added. For example, a $\mathrm{C}_{5}$ structure is a hermiterpene, $\mathrm{C}_{10}$ a monoterpene, $\mathrm{C}_{15}$ a sesquiterpene, $\mathrm{C}_{20}$ is a diterpene, etc. (Manitto, 1981).
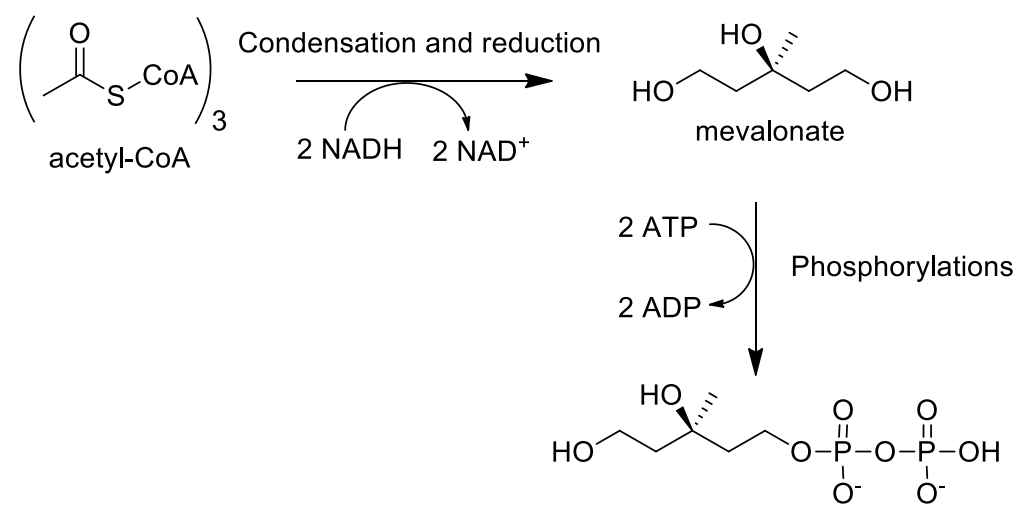

mevalonate pyrophosphate

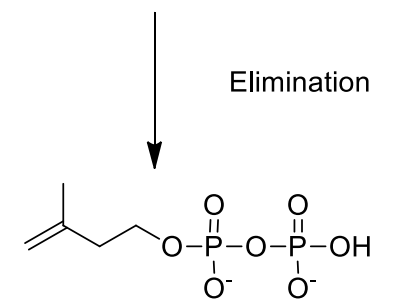

Isopentyl pyrophosphate (IPP)

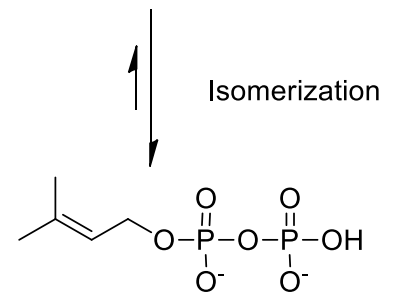

dimethylallyl pyrophosphate

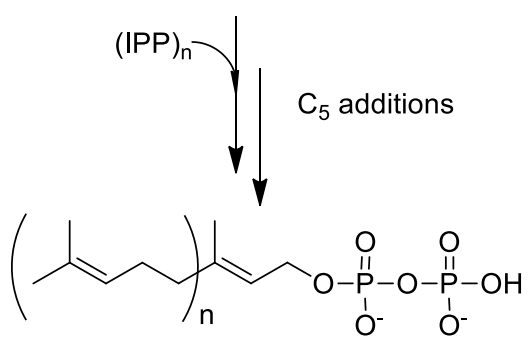

Figure 1.7: Overview of acetyl-CoA being converted into terpene core by the mevalonate pathway (adapted from Keller et al., 2005). 
These long terpene chains are then modified (e.g. cyclize, oxidize, reduce) by terpenoid synthases to increase their chemical diversity (Manitto, 1981). An example of sesquiterpenes isolated from endophytes are the heptelidic acid (HA), HA chlorohydrins and hydro-HA metabolites isolated from a needle endophyte of a balsam fir (Figure 1.8; Calhoun et al., 1992). When assayed against spruce budworm larvae, they found these terpenes to be toxic at concentrations as low as 5 to 15 $\mu$ mol (Calhoun et al., 1992). Diterpenoids have also been isolated from balsam fir endophytes (Figure 1.8). These showed antifeedant properties to spruce budworm larvae at $6 \mu \mathrm{mol}$ (Findlay et al., 1995a).

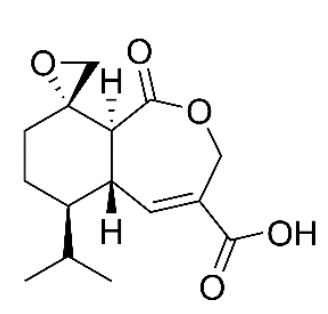

heptelidic acid (HA)

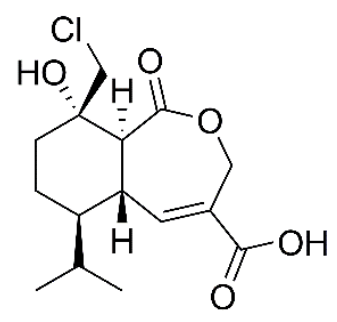

HA chlorohydrins

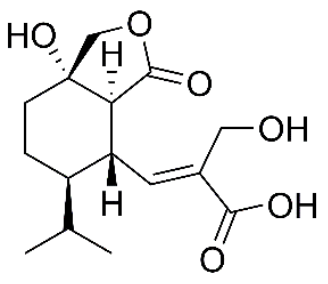

hydro-HA

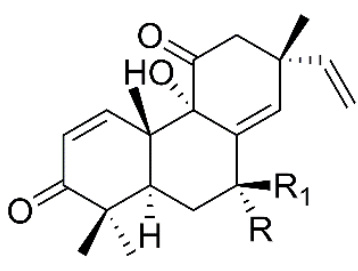

$\mathrm{R}, \mathrm{R}_{1}=\mathrm{O}$

$\mathrm{R}=\mathrm{R}_{1}=\mathrm{H}$

Diterpenoids

Figure 1.8: Chemical structures of heptelidic acid (HA), HA chlorohydrins and hydro-HA, and two diterpenoids toxic to spruce budworm larvae from balsam fir.

The shikimate pathway is the third major route to forming secondary metabolites. This pathway converts shikimic acid into the aromatic amino acids tryptophan, tyrosine and phenylalanine, and then further modifies them into aromatic secondary metabolites including alkaloids, lignans and cinnamic acid derivatives (Haslam, 1974; Dewick, 1997). Shikimic acid is biosynthesized by the condensation of erythrose-4-phosphate from the pentose phosphate pathway and 
phosphoenolpyruvic acid (PEP) from glycolysis (Haslam, 1974). Initially, shikimic acid is coupled to a phosphate group and to another PEP to form 5-enolpyruvylshikimate-3-phosphate (Haslam, 1974). This intermediate is dephosphorylated to yield chorismate. At this point, the pathway branches to form the three aromatic amino acids. For example, the pathway towards tyrosine and phenylalanine begins with an isomerization of chorismate into prephenic acid (Haslam, 1974). Prephenic acid is oxidatively decarboxylated and then transaminated, using glutamate as a nitrogen source, to yield either tyrosine or phenylalanine, depending on whether the aromatic hydroxyl group is conserved (Haslam, 1974). Secondary metabolite enzymes perform a variety of modifications to these aromatic amino acids to form an array of secondary metabolites (Figure 1.9). For example, the grass endophytes that showed toxicity to mammals and insects produced potently bioactive alkaloids and indole diterpenes such as ergonovine and peramine (Figure 1.10; Bush et al., 1997; Clay \& Schardl, 2002).

\section{Red and black spruce metabolites}

As part of the ongoing effort to explore the endophyte ecology of the Acadian forest, 2000 red spruce endophytes were collected from nine areas across New Brunswick, Nova Scotia and Maine (Sumarah et al., 2010). Based on morphological characteristics and sequencing of a portion of the ITS, 150 strains were selected and incubated in liquid culture to study their secondary metabolites (Sumarah et al., 2010). The secondary metabolite extracts were tested for dietary toxicity to spruce budworm at $400 \mu \mathrm{g} \mathrm{g}^{-1}$. Three toxic extracts were chosen for further study as they provided a good representation of geographic, taxonomic and natural product diversity (Sumarah et al., 2010). These further studies led to the characterization of 9 major metabolites (Figure 1.11), where none of these secondary metabolites were common to the three species (Sumarah et al., 2010). 


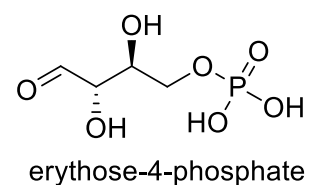<smiles>C=C(C(=O)O)P(=O)(O)O</smiles>

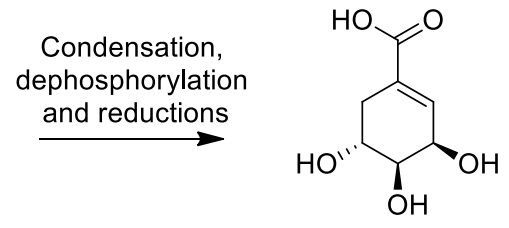

phosphoenolpyruvic acid (PEP)

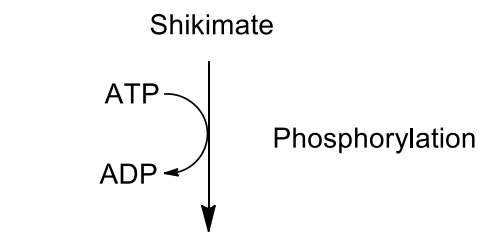<smiles>O=C(O)C1=CC(O)C(O)C(OP(=O)(O)O)C1</smiles>

Shikimate-3-phosphate

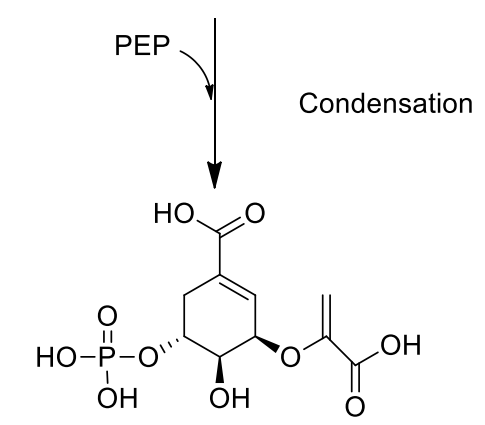

5-enolpyruvylshikimate-3-phosphate

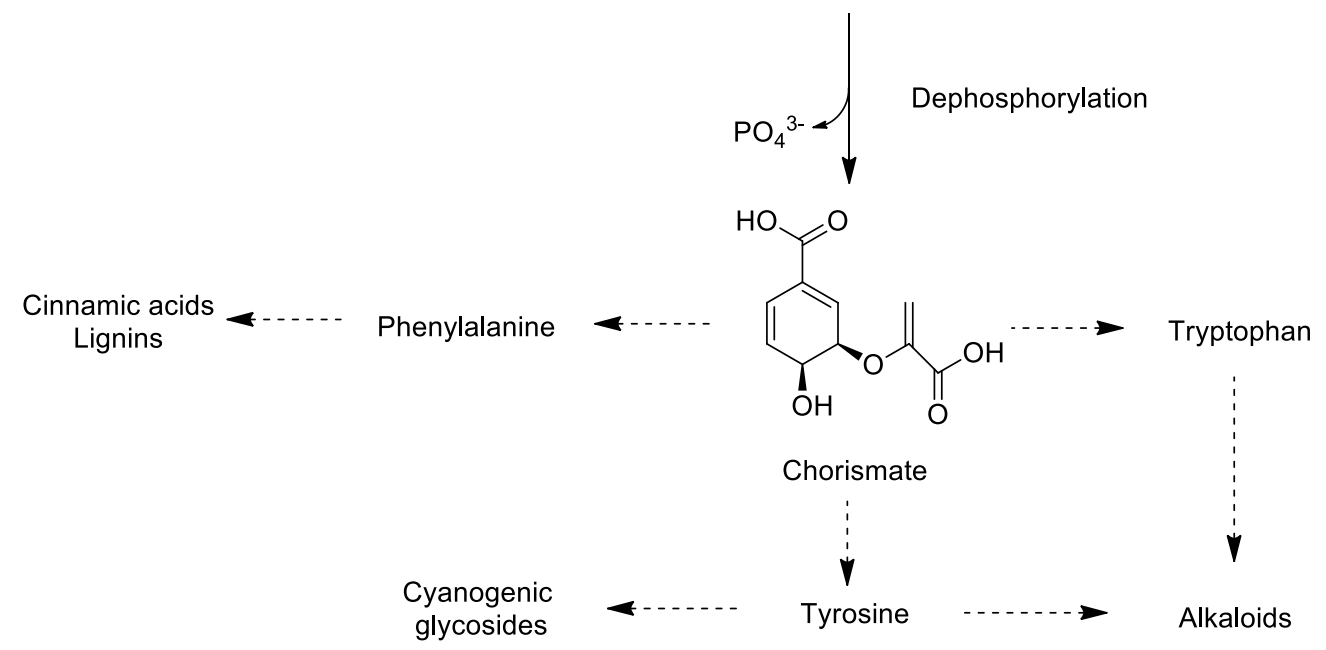

Figure 1.9: Shikimic pathway showing biosynthesis of aromatic amino acids and subsequent secondary metabolite families (adapted from Herrmann, 1995). 


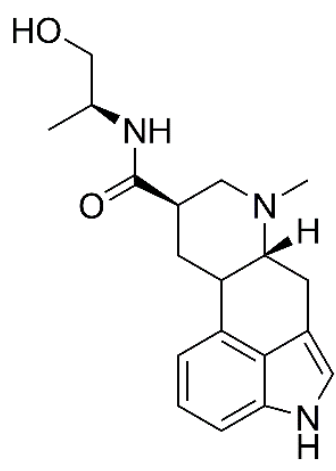

Ergonovine

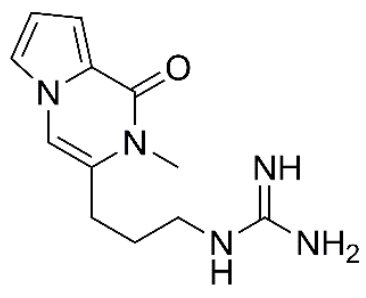

Peramine

Figure 1.10: Structures of ergonovine and peramine alkaloids produced by grass endophytes.

Although two of these endophytes could not be identified, they were deposited in the Centraalbureau voor Schimmelcultures (CBS) as CBS 121942 and CBS 121944. The last endophyte was identified as Dwayaagam colodena and was deposited in the Department of Agriculture, Ottawa, Mycology (DAOM) as DAOM 239833. Compound (A) was attributed for the toxicity of CBS 121942, compounds (D) and (E) for the toxicity of CBS 121944 and a variety of maleic anhydrides with structures similar to $(\mathrm{G})$ for the toxicity of Dwayaagam colodena (Sumarah et al., 2010). Despite these metabolites possessing vastly different structures, all of them are unified in their toxicity to spruce budworm. This is important as toxin mixtures may delay the onset of spruce budworm tolerance. Additionally, inoculating nursery seedlings with a variety of representative endophytes rather than focusing on a single endophyte ensures forest endophyte ecology is maintained (Miller, 2011). 
<smiles>CC1CCCC(=O)C2OC2/C=C\C(O)/C=C/C1=O</smiles>

A

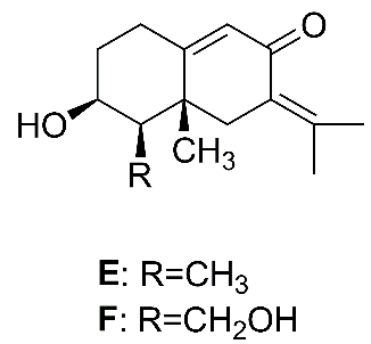<smiles>[R]C(=O)CCC(=O)Cc1ccccc1</smiles>

B: $\mathrm{R}=\mathrm{OH}$

C: $\mathrm{R}=\mathrm{OCH}_{3}$<smiles>O=C1CCC(Cc2ccccc2)O1</smiles>

D<smiles>CC/C=C/C1=C(CC(CC)CC2=C(CC(CC)CC3=C(CCC(=O)O)C(=O)OC3=O)C(=O)OC2=O)C(=O)OC1=O</smiles>

Figure 1.11: Structures secondary metabolites characterized from three red spruce endophyte strains of the Acadian forest.

There has also been a number of polyketide isocourmarins isolated from an endophyte of black spruce (Figure 1.12). Despite their structural similarities, only two of the compounds were found to be toxic to spruce budworm larvae (Findlay et al., 1995b). However, this is not likely a true representation of toxicity. A current theory is that fungi produce mixtures of toxins that combine to act synergistically (Calhoun et al., 1992). For instance, Dowd (1989) reported several non-toxic compounds from Fusarium graminearum that in turn had elevated toxicity and mortality to caterpillars when combined with the trichothecene deoxynivalenol. This phenomenon was also observed with Penicillium and Aspergillus species (Dowd, 1988, 1989). As such, it is possible that the array of isocoumarin metabolites from this endophyte increased in toxicity when acting together. 
<smiles>C[C@@H]1OC(=O)C2=C(O)[C@H]3O[C@H]3C[C@]2(C)[C@H]1O</smiles><smiles>C[C@H]1C[C@H]2CCC[C@@H](O)C2C(=O)O1</smiles><smiles>C[C@@H]1O[C@@H]2CCC(=O)[C@@H](C2)[C@H]1O</smiles><smiles>[R]C1C2([R])C(C)OC(=O)C3=C(O)C=CC[C@@]312</smiles><smiles>[R]C1CC(O)=C2C(=O)O[C@H](C)C[C@H]2C1</smiles><smiles>[R]O[R]</smiles>
$\mathrm{R}=\mathrm{H}, \mathrm{R}_{1}=\mathrm{OH}$

$$
\begin{aligned}
& \mathrm{R}=\mathrm{OH}, \mathrm{R}_{1}=\mathrm{H} \\
& \mathrm{R}=\mathrm{R}_{1}=\mathrm{H} \\
& \mathrm{R}=\mathrm{H}, \mathrm{R}_{1}=\mathrm{OH}
\end{aligned}
$$<smiles>C[C@@H]1OC(=O)c2c(O)cccc2[C@H]1O</smiles>

Figure 1.12: Chemical structures isocoumarins produced by a foliar endophyte of black spruce.

\section{Project Aim}

Research focused on conifer endophyte diversity of the Acadian forest over the past 25 years has resulted in many important discoveries. The first is that conifers grown in nurseries for reforestation purposes have low endophyte diversity as these non-clavicipitaceous endophytes spread through horizontal transmission. It has also been demonstrated that endophytes can be inoculated into conifer seedlings and that they can persist there for over 10 years despite natural needle shedding. After 10 years, the white spruce endophyte $P$. scopiformis continued to produce its dominant rugulosin toxin in planta at concentrations that effectively reduce spruce budworm growth and herbivory (Frasz et al. 2014). This thesis is part of a larger effort to explore the diversity of unknown toxigenic endophytes. The ideal end goal is that this will allow nursery trees intended for reforestation purposes to be inoculated with a variety of toxigenic endophytes.

Specifically, the work in this thesis entails screening endophytes for antifungal activity, choosing 
toxigenic endophytes that have not been previously studied by the Miller group and characterizing the secondary metabolites that are responsible for this observed bioactivity. The aim of the project is to find novel secondary metabolites that are structurally distinct from the current set of metabolites known to be toxigenic to spruce budworm. If successful, future steps will involve in vitro testing of these novel metabolites against spruce budworm and potentially in vivo testing thereafter by inoculating the toxigenic endophyte into conifer seedlings.

\section{Materials and Methods}

\section{Endophyte Collection}

Branches of Picea mariana (black spruce) and P. rubens (red spruce) of various age classes were collected in New Brunswick, Canada and stored in plastic bags at $4 \mathrm{C}$. Endophytic fungi were isolated and subcultured from surface sterilized needles following the methods of Tanney et al. (2016a). Briefly, needles were surface sterilized by dipping each needle in 70\% ethanol (EtOH) for one minute, rinsing with sterile $\mathrm{ddH}_{2} \mathrm{O}$, followed by a 7.5 minute immersion in a $10 \%$ bleach solution. After soaking in the bleach solution, needles were placed in $70 \% \mathrm{EtOH}$ briefly, and rinsed with sterile $\mathrm{ddH}_{2} \mathrm{O}$ again. Using sterilized forceps, each needle was carefully bisected cross-wise and plated on $2 \%$ malt extract agar (MEA). Needles were incubated at $25 \mathrm{C}$ until sufficient growth was observed from the exposed needle tip. Isolates were subsequently subcultured, plated on fresh 2\% MEA and incubated as described above. The collection of foliar endophytes studied here for natural products was maintained on $2 \%$ MEA and stored at $8 \mathrm{C}$, appendix II. 


\section{Fermentation and Extraction}

Small scale fermentations were used to assess the natural product profiles and target fungi producing antimicrobial metabolites for each endophyte reported in appendix II. Under aseptic conditions, a portion of each endophytes $2 \%$ MEA plate was macerated in sterile $\mathrm{ddH}_{2} \mathrm{O}$. The resulting suspension was used to inoculate $(5 \%, \mathrm{v} / \mathrm{v})$ individual Glaxo bottles containing $1 \mathrm{~L}$ of autoclaved 2\% malt extract (Bacto) broth. Cultures were incubated for 8 weeks without agitation at $25 \mathrm{C}$ in darkness.

After the incubation period, the mycelia were separated from the culture filtrate by suction through Whatman \#4 (Whatman GE Healthcare, UK) filter papers. The resulting volume and $\mathrm{pH}$ of the culture filtrates were recorded whereas the mycelia were lyophilized and stored at $-20 \mathrm{C}$. Each culture filtrate was saturated with $\mathrm{NaCl}\left(20-30 \mathrm{~g} \mathrm{~L}^{-1}\right)$ and exhaustively extracted with ACS grade ethyl acetate (EtOAc). The aqueous culture filtrate was discarded and the organic layer was filtered through a Whatman $\# 1$ and anhydrous $\mathrm{Na}_{2} \mathrm{SO}_{4}$ prior to drying by rotary evaporation. The resulting crude extract was suspended in $3 \mathrm{~mL}$ of HPLC grade methanol (MeOH), passed through a $0.2 \mu \mathrm{m}$ PTFE syringe filter (Tisch Scientific, USA), dried under a gentle stream of nitrogen gas and weighed. Crude endophyte culture filtrate extracts were stored dry in amber vials at $-20 \mathrm{C}$ prior to natural product profiling and growth inhibition assays.

Based on LC-UV-MS chromatograms, bioassay result and phylogenetic analysis, from the 61 cultures grown in liquid culture, four were thoroughly investigated for natural products. Often this necessitates medium scale fermentations to isolate adequate amounts of metabolites for structural elucidations and bioassays. For medium scale incubations $(15 \mathrm{~L})$, a two-stage fermentation 
approach was implemented. Fifteen $250 \mathrm{~mL}$ Erlenmeyer flasks containing $50 \mathrm{~mL}$ of $2 \%$ malt extract broth were inoculated as described above with the selected endophytes. Flasks were incubated on a rotary shaker $(100 \mathrm{rpm})$ for 1 week in the dark at $25 \mathrm{C}$. Cultures were subsequently macerated, individually transferred to Glaxo bottles containing $1 \mathrm{~L}$ of the same liquid medium, and incubated without agitation as described above for 8 weeks. The resulting mycelium and culture filtrates were also treated as described above.

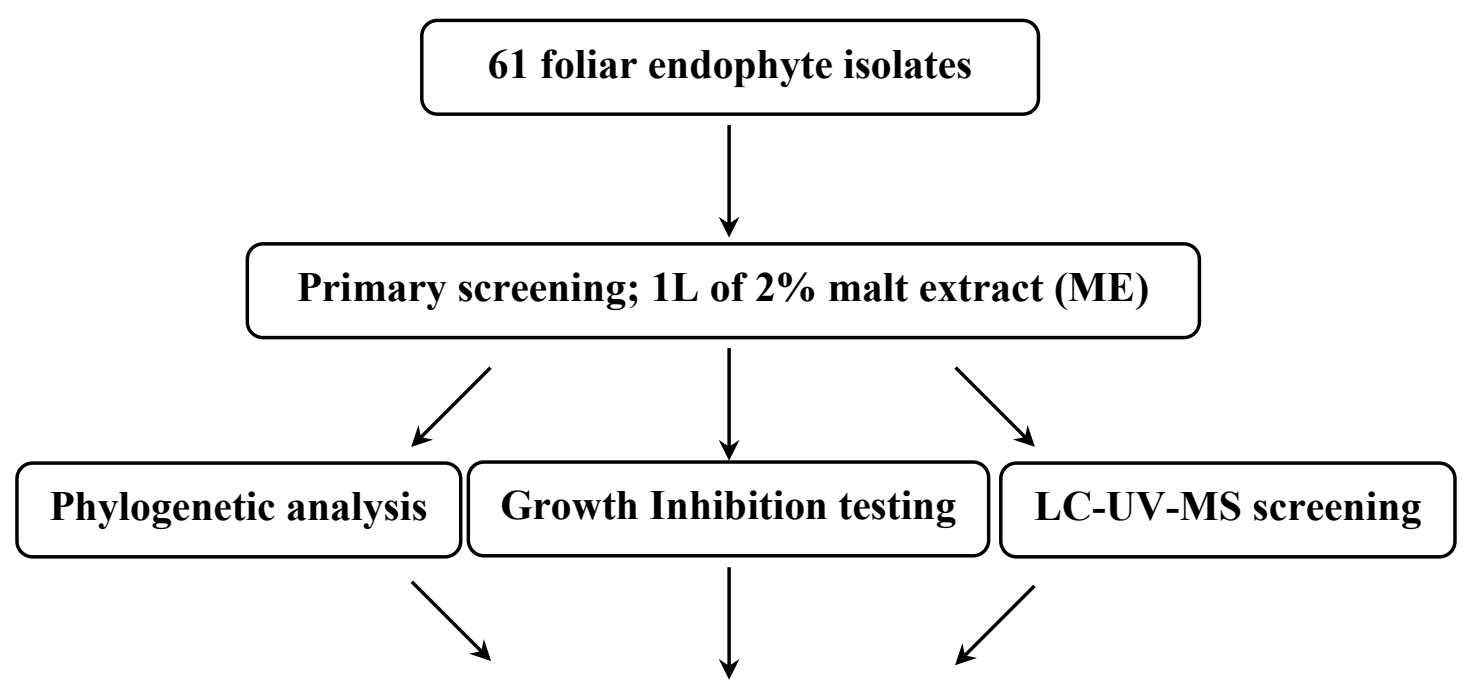

Selection of 4 endophytes for medium scale fermentations; $15 \mathrm{~L}$ of $2 \% \mathrm{ME}$

Metabolite isolation, structural characterization and in vitro antimicrobial assays

Figure 2.1: Flow chart illustrating the screening process used to select four endophyte species for secondary metabolites investigations. 


\section{Metabolite LC-UV-MS Analysis}

Crude endophytes were analyzed by LC-UV-MS to access their natural product profiles. This was performed with a Waters 2795 separations module, Waters 996 diode array detector, and Waters MicroMass Quattro LC mass spectrometer (Waters Corporation, Milford, MA, USA). Metabolites were separated by a Kinetex C18 (100 x $4.6 \mathrm{~mm}, 2.6 \mathrm{~mm})$ column (Phenomenex Inc., Torrance, CA, USA) with a mobile phase consisting of acetonitrile (ACN)- $\mathrm{ddH}_{2} \mathrm{O}$ with formic acid (FA; 0.1 $\%, \mathrm{v} / \mathrm{v})$. The linear solvent gradient was programmed from 5 to $100 \% \mathrm{ACN}-\mathrm{ddH}_{2} \mathrm{O}$ over $13 \mathrm{~min}$

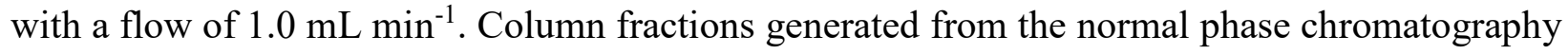
of these extracts were also analyzed as described above. An aliquot of each crude extract (10 mg $\mathrm{mL}^{-1}$ ) or column fraction $\left(5 \mathrm{mg} \mathrm{mL}^{-1}\right)$ was dissolved in HPLC grade MeOH prior to LC-UV-MS analysis.

\section{Metabolite Chromatography}

Medium-scale EtOAc culture filtrate extracts generated to obtain adequate metabolite amounts from selected endophytes were initially separated by flash column chromatography utilizing short silica gel columns. A step gradient elution system employing hexanes-EtOAc (0-100 \%; v/v) in $10 \%$ increments followed by 5, 10, 20, and 50\% EtOAc-MeOH (v/v) was typically utilized. Eluting metabolites were monitored by thin-layer chromatography (TLC) (0.2 mm silica gel 60 $\mathrm{F}_{254}$ pre-coated) using $10 \%(\mathrm{v} / \mathrm{v}) \mathrm{MeOH}$ in chloroform $\left(\mathrm{CHCl}_{3}\right)$ as a mobile phase. TLC plates were visualized under both long $(365 \mathrm{~nm})$ and short wave $(254 \mathrm{~nm})$ light. Similar eluates were combined, dried by rotary evaporation, re-suspended in $5 \mathrm{~mL}$ of $\mathrm{MeOH}$, filtered through a $0.2 \mu \mathrm{m}$ PTFE syringe filter and then dried again under a gentle stream of nitrogen gas. Column fractions were subsequently analyzed by LC-UV-MS as described above. Semi-preparative reverse phase 
HPLC of fractions with interesting metabolite profiles or appreciable mass ( $>100 \mathrm{mg}$ ) were performed with an Agilent 1100 high performance liquid chromatography (HPLC) system (Agilent Technologies, Palo Alto, CA, U.S.A.) equipped with a diode array detector and Kinetex C18 column $\left(250 \times 10 \mathrm{~mm}, 5 \mu \mathrm{m}\right.$; Phenomenex) using a mobile phase consisting of $\mathrm{ACN}$ and $\mathrm{ddH}_{2} \mathrm{O}$ with $0.05 \%$ trifluoroacetic acid (TFA). HPLC elution gradients were metabolite specific; however, all had a flow rate of $4 \mathrm{~mL} \mathrm{~min}^{-1}$. Column fractions were dissolved in HPLC grade $\mathrm{MeOH}$ to a concentration of $50 \mathrm{mg} \mathrm{mL}^{-1}$ and chromatographed in $50 \mu \mathrm{L}$ aliquots.

\section{Phaeocryptopus cf. gaeumannii (NB250-4H, DAOM 250863)}

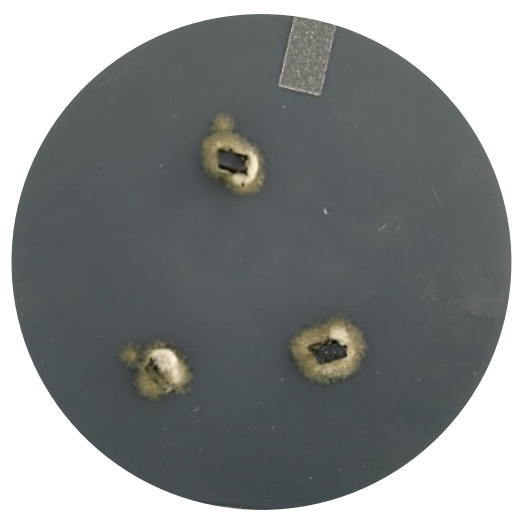

Figure 2.2: Phaeocryptopus cf. gaeumannii (DAOM 250863) growing on a 2\% MEA.

The crude extract mass $(582.3 \mathrm{mg})$ of DAOM 250863 obtained from the $1 \mathrm{~L}$ screening fermentation was unusually high compared to most other foliar endophytes studied. LC-UV-MS analysis of the crude extracts revealed a relatively simple metabolite profile with six major peaks. As such, metabolite purifications for this endophyte were performed on the $1 \mathrm{~L}$ extract rather than conducting a medium scale fermentation that is typically required. The normal phase column chromatography step was also not conducted due to the simplicity of the extract. Instead, the 
extract was directly separated by semi-preparative HPLC. A linear gradient was programmed from 20 to $60 \% \mathrm{ACN}-\mathrm{ddH}_{2} \mathrm{O}$ over 16 minutes to yield compound $\mathbf{1}(3.6 \mathrm{mg}), 2(2.9 \mathrm{mg}), \mathbf{3}(6.3 \mathrm{mg}), 4$ (3.0 $\mathrm{mg})$ and $\mathbf{5}(14.5 \mathrm{mg})$.

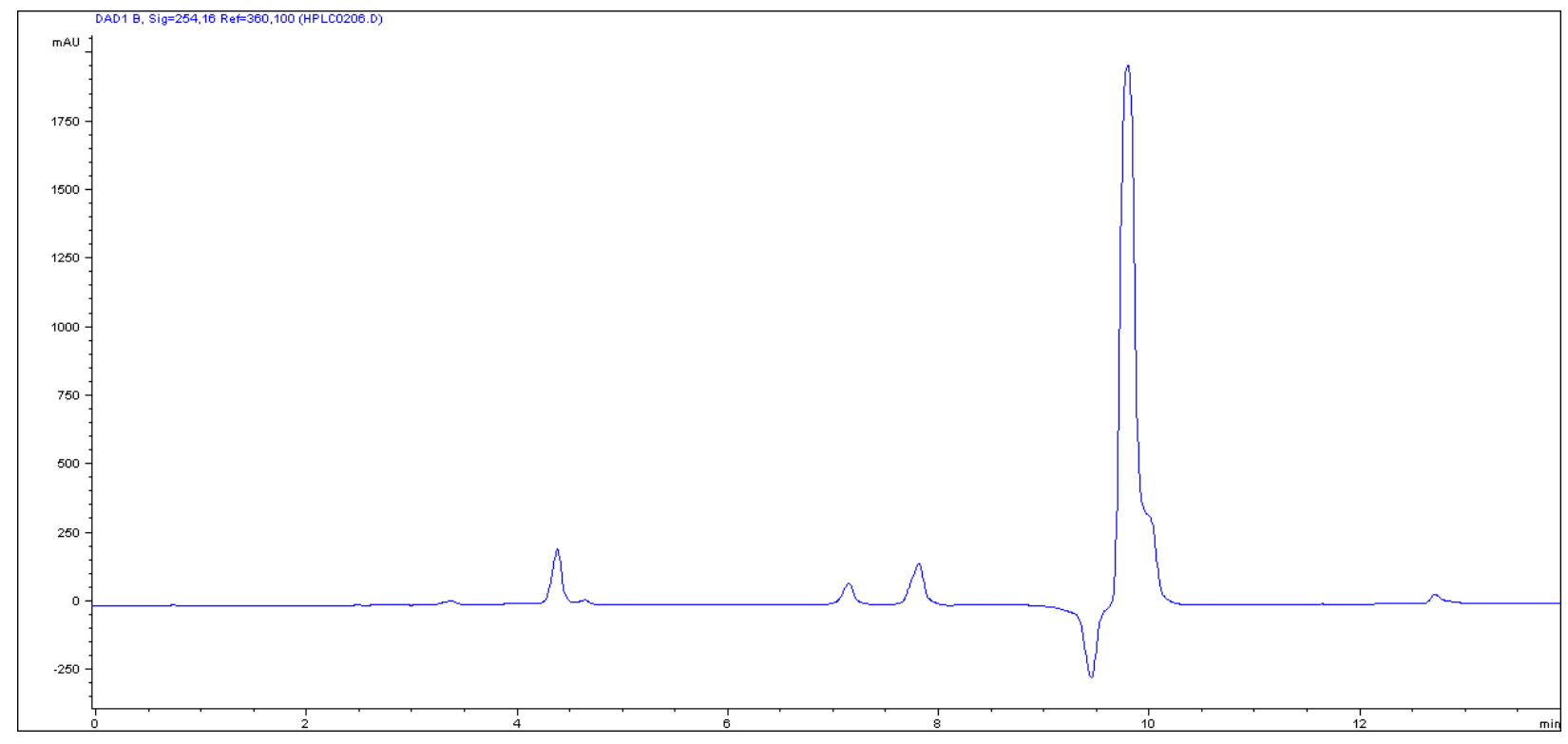

Figure 2.3: HPLC separation outlining major metabolites produced by DAOM $250863(254 \mathrm{~nm})$.

\section{Undescribed Rhytismatales species (NB236-1A)}

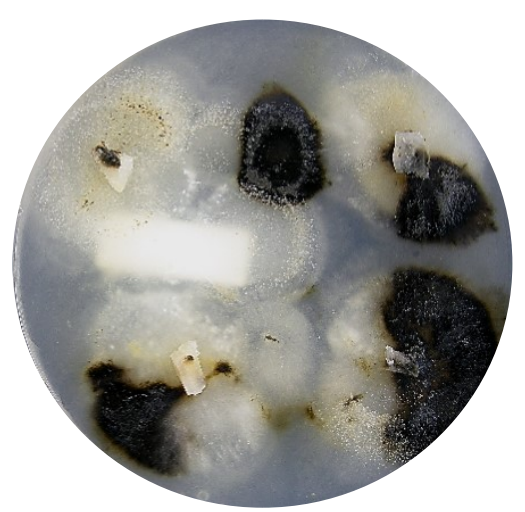

Figure 2.4: Undescribed Rhytismatales species growing on a 2\% MEA. 
The crude EtOAc culture filtrate extract $(3.0 \mathrm{~g})$ of NB236-1A was fractionated by a short silica gel column that yield nine fractions. LC-UV-MS screening identified three chemically distinct fractions that were selected for subsequent metabolite purifications by semi-preparative HPLC. Fraction $1(12.3 \mathrm{mg})$ eluted with 10\% EtOAc in hexanes $(\mathrm{v} / \mathrm{v})$ and was further separated by HPLC using a linear gradient programmed from 55 to $85 \% \mathrm{ACN}-\mathrm{ddH}_{2} \mathrm{O}$ over 23 minutes to afford compounds $10(2.3 \mathrm{mg})$ and $11(3.0 \mathrm{mg})$. Column fraction $4(117.0 \mathrm{mg})$ eluted with $40 \%$ EtOAc in hexanes (v/v) and was separated using a gradient that increased linearly from 20 to $70 \%$ ACN$\mathrm{ddH}_{2} \mathrm{O}$ over 16 minutes that yielded compound $\mathbf{1 2}(5.4 \mathrm{mg})$ and $\mathbf{8}(4.0 \mathrm{mg})$. Compound $\mathbf{9}(4.7 \mathrm{mg})$ was purified from fraction $5(373.2 \mathrm{mg})$ with an HPLC method that increased linearly from 20 to $90 \% \mathrm{ACN}-\mathrm{ddH}_{2} \mathrm{O}$ over 21 minutes. When re-examining the LC-UV-MS chromatograms of the crude extract, two dominant peaks had yet to be isolated from the fractions investigated. Examination of each fractions UV and MS chromatograms indicated these metabolites were present within the polar 1:1 MeOH:EtOAc (v/v) fraction despite eluting in 50\% ACN when performing metabolite screening by LC-UV-MS. Since polar fractions are typically difficult to separate by conventional reverse phase HPLC, $300 \mathrm{mg}$ of fraction $9(621.5 \mathrm{mg})$ was separated by

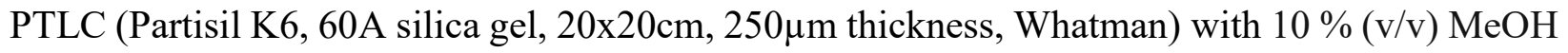
in $\mathrm{CHCl}_{3}$. Six bands were scrapped off the silica plate, filtered through a $0.2 \mu \mathrm{m}$ PTFE syringe filter and screened by LC-UV-MS. The two dominant metabolites present within the crude extract were detected in two of the six silica scrapings. These PTLC fractions were purified separately using an HPLC method that linearly increased from 40 to $80 \% \mathrm{ACN}-\mathrm{ddH}_{2} \mathrm{O}$ over 17 minutes that afforded compounds $6(9.9 \mathrm{mg})$ and $7(9.3 \mathrm{mg})$. 


\section{Diaporthe maritima (NB365-71I, DAOM 628553)}
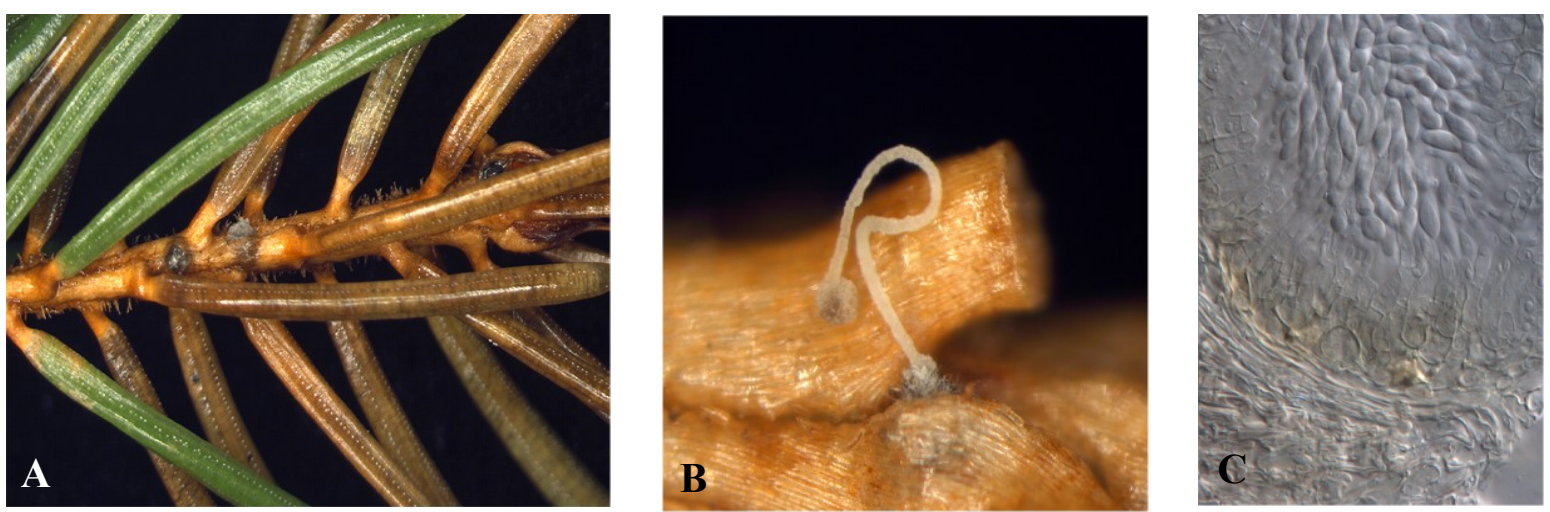

Figure 2.5: Diaporthe maritima (DAOM 628553) growing on a red spruce twig (A), magnified to show pycnidia protruding through the plant tissue (B) and the conidiophores producing conidia $(\mathbf{C})$.

Fractionation of the DAOM 628553 EtOAc culture filtrate extract ( $1.6 \mathrm{~g})$ normal phase column chromatography yielded nine fractions. After screening each by LC-UV-MS, three fractions were selected for metabolite purifications by semi-preparative HPLC. Fraction $3(131.3 \mathrm{mg})$ eluted with $20 \%$ EtOAc in hexanes (v/v) and was further separated using a linear gradient programmed from

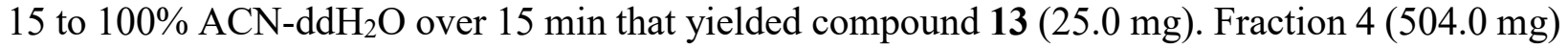
eluted with $30 \%$ EtOAc in hexanes $(\mathrm{v} / \mathrm{v})$ and was separated by a similar HPLC method programmed from 30 to $60 \% \mathrm{ACN}-\mathrm{ddH}_{2} \mathrm{O}$ over 16 min, yielding compound 15 (4.6mg). Fraction $5(227.9 \mathrm{mg})$ eluted with 40\% EtOAc in hexanes (v/v) and was chromatographed with a linear method programmed from 25 to $100 \% \mathrm{ACN}-\mathrm{ddH}_{2} \mathrm{O}$ over 18 min yielding compound 14 (15.3 mg). 


\section{Pezicula sporulosa (NB382-3D, DAOM 250862)}

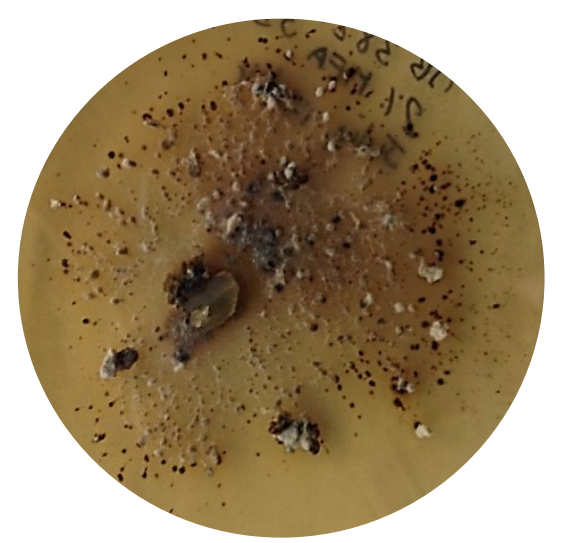

Figure 2.6: Pezicula sporulosa (DAOM 250862) growing on a 2\% MEA.

The crude culture filtrate extract (1.65 g) of DAOM 250862 was separated into 11 fractions by normal phase flash column chromatography. LC-UV-MS analysis indicated major metabolites were predominantly in three fractions. Fraction $2(117.3 \mathrm{mg})$ eluted with $20 \%$ EtOAc in hexanes (v/v) and semi-preparative HPLC employing a linear gradient increasing from 35 to $60 \%$ ACN$\mathrm{ddH}_{2} \mathrm{O}$ over 18 minutes afforded compound $16(37.4 \mathrm{mg})$. Fraction $4(116.1 \mathrm{mg})$ eluted with $40 \%$ EtOAc in hexanes $(\mathrm{v} / \mathrm{v})$ and a linear gradient programmed from 20 to $55 \% \mathrm{ACN}-\mathrm{ddH}_{2} \mathrm{O}$ over 21 minutes yielded compound $17(13.8 \mathrm{mg})$. Fraction 5 eluted with 50\% EtOAc in hexanes (v/v) and was subsequently separated by a linear HPLC gradient increasing from 10 to $70 \% \mathrm{ACN}-\mathrm{ddH}_{2} \mathrm{O}$ over 21 minutes. This fraction yielded $6.2 \mathrm{mg}$ of compound $\mathbf{1 8}$. Compound 19 was detected in the crude culture filtrate of DAOM 250862 by data independent acquisition. Analysing the crude culture filtrate extract by HRMS allowed for comparison to a database of previously isolated secondary metabolites. By observing the correct mass at the appropriate retention time confirmed the presence of compound 19 . 


\section{Growth Inhibition Assays}

The collection of foliar endophytes obtained from the Acadian forest was assessed for the production of antifungal metabolites using the Oxford disk diffusing assay (Vincent \& Vincent, 1944). Crude extracts from the $1 \mathrm{~L}$ screening fermentations were dissolved in HPLC grade $\mathrm{MeOH}$ to prepare concentrations of $50 \mathrm{mg} \mathrm{mL}^{-1}$. Ten $\mu \mathrm{L}$ aliquots were pipetted onto $10 \mathrm{~mm}$ sterile Whatman disks. Nystatin at a concentration of $1 \mathrm{mg} \mathrm{mL}^{-1}$ and HPLC grade $\mathrm{MeOH}$ were the respective positive and negative controls. The $\mathrm{MeOH}$ was allowed to evaporate and disks were subsequently placed on $2 \%$ MEA plates that were previously smeared with $100 \mu \mathrm{L}$ of a 0.10 optical density (OD; $600 \mathrm{~nm}$ ) solution of either Saccharomyces cerevisiae or Microbotryum violaceum. Plates were stored in an incubator at $25 \mathrm{C}$ in the dark and monitored every 24 hours for zones of inhibition. Each endophyte extract was tested in triplicate against both the representative yeast, $S$. cerevisiae, and the biotrophic pathogen $M$. violaceum, which serves as a proxy for C. ribicola (white pine blister rust).

Purified metabolites were tested for in vitro antimicrobial activity against $M$. violaceum, $S$. cerevisiae, Bacillus subtilis (ATCC 23857) and Escherichia coli (ATC 67878). M. violaceum was grown in $20 \mathrm{~g} \mathrm{~L}^{-1}$ malt extract (Bacto), $2.5 \mathrm{~g} \mathrm{~L}^{-1}$ peptone (Bacto), and $2.5 \mathrm{~g} \mathrm{~L}^{-1}$ yeast extract (Sigma, St. Louis, MO, USA), whereas S. cerevisiae was inoculated and grown in $1 \mathrm{~g} \mathrm{~L}^{-1}$ yeast extract supplemented with $10 \mathrm{~g} \mathrm{~L}^{-1}$ glucose. Bacteria were inoculated and grown in $5 \mathrm{~g} \mathrm{~L}^{-1}$ yeast extract, $10 \mathrm{~g} \mathrm{~L}^{-1}$ peptone, and $10 \mathrm{~g} \mathrm{~L}^{-1} \mathrm{NaCl}$. Nystatin was the positive control for antifungal assays and chloramphenicol was the antibiotic positive control. DMSO was the negative control for all assays. Metabolites were tested at 250, 25, and $2.5 \mu \mathrm{M}$ in sterile 96-well microplates (Falcon 353072 Microtest-9, Franklin Lakes, NJ, U.S.A.). A $10 \mu \mathrm{L}$ aliquot of each individual metabolite solution 
dissolved in DMSO was added to $190 \mu \mathrm{L}$ microbial suspension. Assays were performed in triplicate and incubated at $28 \mathrm{C}$ with a rotary table shaker providing gentle agitation $(500 \mathrm{rpm})$. OD readings were taken every 2 hours for S. cerevisiae, B. subtilis and E. coli assays and every 12 hours for M. violaceum assays. OD measurements were made at $600 \mathrm{~nm}$ with a Molecular Devices Spectra Max 340PC reader (Sunnyvale, CA, U.S.A.). Antimicrobial OD data were analyzed by ANOVA followed by Tukey's test $(p<0.05)$ for significant differences (Systat V13.1; Systat Software Inc., Chicago, IL, U.S.A.) compared to the negative control (DMSO).

\section{General experimental protocols}

Metabolite NMR spectra were obtained on a Bruker Avance 400 Spectrometer (Bruker Instruments Inc., Milton, ON, Canada) at $400.13\left({ }^{1} \mathrm{H}\right)$ and $100 \mathrm{MHz}\left({ }^{13} \mathrm{C}\right)$ using a $5 \mathrm{~mm}$ autotuning broadband probe with a Z-gradient. Isolated natural products were dissolved in $600 \mu \mathrm{L}$ of $\mathrm{CD}_{3} \mathrm{OD}(\delta \mathrm{H} 3.30$ and $\delta \mathrm{C} 49.0)$ (CDN Isotopes, Point Claire, QC, Canada) and referenced to the solvent peak. Homonuclear (1H, 13C, COSY, DEPT-135, and NOESY) and heteronuclear (HSQC and HMBC) NMR experiments were used to elucidate natural product structures. LC-HRMS data was acquired with a Thermo Q-Exactive Orbitrap Mass Spectrometer (Thermo Scientific, Waltham, MA, U.S.A), coupled to an Agilent 1290 HPLC system. Crude extracts and pure metabolites were separated by an Agilent Zorbax Eclipse Plus RRHD C18 $(2.1 \times 50 \mathrm{~mm}, 1.8 \mu \mathrm{m})$ at a flow rate of $0.3 \mathrm{~mL} \mathrm{~min}^{-1}$ using mobile phases consisting of $\mathrm{ddH}_{2} \mathrm{O}$ with $0.1 \% \mathrm{FA}$ and $\mathrm{ACN}$ with $0.1 \%$ FA. The chromatographic method held $0 \% \mathrm{ACN}$ for 30 seconds before increasing to $100 \%$ over 3 minutes. After holding at $100 \% \mathrm{ACN}$ for 1 minute, the gradient returned to $0 \% \mathrm{ACN}$ over 30 seconds. Two $\mu \mathrm{L}$ of each crude extract normalized to $1 \mathrm{mg} \mathrm{mL}^{-1}$ were analyzed by $\mathrm{LC}$ HRMS. The LC-HRMS system also collected $\mathrm{HRMS}^{2}$ data for every ionisable metabolite. Silica 
gel (Silicycle; 40-60 $\mu \mathrm{m}$ ) was utilized for all normal phase metabolite separations. UV spectra of all isolated metabolites were obtained using a Varian Cary 3 UV-visible spectrophotometer scanning from 190-800 nm. Optical rotations were determined with an Autopol IV polarimeter (Rudolph Analytical, Hackettstown, NJ, U.S.A.).

\section{Results}

From the foliar conifer endophyte collection obtained from Acadian forest of Eastern Canada screened (Appendix II), four were selected for medium scale fermentations based on bioassay result, crude extract mass, LC-UV-MS chromatograms and novelty of the endophyte strain to the Miller group. Two endophytes were obtained from black spruce, Phaeocryptopus cf. gaeumannii DAOM 250863 and an undescribed Rhytismatales sp., and two from red spruce, Diaporthe maritima DAOM 628553 and Pezicula sporulosa DAOM 250862.

\section{Metabolites of Phaeocryptopus cf. gaeumannii (NB250-4H, DAOM 250863)}

Examination of the NMR (Table 3.1) and physiochemical (Table 3.2) data for compounds 1-5 isolated from DAOM 250863, indicated they were structurally similar isocoumarins. Compound 1 was isolated as a clear solid with the molecular formula $\mathrm{C}_{10} \mathrm{H}_{14} \mathrm{O}_{5}$ determined by HRMS $(\mathrm{m} / z$ $\left.215.0912[\mathrm{M}+\mathrm{H}]^{+}\right)$. This formula indicates four units of unsaturation. The ${ }^{1} \mathrm{H}$ NMR spectrum displayed three oxygenated methines at $\delta 4.28$ (m, H-6), 4.20 (dq, $J=9.3,6.3, \mathrm{H}-3)$ and 3.11 (dd, $J=10.5,9.3, \mathrm{H}-4)$, a methine at $\delta 2.71(\mathrm{~m}, \mathrm{H}-4 \mathrm{a})$, two inequivalent methylenes at $\delta 2.29(\mathrm{~m}, \mathrm{H}-5)$, $1.25(\mathrm{~m}, \mathrm{H}-5), 2.64(\mathrm{~m}, \mathrm{H}-7)$ and $2.33(\mathrm{dd}, J=19.0,1.3, \mathrm{H}-7)$ and a methyl at $\delta 1.40(\mathrm{~d}, J=6.3, \mathrm{H}-$

9). Examination of the ${ }^{13} \mathrm{C}$ and DEPT-135 NMR spectra indicated three of the ten carbon signals 
were quaternary. These signals were attributed to two $\mathrm{sp}^{2}$ carbons at $\delta 175.0(\mathrm{C}-8)$ and $95.7(\mathrm{C}-8 \mathrm{a})$ and a lactone at $\delta 172.3(\mathrm{C}-1)$. COSY cross peaks were observed from H-3 to H-9 and sequentially from $\mathrm{H}-3$ to $\mathrm{H}-7$. HMBC correlations from $\mathrm{H}-4 \mathrm{a}$ to $\mathrm{C}-8, \mathrm{C}-8 \mathrm{a}$ and $\mathrm{C}-1$ also support the presence of an isocoumarin core structure.

Findlay et al. (1995b) has previously reported a family of isocoumarins isolated from a black spruce endophyte. By comparison of their NMR data and optical rotations to previous reports they confirmed that two of their isocoumarins were $(3 R, 4 \mathrm{a} S, 6 R)-6$-hydroxyramulosin and $(3 R, 4 S)-4$ hydroxymellein (Findlay et al., 1995b). The absolute stereochemistry of the remaining, structurally-similar isocoumarins was reported on the biological synthesis assumption that the $R$ stereochemistry at C-3 is common to all (Findlay et al., 1995b). This assumption is continued with the isocoumarins reported here. For compound 1, NOE correlations were observed from H-3 to H4a and from $\mathrm{H}-4$ to $\mathrm{H}-9$. A lack of NOE correlation between $\mathrm{H}-4 \mathrm{a}$ and $\mathrm{H}-6$ indicates the position 6 is of the $R$ configuration, which is the same as an isocoumarin reported by Findlay et al. (1995b). Compound 1 is reported here as a new isocoumarin, $(3 R, 4 S, 4 \mathrm{a} R, 6 R)-4,6,8$-trihydroxy-3-methyl3,4,4a,5,6,7-hexahydro-1H-isochromen-1-one, figure 3.1. 


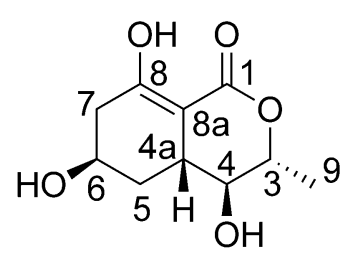

1<smiles>C[C@@H]1C[C@H]2C[C@H](O)CC(O)=C2C(=O)O1</smiles>

2<smiles>C[C@H]1OC(=O)c2c(O)cccc2[C@H]1O</smiles>

3<smiles>C[C@@H]1OC(=O)C2=C(O)C=CC[C@H]2[C@H]1O</smiles>

4<smiles>C[C@@H]1OC(=O)C2=C(O)CCC[C@H]2[C@H]1O</smiles>

5

Figure 3.1: Structures of isocoumarins (1-5) isolated from Phaeocryptopus cf. gaeumannii (DAOM 250863).

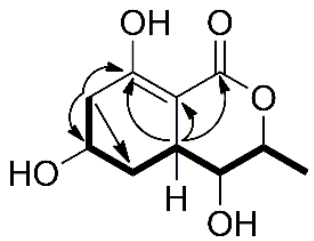

Figure 3.2: Key HMBC and COSY correlations observed for compound 1.

Compound 2 was isolated as a clear solid with the molecular formula $\mathrm{C}_{10} \mathrm{H}_{14} \mathrm{O}_{4}$ determined by a HRMS $[\mathrm{M}+\mathrm{H}]^{+}$peak at $m / z$ 199.0963, indicating four units of unsaturation. The ${ }^{1} \mathrm{H}$ and ${ }^{13} \mathrm{C}$ data for compounds $\mathbf{1}$ and $\mathbf{2}$ were very similar (Table 3.1). The ${ }^{1} \mathrm{H}$ spectra of compound $\mathbf{2}$ revealed an additional methylene at $\delta 1.32(\mathrm{~m}, \mathrm{H}-4)$ and only two oxygenated methines at $\delta 4.56(\mathrm{~m}, \mathrm{H}-3)$ and 4.25 (m, H-6). COSY correlations were observed sequentially from H-3 to H-7, supporting an isocoumarin structure similar to compound $\mathbf{1}$ with a methylene at position 4 opposed to bearing a hydroxyl moiety. The experimentally obtained optical rotation $\left([\alpha]^{25} \mathrm{D} 31.3\right.$ (c $\left.\left.0.06, \mathrm{CHCl}_{3}\right)\right)$ closely matched the previously isolated natural product $\left([\alpha]^{25} 40.8\left(\mathrm{c} 0.0009, \mathrm{CHCl}_{3}\right)\right.$ by Findlay et al. (1995b). As such, compound 2 is reported here as $(3 R, 4 a S, 6 R)-6,8$-dihydroxy-3-methyl3,4,4a,5,6,7-hexahydro-1H-isochromen-1-one. 
Compound 3 was isolated as a white solid with the molecular formula $\mathrm{C}_{10} \mathrm{H}_{10} \mathrm{O}_{4}$ determined by HRMS $\left(m / z 195.0653[\mathrm{M}+\mathrm{H}]^{+}\right)$, indicative of six units of unsaturation. The UV spectra showed absorption maxima at 220, 245 and $315 \mathrm{~nm}$, suggesting the presence of an aromatic ring within the structure. The ${ }^{1} \mathrm{H}$ NMR displayed three aromatic signals at $\delta 7.08$ (dd, $\left.J=7.5,0.8, \mathrm{H}-5\right), 7.57$ $(\mathrm{dd}, J=8.4,7.6, \mathrm{H}-6)$ and $6.94(\mathrm{dd}, J=8.4,0.8, \mathrm{H}-7)$, two oxygenated methines at $\delta 4.56(\mathrm{o}, \mathrm{H}-3)$ and $4.55(\mathrm{o}, \mathrm{H}-4)$ and a methyl group at $\delta 1.47(\mathrm{~d}, J=6.0, \mathrm{H}-9)$. Examination of the ${ }^{13} \mathrm{C}$ and DEPT135 spectra showed four of the ten carbons were quaternary. These signals were ascribed to three $\mathrm{sp}^{2}$ carbons at $\delta 144.1(\mathrm{C}-4 \mathrm{a}), 162.9(\mathrm{C}-8)$ and $108.0(\mathrm{C}-8 \mathrm{a})$ and a lactone at $\delta 170.2(\mathrm{C}-1)$. COSY cross peaks were observed from H-5 through $\mathrm{H}-7$ and from $\mathrm{H}-3$ to $\mathrm{H}-4$ and H-9 suggesting a similar isocoumarin structure as the previously elucidated metabolites 1-2. The experimentally obtained OR $[\alpha]^{25} \mathrm{D}-13.8\left(\mathrm{c} 0.13, \mathrm{CHCl}_{3}\right)$ was in agreement with the natural product $(3 R, 4 S)-4,8$ dihydroxy-3-methylisochroman-1-one, previously reported with an OR of $[\alpha]^{25}-11$ (c 0.0038 , $\mathrm{CHCl}_{3}$ ) by Findlay et al. (1995b).

Compound 4 was isolated as a clear solid with the molecular formula $\mathrm{C}_{10} \mathrm{H}_{12} \mathrm{O}_{4}$ determined by an $[\mathrm{M}+\mathrm{H}]^{+}$peak at $m / z$ 197.0809, indicative of five units of unsaturation. The NMR signals were highly similar to the compounds described above. In comparison to $\mathbf{3}$, compound $\mathbf{4}$ possessed a methine at $\delta 2.68(\mathrm{o}, \mathrm{H}-4 \mathrm{a})$, an inequivalent methylene group at $\delta 2.68(\mathrm{o}, \mathrm{H}-5)$ and $\delta 1.98(\mathrm{~m}, \mathrm{H}-$ 5) and two olefinic protons at $\delta 6.61(\mathrm{~m}, \mathrm{H}-6)$ and $6.07(\mathrm{dd}, J=9.9,3.3, \mathrm{H}-7)$. The reduction of the olefin group at C-4a to C-5 is supported a COSY correlation between H-4a and H-5 as observed for compounds $\mathbf{1}$ and 2. Comparison of the experimentally obtained ${ }^{1} \mathrm{H}$ and ${ }^{13} \mathrm{C} \mathrm{NMR}$ was in accordance an isocoumarin reported by Findlay et al. (1995b). The experimental optical rotation $\left([\alpha]^{25} \mathrm{D} 94.4\left(\mathrm{c} 0.03, \mathrm{CHCl}_{3}\right)\right)$ had the same sign and similar magnitude to this isocoumarin $\left([\alpha]^{25} \mathrm{D}\right.$ 
164.0 (c 0.014, $\mathrm{CHCl}_{3}$; Findlay et al., 1995b)). As such, compound 4 is reported here as $(3 R, 4 S, 4 \mathrm{a} R)$-4,8-dihydroxy-3-methyl-3,4,4a,5-tetrahydro-1H-isochromen-1-one, figure 3.1 .

Compound 5 was also isolated as a white solid with the molecular formula $\mathrm{C}_{10} \mathrm{H}_{14} \mathrm{O}_{4}$ determined by HRMS $m / z 199.0963[\mathrm{M}+\mathrm{H}]]^{+}$, indicative of four units of unsaturation. The ${ }^{1} \mathrm{H}$ and ${ }^{13} \mathrm{C}$ data for compound $\mathbf{5}$ were very similar to other biosynthetically related isocoumarins isolated from DAOM 250863 (Table 3.1). In comparison to $\mathbf{4}$, compound 5 contrasted by the presence of an additional inequivalent methylene group at $\delta 1.99(\mathrm{~m}, \mathrm{H}-6)$ and $1.63(\mathrm{~m}, \mathrm{H}-6)$, a methylene group at $\delta 2.37$ $(\mathrm{o}, \mathrm{H}-7)$ and a lack of olefinic signals. Reduction of the C-6 to C-7 double bond in compound 4 is supported by the chemical shifts and COSY cross peaks observed sequentially from H-4a to H-7. Comparison of the experimentally obtained ${ }^{1} \mathrm{H}$ and ${ }^{13} \mathrm{C}$ NMR was in accordance an isocoumarin reported by Findlay et al. (1995b). The experimental optical rotation of $[\alpha]^{25} \mathrm{D} 10.9\left(\mathrm{c} 0.5, \mathrm{CHCl}_{3}\right)$ was in accordance that reported $\left([\alpha]^{25} \mathrm{D} 16.7\left(\mathrm{c} 0.001, \mathrm{CHCl}_{3}\right)\right.$ by Findlay et al. (1995b). Compound 5 is reported here as $(3 R, 4 S, 4 \mathrm{a} R)-4,8$-dihydroxy-3-methyl-3,4,4a,5,6,7-hexahydro- $1 \mathrm{H}$ isochromen-1-one. 
Table 3.1: ${ }^{1} \mathrm{H}$ and ${ }^{13} \mathrm{C}$ NMR data of isocoumarins 1-5 in $\mathrm{CD}_{3} \mathrm{OD}$.

\begin{tabular}{|c|c|c|c|c|c|c|c|c|c|c|}
\hline \multirow[b]{2}{*}{ Position } & \multicolumn{2}{|c|}{1} & \multicolumn{2}{|c|}{2} & \multicolumn{2}{|c|}{3} & \multicolumn{2}{|c|}{4} & \multicolumn{2}{|c|}{5} \\
\hline & $\delta_{\mathrm{C}}$, type & $\delta_{\mathrm{H}}(J, \mathbf{H z})$ & $\delta_{\mathrm{C}}$, type & $\delta_{\mathrm{H}}(J, \mathbf{H z})$ & $\delta_{\mathrm{C}}$, type & $\delta_{\mathrm{H}}(J, \mathbf{H z})$ & $\delta_{\mathrm{C}}$, type & $\delta_{\mathrm{H}}(J, \mathrm{~Hz})$ & $\begin{array}{c}\delta_{\mathrm{C}} \\
\text { type }\end{array}$ & $\delta_{\mathrm{H}}(J, \mathbf{H z})$ \\
\hline 1 & 172.3 & & 173.3 & & 170.2 & & 172.7 & & 172.5 & \\
\hline 3 & $81, \mathrm{CH}$ & $\begin{array}{c}4.2, \mathrm{dq} \\
(9.3,6.3)\end{array}$ & 78.6, CH & $4.56, \mathrm{~m}$ & $81, \mathrm{CH}$ & 4.56, o & $80.1, \mathrm{CH}$ & $\begin{array}{c}4.15, \mathrm{dq} \\
(9.4,6.3)\end{array}$ & $80.5, \mathrm{CH}$ & $\begin{array}{c}4.16, \mathrm{dq} \\
(9.3,6.2)\end{array}$ \\
\hline 4 & 73.8, CH & $\begin{array}{c}3.11, \mathrm{dd} \\
(10.5,9.3)\end{array}$ & $36.7, \mathrm{CH}_{2}$ & $1.32, \mathrm{~m}$ & $69.5, \mathrm{CH}$ & $4.55, \mathrm{o}$ & $74.9, \mathrm{CH}$ & $3.32, \mathrm{o}$ & 73.9, $\mathrm{CH}$ & $\begin{array}{c}3.04, \mathrm{t} \\
(9.3)\end{array}$ \\
\hline $4 a$ & $34.9, \mathrm{CH}$ & $2.71, \mathrm{~m}$ & 27.7, $\mathrm{CH}$ & $2.88, \mathrm{~m}$ & 144.1 & & $38.8, \mathrm{CH}$ & $2.68, \mathrm{o}$ & $40.9, \mathrm{CH}$ & $2.35, \mathrm{o}$ \\
\hline \multirow[t]{2}{*}{5} & $33.3, \mathrm{CH}_{2}$ & & $37.9, \mathrm{CH}_{2}$ & $1.96, \mathrm{~m}$ & $117.4, \mathrm{CH}$ & $\begin{array}{c}7.08, \mathrm{dd} \\
(7.5,0.8)\end{array}$ & $28.7, \mathrm{CH}_{2}$ & $2.68, \mathrm{o}$ & 27.1, $\mathrm{CH}_{2}$ & $2.24, \mathrm{~m}$ \\
\hline & & $1.25, \mathrm{~m}$ & & & & & & $1.98, \mathrm{~m}$ & & $1.10, \mathrm{~m}$ \\
\hline \multirow[t]{2}{*}{6} & $64.1, \mathrm{CH}$ & $4.28, \mathrm{~m}$ & $64.3, \mathrm{CH}$ & $4.25, \mathrm{~m}$ & $137.6, \mathrm{CH}$ & $\begin{array}{c}7.57, \mathrm{dd} \\
(8.4,7.6)\end{array}$ & $142.4, \mathrm{CH}$ & $6.61, \mathrm{~m}$ & 21.4, $\mathrm{CH}_{2}$ & $1.99, \mathrm{~m}$ \\
\hline & & & & & & & & & & $1.63, \mathrm{~m}$ \\
\hline \multirow[t]{2}{*}{7} & $38, \mathrm{CH}_{2}$ & $2.64, \mathrm{~m}$ & $38, \mathrm{CH}_{2}$ & $\begin{array}{c}2.65, \mathrm{dq} \\
(19.4,2.6)\end{array}$ & $117.5, \mathrm{CH}$ & $\begin{array}{c}6.94, \mathrm{dd} \\
(8.4,0.8)\end{array}$ & $124.8, \mathrm{CH}$ & $\begin{array}{c}6.07, \mathrm{dd} \\
(9.9,3.3)\end{array}$ & 29.7, $\mathrm{CH}_{2}$ & $2.37, \mathrm{o}$ \\
\hline & & $\begin{array}{c}2.33, \mathrm{dd} \\
(19.0,1.3)\end{array}$ & & $\begin{array}{c}2.33, \mathrm{dq} \\
(19.4,1.4)\end{array}$ & & & & & & \\
\hline 8 & 175.0 & & 173.8 & & 162.9 & & 170.2 & & 177.4 & \\
\hline $8 a$ & 95.7 & & 97.6 & & 108 & & 92.2 & & 96.1 & \\
\hline 9 & $18.9, \mathrm{CH}_{3}$ & $\begin{array}{c}1.40, \mathrm{~d} \\
(6.3)\end{array}$ & $22, \mathrm{CH}_{3}$ & $\begin{array}{c}1.37, \mathrm{~d} \\
(6.3)\end{array}$ & $17.8, \mathrm{CH}_{3}$ & $\begin{array}{c}1.47, \mathrm{~d} \\
(6.0)\end{array}$ & $18.3, \mathrm{CH}_{3}$ & $\begin{array}{c}1.42, \mathrm{~d} \\
(6.3)\end{array}$ & $18.7, \mathrm{CH}_{3}$ & $\begin{array}{l}1.4, \mathrm{~d} \\
(6.4)\end{array}$ \\
\hline
\end{tabular}


Table 3.2: Physicochemical data for isocoumarin compounds 1-5.

\begin{tabular}{|c|c|c|c|c|c|}
\hline Properties & 1 & 2 & 3 & 4 & 5 \\
\hline Appearance & clear solid & clear solid & white solid & clear solid & white solid \\
\hline $\begin{array}{l}\text { Empirical } \\
\text { formula }\end{array}$ & $\mathrm{C}_{10} \mathrm{H}_{14} \mathrm{O}_{5}$ & $\mathrm{C}_{10} \mathrm{H}_{14} \mathrm{O}_{4}$ & $\mathrm{C}_{10} \mathrm{H}_{10} \mathrm{O}_{4}$ & $\mathrm{C}_{10} \mathrm{H}_{12} \mathrm{O}_{4}$ & $\mathrm{C}_{10} \mathrm{H}_{14} \mathrm{O}_{4}$ \\
\hline $\mathrm{HRMS}[\mathrm{M}+\mathrm{H}]^{+}$ & 215.0912 & 199.0963 & 195.0653 & 197.0809 & 199.0963 \\
\hline $\begin{array}{c}\text { Calculated } \\
{[\mathrm{M}+\mathrm{H}]^{+}}\end{array}$ & 215.0914 & 199.0965 & 195.0652 & 197.0808 & 199.0965 \\
\hline $\begin{array}{l}\mathrm{OR}[\alpha]^{25} \mathrm{D} \\
\left(\mathrm{CHCl}_{3}\right)\end{array}$ & $\begin{array}{c}17.8 \\
(\mathrm{c} 0.18)^{*}\end{array}$ & $\begin{array}{c}31.3 \\
(\mathrm{c} 0.06)\end{array}$ & $\begin{array}{c}-13.8 \\
(c 0.13)\end{array}$ & $\begin{array}{c}94.4 \\
(\mathrm{c} 0.03)\end{array}$ & $\begin{array}{c}10.9 \\
(\mathrm{c} 0.5)\end{array}$ \\
\hline $\begin{array}{c}\mathrm{UV}(\mathrm{MeOH}) \\
\lambda \max \mathrm{nm}(\log \varepsilon)\end{array}$ & $\begin{array}{l}200(3.12), \\
265(3.50)\end{array}$ & $\begin{array}{l}200(3.10) \\
265(3.60)\end{array}$ & $\begin{array}{l}220(3.32) \\
245(3.23) \\
315(3.06)\end{array}$ & $\begin{array}{l}205(3.41) \\
320(3.36)\end{array}$ & $\begin{array}{l}200(2.21), \\
265(3.89)\end{array}$ \\
\hline
\end{tabular}

\section{Metabolites of an Undescribed Rhytismatales species (NB236-1A)}

The major metabolite from NB-236-1A was isolated as light yellow solid with the molecular formula $\mathrm{C}_{14} \mathrm{H}_{20} \mathrm{O}_{6}$ determined by HRMS $\left(\mathrm{m} / z\right.$ 285.1332 $\left.[\mathrm{M}+\mathrm{H}]^{+}\right)$. The ${ }^{1} \mathrm{H}$ and ${ }^{13} \mathrm{C}$ spectra revealed eighteen proton and fourteen carbon signals (Table 3.3), respectively. The UV spectrum displayed absorption maxima at 205, 230 and $270 \mathrm{~nm}$. Examination of the mass spectrometry and spectroscopic data (Table 3.4) suggested compound $\mathbf{6}$ possessed a trisubstituted dihydropyrone-2one core structure with five units of unsaturation attributed to one ring and four double bonds. The 
${ }^{1} \mathrm{H}$ NMR spectrum displayed a single terminal methyl at $\delta 0.89(\mathrm{t}, J=7.0)$, five aliphatic methylene signals between $\delta 1.28$ and 1.64, an inequivalent methylene at $\delta 2.76(\mathrm{dd}, J=17.2,6.6)$ and 2.96 (dd, $J=17.2,4.0)$, a methylene adjacent to a carbonyl at $\delta 2.85(\mathrm{dt}, J=7.1,1.4)$ and an oxygenated methine at $\delta$ 4.90. Examination of the ${ }^{13} \mathrm{C}$ and DEPT spectra revealed five of the fourteen carbon signals were quaternary. These signals are attributed to a ketone at $\delta 195.3$, a lactone at $\delta 174.1$, a carboxylic acid at $\delta 172.6$, and two $\mathrm{sp}^{2}$ carbons at $\delta 99.6$ and 197.5. COSY corrections were observed sequentially from the triplet methyl H-8' $(\delta 0.89)$ to H-2' $(2.85)$ where five of the methylene signals $(\delta 0.89-1.65)$ appeared in the aliphatic region of the ${ }^{1} \mathrm{H}$ NMR spectrum. The chemical shift of $\mathrm{H}-2$ ' and an $\mathrm{HMBC}$ correlation from $\mathrm{H}-2$ ' to $\mathrm{Cl}^{\prime}$ ' $\delta$ 195.3) place $\mathrm{H}-2$ ' vicinal to a carbonyl supporting the presence of a 1-octanal moiety in compound $\mathbf{6}$. Moreover, the dominant $\mathrm{MS}^{2}$ fragment ion of compound $\mathbf{6}$ at $\mathrm{m} / \mathrm{z} 127.1[\mathrm{M}+\mathrm{H}]^{+}$suggested a $\mathrm{C}_{8}$ side-chain bearing a single oxygen atom. The remaining COSY cross-peak was observed between H-5 ( $\delta 2.76$ and 2.96$)$ and H-6 ( $\delta 4.90)$. HMBC correlations were observed from both H-5 and H-6 to C-4 $(\delta 197.5)$ and C-7 ( $\delta$ 172.6), where H-6 showed an additional correlation to C-2 $(\delta 174.1)$. These data established the presence of a trisubstituted 5,6-dihydropyrone-2-one core structure with a carboxylic acid functionality bound to $\mathrm{C}-6$. The chemical shifts of $\mathrm{C}-3$ and $\mathrm{C}-4$, and the fact compound $\mathbf{6}$ undergoes a slow keto/enol tautomerization when left in $\mathrm{CD}_{3} \mathrm{OD}$ indicated the 1-octanal moiety is attached at C-3. This type of chemical equilibrium was observed for podoblastin A, a metabolite with a similar 3-acyl-4-hydroxy-5,6-dihydropyrones core structure (Miyakado et al., 1982).

The absolute configuration of compound $\mathbf{6}$ at C-6 was determined to be $R$ based on comparison of its experimentally determined optical rotation, $[\alpha]^{25} \mathrm{D}-30\left(\mathrm{c} 0.04, \mathrm{CHCl}_{3}\right)$, to structurally similar compounds with a single chiral center. The absolute stereochemistry of podoblastin A at C-6 was 
determined to be $R$ by stereoselective synthesis which had an optical rotation of $[\alpha]_{\mathrm{D}}-27.08$ (c 1.12, $\mathrm{CHCl}_{3}$; Ichimoto et al., 1988; Miyakado et al., 1982). Dictyopyrone A shares the same core structure and is of the $S$ configuration at C-6. The optical rotation of this metabolite as a natural product is reported as $[\alpha]^{25} \mathrm{D} 33.8\left(\mathrm{c} 0.07, \mathrm{CHCl}_{3}\right)$ and $[\alpha]^{25} \mathrm{D} 33.9\left(\mathrm{c} 1.23, \mathrm{CHCl}_{3}\right)$ when prepared synthetically using chiral reagents (Takaya et al., 2000). Since all of the structurally similar dihydropyrones have one chiral center at the same position, compound $\mathbf{6}$ is reported here as a new structure, (R)-4-hydroxy-5-octanoyl-6-oxo-3,6-dihydro-2H-pyran-2-carboxylic acid or rhytismatone A.

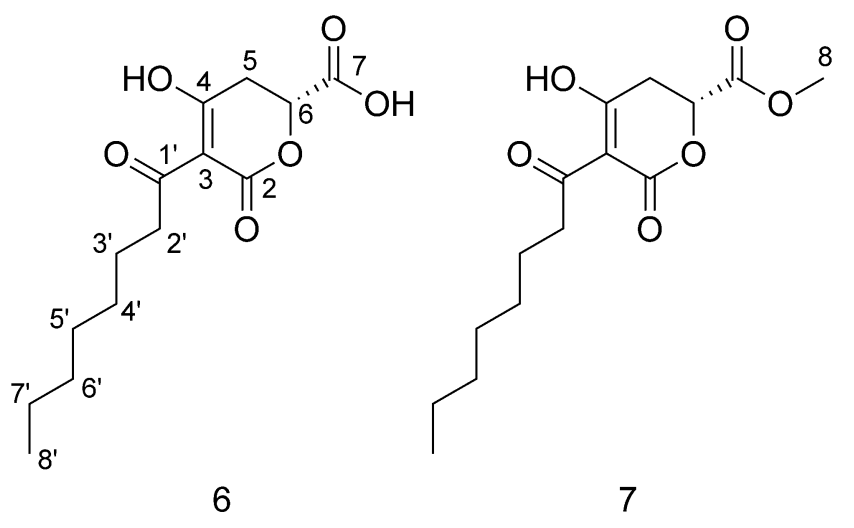

Figure 3.3: Structures of rhytismatones A (6) and B (7) isolated from the unidentified Rhytismatales sp. 


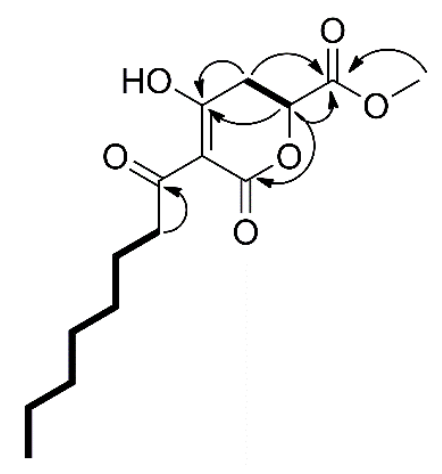

Figure 3.4: Key HMBC and COSY correlations observed for compound 7.

Compound 7 was isolated as a light yellow solid with the molecular formula $\mathrm{C}_{15} \mathrm{H}_{22} \mathrm{O}_{6}$ determined by $\operatorname{HRSM}\left(\mathrm{m} / \mathrm{z} 299.1489[\mathrm{M}+\mathrm{H}]^{+}\right)$. The increase in mass for compound 7 compared to 6 corresponds to the addition of a methyl group. Examination of the $\mathrm{MS}^{2}$ spectra compound 7 revealed the same dominant $m / z$ 127.1 $[\mathrm{M}+\mathrm{H}]^{+}$fragment ion suggesting it also possessed a 1octanal moiety. The ${ }^{1} \mathrm{H}$ and ${ }^{13} \mathrm{C}$ NMR spectra (Table 3.3) of compounds 6 and 7 were very similar. However, the ${ }^{1} \mathrm{H}$ and ${ }^{13} \mathrm{C}$ spectra of 7 displayed additional signals at $\delta 3.67$ (s) and $\delta 52.5$, respectively, indicative of a methyl ester functionality. An HMBC correlation from the singlet methyl H-8 ( $\delta$ 3.67) to C-7 ( $\delta$ 171.4) supported the presence of a methyl ester in compound 7 , compared to the carboxylic acid in compound 6. The optical rotation of compound $7[\alpha]_{D}-67.7(\mathrm{c}$ $0.4 \mathrm{CHCl}_{3}$ ) was also negative indicating an $R$ configuration at C-6. Compound 7 is reported here as a new structure, $(R)$-methyl 4-hydroxy-5-octanoyl-6-oxo-3,6-dihydro-2H-pyran-2-carboxylate or rhytismatone B. 
Table 3.3: ${ }^{1} \mathrm{H}$ and ${ }^{13} \mathrm{C}$ NMR data of compounds 6-7 in $\mathrm{CD}_{3} \mathrm{OD}$.

\begin{tabular}{|c|c|c|c|c|}
\hline \multirow[b]{2}{*}{ Position } & \multicolumn{2}{|r|}{6} & \multicolumn{2}{|r|}{7} \\
\hline & $\delta \mathrm{c}$, type & $\delta_{\mathrm{H}}(J, \mathbf{H z})$ & $\delta \mathrm{c}$, type & $\delta_{\mathrm{H}}(\mathrm{J}, \mathrm{Hz})$ \\
\hline 2 & 174.1 & & 174.1 & \\
\hline 3 & 99.6 & & 99.6 & \\
\hline 4 & 197.5 & & 197.6 & \\
\hline \multirow[t]{2}{*}{5} & $36.6, \mathrm{CH}_{2}$ & $2.96, \mathrm{dd}(17.2,4.0)$ & $36.5, \mathrm{CH}_{2}$ & $3.00, \mathrm{dd}(17.1,3.9)$ \\
\hline & & $2.76, \mathrm{dd}(17.2,6.6)$ & & $2.85, \mathrm{o}$ \\
\hline 6 & $79.1, \mathrm{CH}$ & $4.90, \mathrm{o}^{*}$ & $78.9, \mathrm{CH}$ & $4.93, \mathrm{o}^{*}$ \\
\hline 7 & 172.6 & & 171.4 & \\
\hline 8 & & & $52.5, \mathrm{CH}_{3}$ & $3.67, \mathrm{~s}$ \\
\hline 1 ' & 195.3 & & 195.8 & \\
\hline 2 & $36.5, \mathrm{CH}_{2}$ & $2.85, \mathrm{dt}(7.1,1.4)$ & $36.5, \mathrm{CH}_{2}$ & $2.85, \mathrm{o}$ \\
\hline 3 ' & 26.7, $\mathrm{CH}_{2}$ & $1.65, \mathrm{p}(7.4)$ & 26.6, $\mathrm{CH}_{2}$ & $1.65, \mathrm{p}(7.4)$ \\
\hline 4 ' & $30.1, \mathrm{CH}_{2}$ & $1.33, \mathrm{o}$ & $30.1, \mathrm{CH}_{2}$ & $1.33, \mathrm{o}$ \\
\hline 5 , & $30.4, \mathrm{CH}_{2}$ & $1.33, \mathrm{o}$ & $30.4, \mathrm{CH}_{2}$ & $1.33, \mathrm{o}$ \\
\hline 6' & $32.8, \mathrm{CH}_{2}$ & $1.28, \mathrm{o}$ & $32.8, \mathrm{CH}_{2}$ & $1.28, \mathrm{o}$ \\
\hline 7 & $23.6, \mathrm{CH}_{2}$ & $1.31, \mathrm{o}$ & $23.6, \mathrm{CH}_{2}$ & $1.31, \mathrm{o}$ \\
\hline 8 & $14.4, \mathrm{CH}_{3}$ & $0.89, \mathrm{t}(7.0)$ & $14.4, \mathrm{CH}_{3}$ & $0.89, \mathrm{t}(7.0)$ \\
\hline
\end{tabular}

*-Overlapping with $\mathrm{CD}_{3} \mathrm{OD}$ solvent peak at $4.90 \mathrm{ppm}$. 
Table 3.4: Physicochemical data for rhytismatones A and B (6-7).

\begin{tabular}{c|cc} 
Properties & $\mathbf{6}$ & 7 \\
Appearance & light yellow solid & light yellow solid \\
Molecular formula & $\mathrm{C}_{14} \mathrm{H}_{20} \mathrm{O}_{6}$ & $\mathrm{C}_{15} \mathrm{H}_{22} \mathrm{O}_{6}$ \\
HRMS $[\mathrm{M}+\mathrm{H}]^{+}$ & 285.1332 & 299.1489 \\
Calculated $[\mathrm{M}+\mathrm{H}]^{+}$ & 285.1332 & 299.1489 \\
OR $[\alpha]^{25}\left(\mathrm{CHCl}{ }_{3}\right)$ & $-30.0(\mathrm{c} 0.04)$ & $-67.7(\mathrm{c} 0.4)$ \\
$\mathrm{UV}(\mathrm{MeOH}) \lambda$ max nm $(\log \varepsilon)$ & $205(3.72), 230(3.70)$, & $230(4.02), 270(4.21)$
\end{tabular}

Compound 8 was isolated as a white solid with the molecular formula $\mathrm{C}_{11} \mathrm{H}_{12} \mathrm{O}_{4}$ determined by HRMS $\left(m / z\right.$ of $\left.209.0808[\mathrm{M}+\mathrm{H}]^{+}\right)$, indicating six units of unsaturation. The UV spectrum displayed absorption maxima at 235 and $265 \mathrm{~nm}$ suggesting an aromatic ring within the structure. The ${ }^{1} \mathrm{H}$ NMR spectrum displayed a methoxy functionality at $\delta 3.92(\mathrm{~s}, \mathrm{H}-10)$, an oxygenated methylene at $\delta 5.19(\mathrm{~s}, \mathrm{H}-3)$ and two methyl groups at $\delta 2.12(\mathrm{~s}, \mathrm{H}-8)$ and $2.15(\mathrm{~s}, \mathrm{H}-9)$. The ${ }^{13} \mathrm{C}$ and DEPT-135 revealed that seven of the eleven carbon signals were quaternary. These signals were attributed to two oxygenated $\mathrm{sp}^{2}$ carbons at $\delta 161.8(\mathrm{C}-5)$ and $157.3(\mathrm{C}-7)$, four $\mathrm{sp}^{2}$ carbons at $\delta 148.2(\mathrm{C}-3 \mathrm{a}), 114.5(\mathrm{C}-4), 119.6(\mathrm{C}-6), 108.8(\mathrm{C}-7 \mathrm{a})$ and a lactone at $\delta 172.0(\mathrm{C}-1)$. All signals from the ${ }^{1} \mathrm{H}$ spectrum appeared as singlets, thus, no COSY correlations were observed. HMBC correlations observed from $\mathrm{H}-8$ to $\mathrm{C}-3 \mathrm{a}, \mathrm{C}-4$ and $\mathrm{C}-5$, from $\mathrm{H}-9$ to $\mathrm{C}-5, \mathrm{C}-6$ and $\mathrm{C}-7$ as well as from $\mathrm{H}-10$ to $\mathrm{C}-7$ suggested the presence of a fully substituted aromatic ring. The observed HMBC 
correlations indicate the methyl groups are meta arranged since they both couple to the hydroxylated C-5. Additional HMBC cross peaks were observed from the $\mathrm{H}-3$ to $\mathrm{C}-1, \mathrm{C}-3 \mathrm{a}$ and C-7a that indicate compound $\mathbf{8}$ is a phthalide. The ${ }^{1} \mathrm{H}$ NMR data (Table 3.5) for compound $\mathbf{8}$ is in accordance with the synthetic product 5-hydroxy-7-methoxy-4,6-dimethylisobenzofuran-1(3H)one (Katoh et al., 2008).

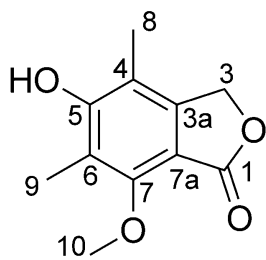

8

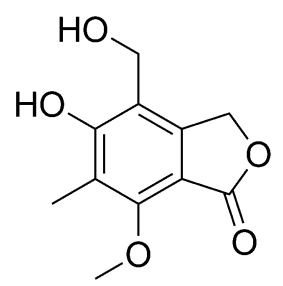

9

Figure 3.5: Structures of phthalides (8-9) isolated from the unidentified Rhytismatales sp.

Compound 9 was isolated as a white solid with the molecular formula $\mathrm{C}_{11} \mathrm{H}_{12} \mathrm{O}_{5}$ determined by an $[\mathrm{M}+\mathrm{H}]]^{+}$ion at $m / z$ 225.0757. The ${ }^{1} \mathrm{H}$ and ${ }^{13} \mathrm{C}$ NMR data (Table 3.5) for compounds 8 and 9 were very similar, indicating both structures were substituted phthalides. Compound 9 was $16 \mathrm{Da}$ heavier compared to $\mathbf{8}$, corresponding to an additional oxygen atom. The ${ }^{1} \mathrm{H}$ NMR spectrum displayed an additional hydroxylated methylene at $\delta 4.75(\mathrm{~s}, \mathrm{H}-8)$ that replaced a methyl functionality. HMBC correlations were observed from H-8 to C-3a, C-4 and C-5 demonstrated the methyl group of compound $\mathbf{8}$ at position 8 was replaced by a hydroxylated methylene. The ${ }^{1} \mathrm{H}$ data for 9 are in accordance with the synthetic intermediate 5-hydroxy-4-(hydroxymethyl)-7-methoxy6-methylisobenzofuran-1(3H)-one reported by Cimmino et al. (2013). 
Table 3.5: ${ }^{1} \mathrm{H}$ and ${ }^{13} \mathrm{C}$ NMR data for phthalides 8 and 9 in $\mathrm{CD}_{3} \mathrm{OD}$.

\begin{tabular}{ccccc}
\hline \multirow{2}{*}{ Position } & \multicolumn{3}{c}{$\mathbf{8}$} & \multicolumn{2}{c}{$\mathbf{9}$} \\
\cline { 2 - 5 } $\mathbf{1}$ & $\boldsymbol{\delta}_{\mathbf{C}, \text { type }}$ & $\boldsymbol{\delta}_{\mathbf{H}}(\boldsymbol{J}, \mathbf{H z})$ & 171.7 & $\boldsymbol{\delta}_{\mathbf{H}}(\boldsymbol{J}, \mathbf{H z})$ \\
$\mathbf{3}$ & 172.0 & & $70.1, \mathrm{CH}_{2}$ & $5.30, \mathrm{~s}$ \\
$\mathbf{3 a}$ & $69.8, \mathrm{CH}_{2}$ & $5.19, \mathrm{~s}$ & 147.6 & \\
$\mathbf{4}$ & 148.2 & & 117.4 & \\
$\mathbf{5}$ & 114.5 & & 162 & \\
$\mathbf{6}$ & 161.8 & & 120.1 & \\
$\mathbf{7}$ & 119.6 & & 158.6 & \\
$\mathbf{7}$ & 157.3 & & 109.2 & $4.75, \mathrm{~s}$ \\
$\mathbf{8}$ & 108.8 & $2.12, \mathrm{~s}$ & $58.9, \mathrm{CH}_{2}$ & $2.15, \mathrm{~s}$ \\
$\mathbf{9}$ & $11.3, \mathrm{CH}_{3}$ & $2.15, \mathrm{~s}$ & $8.8, \mathrm{CH}_{3}$ & $3.95, \mathrm{~s}$ \\
\hline $\mathbf{1 0}$ & $9.1, \mathrm{CH}_{3}$ & $3.92, \mathrm{~s}$ & $62.5, \mathrm{CH}_{3}$ & \\
\hline
\end{tabular}

Table 3.6: Physicochemical data for phthalide metabolites (8-9).

\begin{tabular}{c|cc} 
Properties & $\mathbf{8}$ & $\mathbf{9}$ \\
Appearance & white solid & white solid \\
Empirical formula & $\mathrm{C}_{11} \mathrm{H}_{12} \mathrm{O}_{4}$ & $\mathrm{C}_{11} \mathrm{H}_{12} \mathrm{O}_{5}$ \\
HRMS $[\mathrm{M}+\mathrm{H}]^{+}$ & 209.0808 & 225.0757 \\
Calculated $[\mathrm{M}+\mathrm{H}]^{+}$ & 209.0808 & 225.0757 \\
OR $[\alpha]^{25}(\mathrm{MeOH})$ & & \\
$\mathrm{UV}(\mathrm{MeOH}) \lambda \max \mathrm{nm}(\log \varepsilon)$ & $230(3.44), 265(3.48)$ & $230(3.41), 265(3.45)$
\end{tabular}


Interpretation of the ${ }^{1} \mathrm{H}$ and ${ }^{13} \mathrm{C}$ NMR data (Table 3.7) for compounds $\mathbf{1 0}$ and $\mathbf{1 1}$ determined they were structurally similar isocoumarins. Their physiochemical properties are reported in Table 3.8. Compound $\mathbf{1 0}$ was isolated as a white solid with the molecular formula $\mathrm{C}_{11} \mathrm{H}_{10} \mathrm{O}_{4}$ determined by HRMS $\left(m / z 207.0651[\mathrm{M}+\mathrm{H}]^{+}\right)$, indicative of seven units of unsaturation. The ${ }^{1} \mathrm{H}$ NMR spectrum displayed resonances at $\delta 3.86$ (s, H-6-OMe) suggesting a methoxy functionality, two metacoupled aromatic protons at $\delta 6.44(\mathrm{~d}, J=2.1, \mathrm{H}-5)$ and $\delta 6.45(\mathrm{~d}, J=2.1, \mathrm{H}-7)$, an olefinic proton $\delta 6.39$ (q, $J=0.8, \mathrm{H}-4)$ and a methyl group at $\delta 2.24\left(\mathrm{~d}, J=0.8, \mathrm{H}-1^{\prime}\right)$. Examination of the ${ }^{13} \mathrm{C}$ and DEPT-135 spectra determined six of the eleven carbon signals were quaternary. These signals represented three oxygenated carbons at $\delta 155.9$ (C-3), 168.8 (C-6) and 164.8 (C-8), two conjugated $\mathrm{sp}^{2}$ carbons at $\delta 142.1(\mathrm{C}-4 \mathrm{a})$ and $100.6(\mathrm{C}-8 \mathrm{a})$ and a carbonyl at $\delta 170.5(\mathrm{C}-1)$. COSY cross peaks from $\mathrm{H}-5$ to $\mathrm{H}-7$ and $\mathrm{H}-4$ to $\mathrm{H}-9$ as well as an $\mathrm{HMBC}$ correlation from $\mathrm{H}-5$ to $\mathrm{C}-4$ support a fully conjugated isocoumarin structure. The ${ }^{1} \mathrm{H}$ NMR data reported here are in accordance with the synthetic product 8-hydroxy-6-methoxy-3-methyl-isochromen-1-one reported by Nozawa et al. (1980).

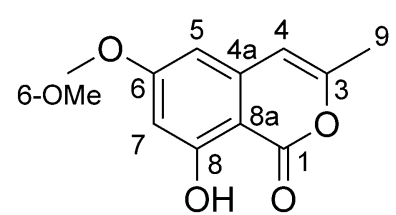

10

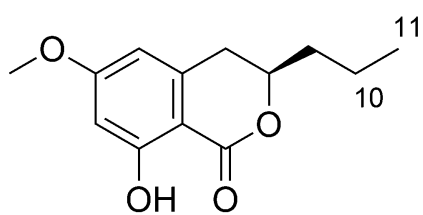

11

Figure 3.6: Structures of isocoumarins (10-11) isolated from Rhytismatales sp.

Compound 11 was isolated as a light yellow solid with the molecular formula $\mathrm{C}_{13} \mathrm{H}_{16} \mathrm{O}_{4}$ determined by HRMS $\left(\mathrm{m} / z\right.$ of $\left.237.1112[\mathrm{M}+\mathrm{H}]^{+}\right)$, indicative of six units of unsaturation. Similar to $\mathbf{1 0}$, the ${ }^{1} \mathrm{H}$ 
NMR spectrum of compound 11 revealed a methoxy group at $\delta 3.82$ (s, H-6-OMe) and two metacoupled aromatic protons at $\delta 6.37(\mathrm{~d}, J=2.3, \mathrm{H}-5)$ and $\delta 6.38(\mathrm{~d}, J=2.3, \mathrm{H}-7)$. In contrast, three inequivalent methylene groups at $\delta 2.95$ (dd, $J=16.3,3.6 \mathrm{~Hz}, \mathrm{H}-4), 2.87$ (dd, $J=16.3,11.2, \mathrm{H}-4)$, $\delta 1.80(\mathrm{~m}, \mathrm{H}-9), 1.69(\mathrm{~m}, \mathrm{H}-9)$, and $\delta 1.59(\mathrm{~m}, \mathrm{H}-10), 1.50(\mathrm{~m}, \mathrm{H}-10)$, an oxygenated proton at $\delta$ $4.55(\mathrm{~m}, \mathrm{H}-3)$ and alkyl methyl moiety at $\delta 0.99(\mathrm{t}, 7.2, \mathrm{H}-11)$ were observed. COSY cross peaks from $\mathrm{H}-3$ to $\mathrm{H}-4$ and $\mathrm{H}-9$ and sequentially from $\mathrm{H}-9$ to $\mathrm{H}-11$ indicated a reduced isocoumarin structure with a longer aliphatic chain compared to compound 10. The lack of olefin group creates a chiral center at position 3 , which is supported by the alkyl chain protons having inequivalent methylene signals. The stereochemistry at $\mathrm{C}-3$ was determined to be $(R)$ based on comparisons of the experimental optical rotation $\left([\alpha]^{25} \mathrm{D}-8.0\left(\mathrm{c} 0.15, \mathrm{CHCl}_{3}\right)\right)$ to the published data for the synthetic $(R)\left([\alpha]^{19} \mathrm{D}-151\left(\mathrm{c} 1.10, \mathrm{CHCl}_{3}\right)\right)$ and $(S)\left([\alpha]^{24} \mathrm{D}+150\left(\mathrm{c} 1.46, \mathrm{CHCl}_{3}\right)\right)$ configurations (Uchida et al., 1998). Compound 11 was determined to be (R)-8-hydroxy-6-methoxy-3-propylisochroman-1one. The structures of compounds $\mathbf{1 0}$ and $\mathbf{1 1}$ are shown in Figure 3.6 below. 
Table 3.7: ${ }^{1} \mathrm{H}$ and ${ }^{13} \mathrm{C}$ NMR data for isocoumarins $\mathbf{1 0 - 1 1}$ in $\mathrm{CD}_{3} \mathrm{OD}$.

\begin{tabular}{|c|c|c|c|c|}
\hline \multirow[b]{2}{*}{ Position } & \multicolumn{2}{|c|}{10} & \multicolumn{2}{|r|}{11} \\
\hline & $\delta_{\mathrm{C}}$, type & $\delta_{\mathrm{H}}(J, \mathrm{~Hz})$ & $\delta_{\mathrm{c}}$, type & $\delta_{\mathrm{H}}(J, \mathrm{~Hz})$ \\
\hline 1 & 170.5 & & 171.6 & \\
\hline 3 & 155.9 & & $80.6, \mathrm{CH}$ & $4.55, \mathrm{~m}$ \\
\hline \multirow[t]{2}{*}{4} & $105.5, \mathrm{CH}$ & $6.39, \mathrm{q}(0.8)$ & $34, \mathrm{CH}_{2}$ & 2.95, dd $(16.3,3.6)$ \\
\hline & & & & $2.87, \mathrm{dd}(16.3,11.2)$ \\
\hline $4 \mathbf{a}$ & 142.1 & & 143.3 & \\
\hline 5 & $101.6, \mathrm{CH}$ & $6.45, \mathrm{~d}(2.1)$ & 107.1, CH & $6.38, \mathrm{~d}(2.3)$ \\
\hline 6 & 168.8 & & 167.6 & \\
\hline 7 & 101.4, CH & $6.44, \mathrm{~d}(2.1)$ & $100.4, \mathrm{CH}$ & $6.37, \mathrm{~d}(2.3)$ \\
\hline 8 & 164.8 & & 165.6 & \\
\hline $\mathbf{8 a}$ & 100.6 & & 102.7 & \\
\hline \multirow[t]{2}{*}{9} & $19, \mathrm{CH}_{3}$ & $2.24, \mathrm{~d}(0.8)$ & $38, \mathrm{CH}_{2}$ & $1.80, \mathrm{~m}$ \\
\hline & & & & $1.69, \mathrm{~m}$ \\
\hline \multirow[t]{2}{*}{10} & & & $19.3, \mathrm{CH}_{2}$ & $1.59, \mathrm{~m}$ \\
\hline & & & & $1.50, \mathrm{~m}$ \\
\hline 11 & & & $14.1, \mathrm{CH}_{3}$ & $0.99, \mathrm{t}(7.2)$ \\
\hline 6-OMe & $56.2, \mathrm{CH}_{3}$ & $3.86, \mathrm{~s}$ & $56.1, \mathrm{CH}_{3}$ & $3.82, \mathrm{~s}$ \\
\hline
\end{tabular}


Table 3.8: Physicochemical properties of isocoumarins (10-11).

\begin{tabular}{|c|c|c|}
\hline Properties & 10 & 11 \\
\hline Appearance & white solid & light yellow solid \\
\hline Molecular formula & $\mathrm{C}_{11} \mathrm{H}_{10} \mathrm{O}_{4}$ & $\mathrm{C}_{13} \mathrm{H}_{16} \mathrm{O}_{4}$ \\
\hline $\mathrm{HRMS}[\mathrm{M}+\mathrm{H}]^{+}$ & 207.0651 & 237.1112 \\
\hline Calculated $[\mathrm{M}+\mathrm{H}]^{+}$ & 207.0652 & 237.1121 \\
\hline $\mathrm{OR}[\alpha]^{25}\left(\mathrm{CHCl}_{3}\right)$ & & $-8.0(\mathrm{c} 0.15)$ \\
\hline $\mathrm{UV}(\mathrm{MeOH}) \lambda_{\max } \mathrm{nm}(\log \varepsilon)$ & $\begin{array}{c}240(3.71), 277(3.14) \\
327(3.06)\end{array}$ & $\begin{array}{c}222(3.61), 267(3.61), \\
302(3.23)\end{array}$ \\
\hline
\end{tabular}

Compound 12 was isolated as a brown solid with the molecular formula $\mathrm{C}_{8} \mathrm{H}_{10} \mathrm{O}_{2}$ determined by an $[\mathrm{M}+\mathrm{H}]^{+}$peak in the HRMS spectrum at $m / z 139.0764$ (calculated $\left[\mathrm{C}_{8} \mathrm{H}_{11} \mathrm{O}_{2}\right]^{+}$139.0753). UV maxima $(\log \varepsilon)$ in $\mathrm{MeOH}$ were observed at 230 (3.12) and 278 (2.80) nm. The ${ }^{1} \mathrm{H}$ NMR data showed four aromatic methines, two at $\delta 7.03(\mathrm{~d}, J=8.3, \mathrm{H}-3)$ and two at $\delta 6.70(\mathrm{~d}, J=8.3, \mathrm{H}-2)$ as well as an oxygenated methylene at $\delta 3.68(\mathrm{t}, J=7.2, \mathrm{H}-6)$ and a methylene at $\delta 2.71(\mathrm{t}, J=7.2$, H-5). These NMR resonances are in accordance with the simple amino acid derived metabolite tyrosol (Figure 3.7; Takaya et al., 2007, Brenna et al., 2003). 


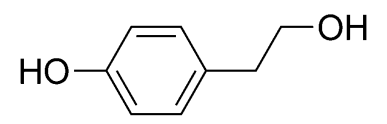

12

Figure 3.7: Structure of tyrosol (12) isolated from an undescribed Rhytismatales sp.

\section{Metabolites of Diaporthe maritima (NB365-71I, DAOM 628553)}

Compound 13 was isolated as a yellow oil with the molecular formula $\mathrm{C}_{15} \mathrm{H}_{18} \mathrm{O}_{6}$ determined by HRMS $\left(m / z 295.1175[\mathrm{M}+\mathrm{H}]^{+}\right)$, indicative of seven units of unsaturation. The ${ }^{1} \mathrm{H}$ NMR spectrum revealed five olefinic protons at $\delta 6.26(\mathrm{~d}, J=9.7, \mathrm{H}-3), 7.14(\mathrm{dd}, J=9.8,5.9, \mathrm{H}-4), 6.39(\mathrm{dd}, J=$ $11.8,6.9, \mathrm{H}-1^{\prime}$ ), 6.71 (dd, $J=11.8,1.7, \mathrm{H}-2$ ') and 6.87 (q, $J=7.2, \mathrm{H}-3$ '”), three oxygenated methines at $\delta 5.68(\mathrm{dd}, J=5.9,2.9, \mathrm{H}-5), 6.01(\mathrm{~m}, \mathrm{H}-6)$ and $4.30\left(\mathrm{q}, J=7.0, \mathrm{H}-4^{\prime}\right)$, and three methyl groups at $\delta 1.79$ (s, H-2"-Me), $1.80\left(\mathrm{~d}, J=6.3, \mathrm{H}-4\right.$ "') and $1.32\left(\mathrm{~d}, J=7.0, \mathrm{H}-5\right.$ '). Examination of the ${ }^{13} \mathrm{C}$ and DEPT-135 showed four of the fifteen carbon signals were quaternary. These signals are attributed to three carbonyls, a lactone at $\delta 164.1$ (C-2), a ketone at $\delta 204.3$ (C-3'), an ester at $\delta$ 167.7 (C-1"), and a sp ${ }^{2}$ carbon at $\delta 128.7$ (C-2"). COSY cross peaks observed sequentially from H-3 to H-2', HMBC correlations from H-3 and H-6 to C-2 and the chemical shift of C-5 and C-6 indicate compound $\mathbf{1 3}$ possessed a dihydro-pyran-2-one core structure substituted at positions 5 and 6. The magnitude of the coupling constant, $J=11.8 \mathrm{~Hz}$, between $\mathrm{H}-1$ ' and $\mathrm{H}-2$ ' indicated a cis olefinic group. The COSY cross peaks from H-2" to H-4", an HMBC correlation from $\mathrm{H}-5$ to C2" and the chemical shift of C-5 suggested a tiglic ester is attached at C-5. An additional COSY cross peak was observed from $\mathrm{H}-4$ ' to $\mathrm{H}-5$ ' and $\mathrm{HMBC}$ correlations from $\mathrm{H}-4$ ' and $\mathrm{H}-2$ ' indicate C-3' is a ketone. The ${ }^{1} \mathrm{H}$ and ${ }^{13} \mathrm{C}$ NMR data and molecular connectivity elucidated for compound 13 were in accordance with the polyketide metabolite phomopsolide A (Grove, 1985; Stierle et al., 
1997).

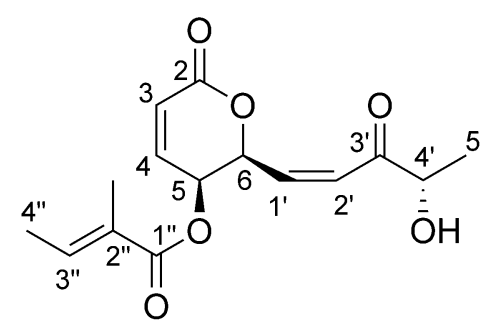

13

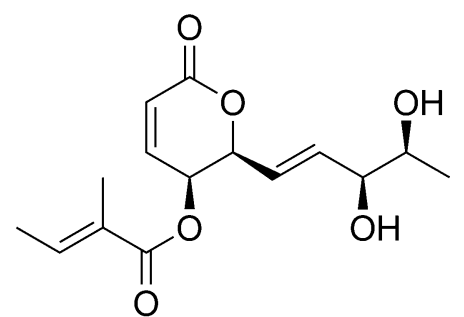

14

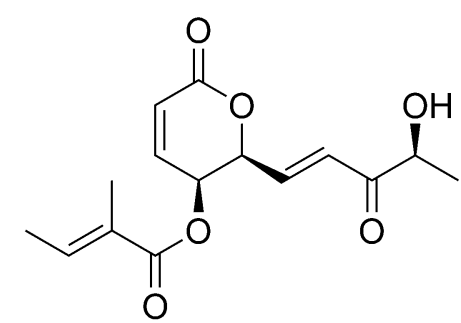

15

Figure 3.8: Structure of phomopsolides A-C (13-15) isolated from D. maritima DAOM 628553.

Compound 14 was also isolated as a yellow oil with the molecular formula $\mathrm{C}_{15} \mathrm{H}_{20} \mathrm{O}_{6}$ determined by an $[\mathrm{M}+\mathrm{H}]^{+}$peak at $m / z$ of 297.1332 , indicative of six units of unsaturation. The ${ }^{1} \mathrm{H}$ and ${ }^{13} \mathrm{C}$ NMR spectra of compound 14 suggested a structure very similar to phomopsolide A (13) except for the reduction of the ketone moiety at C-3' that coincides with the loss of a unit of unsaturation. Instead, carbon and proton signals were observed at $\delta 76.9$ (C-3') and $\delta 3.91$ (m, H-3'), respectively, for comp 14. The magnitude of the coupling constant $(J=15.7 \mathrm{~Hz})$ between $\mathrm{H}-1$ ' and H-2' indicated a trans olefinic group. Additionally, COSY cross peaks were observed sequentially from $\mathrm{H}-3$ to $\mathrm{H}-4$ '. The ${ }^{1} \mathrm{H}$ and ${ }^{13} \mathrm{C}$ data for compound $\mathbf{1 4}$ are in agreement with phomopsolide $\mathrm{B}$ (Grove, 1985; Stierle et al., 1997).

Compound 15 was isolated as a yellow oil with the molecular formula $\mathrm{C}_{15} \mathrm{H}_{18} \mathrm{O}_{6}$ determined by HRMS $\left(m / z 295.1175[\mathrm{M}+\mathrm{H}]^{+}\right)$, indicative of seven units of unsaturation. Compound 15 and phomopsolide A (13) had very similar ${ }^{1} \mathrm{H}$ and ${ }^{13} \mathrm{C}$ NMR spectra, which suggested a geometric isomer. The magnitude of the coupling constant between $\mathrm{H}-1$ ' and H-2' was $15.8 \mathrm{~Hz}$, indicative of a trans double bond, opposed to the cis olefinic group of phomopsolide A (13). The NMR and 
spectroscopic data for compound $\mathbf{1 5}$ was in accordance with phomopsolide C (Stierle et al. 1997). The structures of phomopsolides A-C (13-15) are displayed in Figure 3.8 and their accompanying NMR resonances (Table 3.9) and physicochemical data (Table 3.10) are reported below. 
Table 3.9: ${ }^{1} \mathrm{H}$ and ${ }^{13} \mathrm{C}$ NMR data for phomopsolides A-C (13-15) in $\mathrm{CD}_{3} \mathrm{OD}$.

\begin{tabular}{|c|c|c|c|c|c|c|}
\hline \multirow[b]{2}{*}{ Position } & \multicolumn{2}{|r|}{13} & \multicolumn{2}{|r|}{14} & \multicolumn{2}{|r|}{15} \\
\hline & $\delta \mathrm{c}$, type & $\delta_{\mathrm{H}}(J, \mathbf{H z})$ & $\delta \mathrm{c}$, type & $\delta_{\mathrm{H}}(J, \mathbf{H z})$ & $\delta \mathrm{c}$, type & $\delta_{\mathrm{H}}(J, \mathbf{H z})$ \\
\hline 2 & 164.1 & & 164.9 & & 164.0 & \\
\hline 3 & $125.3, \mathrm{CH}$ & $6.26, \mathrm{~d}(9.7)$ & $125.0, \mathrm{CH}$ & $6.21, \mathrm{~d}(9.8)$ & $125.3, \mathrm{CH}$ & $6.28, \mathrm{~d}(9.7)$ \\
\hline 4 & $142.4, \mathrm{CH}$ & $7.14, \mathrm{dd}(9.8,5.9)$ & $143.1, \mathrm{CH}$ & 7.09, dd $(9.9,5.6)$ & $142.6, \mathrm{CH}$ & $7.13, \mathrm{dd}(9.8,5.9)$ \\
\hline 5 & $64.7, \mathrm{CH}$ & $5.68, \mathrm{dd}(5.9,2.9)$ & $65.3, \mathrm{CH}$ & $5.41, \mathrm{dd}(5.6,3.0)$ & $64.2, \mathrm{CH}$ & $5.57, \mathrm{dd}(5.9,2.9)$ \\
\hline 6 & $78.4, \mathrm{CH}$ & $6.01, \mathrm{~m}$ & $80.5, \mathrm{CH}$ & $5.21, \mathrm{dd}(6.2,2.9)$ & $79.2, \mathrm{CH}$ & $5.47, \mathrm{~m}$ \\
\hline $\mathbf{1}^{\prime}$ & $142.4, \mathrm{CH}$ & $6.39, \mathrm{dd}(11.8,6.9)$ & $136.4, \mathrm{CH}$ & 5.98, ddd $(15.7,5.8,1.1)$ & $140.5, \mathrm{CH}$ & $6.88, \mathrm{dd}(15.8,3.5)$ \\
\hline $\mathbf{2}^{\prime}$ & $126.1, \mathrm{CH}$ & $6.71, \mathrm{dd}(11.8,1.7)$ & $125.7, \mathrm{CH}$ & 5.88, ddd $(15.7,6.3,1.3)$ & $127.5, \mathrm{CH}$ & $6.89, \mathrm{dd}(15.8,1.2)$ \\
\hline $3^{\prime}$ & 204.3 & & $76.9, \mathrm{CH}$ & $3.91, \mathrm{~m}$ & 202.5 & \\
\hline $4^{\prime}$ & $74.2, \mathrm{CH}$ & $4.30, \mathrm{q}(7.0)$ & $71.5, \mathrm{CH}$ & 3.59 , quint (7.0) & $73.2, \mathrm{CH}$ & $4.39, \mathrm{q}(7.0)$ \\
\hline $5^{\prime}$ & $19.6, \mathrm{CH}_{3}$ & $1.32, \mathrm{~d}(7.0)$ & $18.7, \mathrm{CH}_{3}$ & $1.07, \mathrm{~d}(6.5)$ & $19.9, \mathrm{CH}_{3}$ & $1.29, \mathrm{~d}(7.0)$ \\
\hline $1^{\prime \prime}$ & 167.7, C & & 167.9 & & 167.8 & \\
\hline $2^{\prime \prime}$ & 128.7, C & & 128.9 & & 128.7 & \\
\hline $3^{\prime \prime}$ & $140.4, \mathrm{CH}$ & $6.87, \mathrm{q}(7.2)$ & $140.4, \mathrm{CH}$ & $6.88, \mathrm{q}(7.2)$ & 140.2 & $6.84, \mathrm{~m}$ \\
\hline $4^{\prime \prime}$ & $14.5, \mathrm{CH}_{3}$ & $1.80, \mathrm{~d}(6.3)$ & $14.5, \mathrm{CH}_{3}$ & $1.80, \mathrm{~d}(6.3)$ & $14.5, \mathrm{CH}_{3}$ & $1.81, \mathrm{~d}(6.3)$ \\
\hline 2"'-Me & $12.1, \mathrm{CH}_{3}$ & $1.79, \mathrm{~s}$ & $12.9, \mathrm{CH}_{3}$ & $1.82, \mathrm{~s}$ & $12.0, \mathrm{CH}_{3}$ & $1.77, \mathrm{~s}$ \\
\hline
\end{tabular}


Table 3.10: Physicochemical properties of phomopsolides A-C (13-15).

\begin{tabular}{c|ccc} 
Properties & $\mathbf{1 3}$ & $\mathbf{1 4}$ & $\mathbf{1 5}$ \\
\hline Appearance & Yellow oil & Yellow oil & Yellow oil \\
Empirical formula & $\mathrm{C}_{15} \mathrm{H}_{18} \mathrm{O}_{6}$ & $\mathrm{C}_{15} \mathrm{H}_{20} \mathrm{O}_{6}$ & $\mathrm{C}_{15} \mathrm{H}_{18} \mathrm{O}_{6}$ \\
HRMS $[\mathrm{M}+\mathrm{H}]^{+}$ & 295.1175 & 297.1332 & 295.1175 \\
Calculated $[\mathrm{M}+\mathrm{H}]^{+}$ & 295.1176 & 297.1333 & 295.1176 \\
OR $[\alpha]^{25}(\mathrm{MeOH})$ & +366 & +136 & +63 \\
$\mathrm{UV}(\mathrm{MeOH})$ & $(\mathrm{c} 0.3)$ & $(\mathrm{c} 0.3)$ & $(\mathrm{c} 0.2)$ \\
$\lambda \max \mathrm{nm}(\log \varepsilon)$ & $218(4.41), 320(3.12)$ & $224(3.62), 326(2.10)$ & $218(3.53), 320(2.68)$
\end{tabular}

\section{Metabolites of Pezicula sporulosa (NB382-3D, DAOM 250862)}

Compound 16 was isolated as a yellow solid with the molecular formula $\mathrm{C}_{10} \mathrm{H}_{10} \mathrm{Cl}_{2} \mathrm{O}_{4}$ determined by an $[\mathrm{M}+\mathrm{H}]^{+}$peak in the HRMS spectra at $m / z 265.0029$, indicative of five units of unsaturation. The isotopic peak distribution of compound $\mathbf{1 6}$ which displayed an $[\mathrm{M}+\mathrm{H}+2]^{+}$peak with approximately $70 \%$ the abundance of the $[\mathrm{M}+\mathrm{H}]^{+}$ion, as well as an $[\mathrm{M}+\mathrm{H}+4]^{+}$peak, indicated the presence of two chlorine atoms. The ${ }^{1} \mathrm{H}$ NMR spectra displayed two olefinic signals at $\delta 6.96$ (dq, $\left.J=16.0,7.0, \mathrm{H}-2^{\prime}\right)$ and $6.56\left(\mathrm{dq}, J=16.0,1.7, \mathrm{H}-1^{\prime}\right)$, a deshielded methine at $\delta 4.79(\mathrm{~s}, \mathrm{H}-5)$, a methoxy moiety at $\delta 3.73$ (s, H-2”) and methyl group at $\delta 1.96$ (dd, 7.0, 1.7, H-3'). Examination of the ${ }^{13} \mathrm{C}$ and DEPT-135 spectra revealed that five of the ten carbon signals are quaternary. These signals were a result of a ketone at $\delta 190.0$ (C-4), an ester carbonyl at $\delta 171.0$ (C-1"), two sp ${ }^{2}$ carbons at $\delta 159.7(\mathrm{C}-2)$ and $130.1(\mathrm{C}-3)$ and a sp ${ }^{3}$ carbon at $\delta 84.5(\mathrm{C}-1)$. COSY cross peaks were 
observed sequentially from $\mathrm{H}-1$ ' to $\mathrm{H}-3$ ' and $\mathrm{HMBC}$ correlations from $\mathrm{H}-1$ ' and $\mathrm{H}-2$ ' to $\mathrm{C}-2$ connect a propanene moiety to C-2. The magnitude of the coupling constant, $J=16.0 \mathrm{~Hz}$, between H-1' and H-2' indicated the double bond was trans. The chemical shift of H-5 and HMBC correlations from $\mathrm{H}-5$ to $\mathrm{C}-1$ ", C-1 and C-4 suggested the presence of a chlorinated five membered ring. The ${ }^{1} \mathrm{H}$ and ${ }^{13} \mathrm{C}$ data for compound $\mathbf{1 6}$ are in agreement with $(+)$ cryptosporiopsin (Figure 3.9), that is of the $S$ configuration at both positions 1 and 5 (Strunz et al., 1969; Schulz et al., 1995). The optical rotation of cryptosporiopsin isolated in this study was $[\alpha]_{\mathrm{D}} 114.6\left(\mathrm{c} 1.71, \mathrm{CHCl}_{3}\right)$ which was in agreement with reported optical rotation values, $[\alpha]_{\mathrm{D}} 130$ (c 1.33, $\mathrm{CHCl}_{3}$, Schulz et al., 1995; $\alpha]_{\mathrm{D}} 129$ (c 1.35, $\mathrm{CHCl}_{3}$; Strunz et al., 1969), for this metabolite.

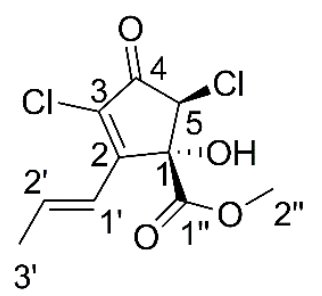

16

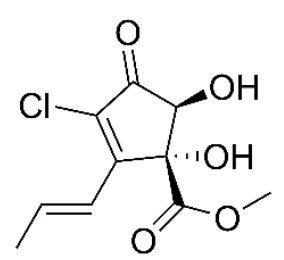

17

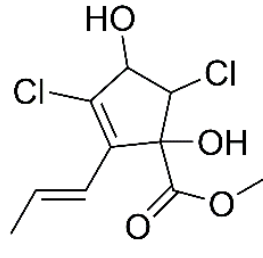

18<smiles>C[C@@H]1Cc2cccc(O)c2C(=O)O1</smiles>

19

Figure 3.9: Structure of cryptosporiopsin related metabolites (16-18) and $(R)$-mellein (19) isolated from DAOM 250862.

Compound 17 was isolated as a yellow oil with the molecular formula $\mathrm{C}_{10} \mathrm{H}_{11} \mathrm{ClO}_{5}$ by an $[\mathrm{M}+\mathrm{H}]^{+}$ peak at $m / z$ 247.0368. An approximate 3:1 isotopic peak distribution of $[\mathrm{M}+\mathrm{H}]^{+}:[\mathrm{M}+\mathrm{H}+2]^{+}$is indicative of a single chlorine atom within the structure. The ${ }^{1} \mathrm{H}$ and ${ }^{13} \mathrm{C}$ data for compound 17 were similar to compound $\mathbf{1 6}$ (Table 3.11). The carbon and proton chemical shift at position 5 increased from $\delta 67.0$ to $\delta 83.1$ and decreased from $\delta 4.79$ to $\delta 4.37$ in compound 17 compared to 16, respectively. Additionally, the chemical shift of the adjacent carbonyl at C-4 increased from $\delta$ 
190.0 to $\delta$ 196.5. The HRMS data, isotopic peak profile and increased chemical shift of C-5 indicated the chlorine at position 5 for $\mathbf{1 6}$ was exchanged with a hydroxyl group in compound 17. This establishes the structure of $\mathbf{1 7}$ as the 1,5-dihydroxy, 3-chloro analog of cryptosporiopsin. Compound 17 was previously characterized from a Crytosporiopsis species along with crytosporiopsin (16) with $1 R$ and $5 S$ configurations (Strunz et al., 1974).

Compound 18 was isolated as a clear solid with the molecular formula $\mathrm{C}_{10} \mathrm{H}_{12} \mathrm{Cl}_{2} \mathrm{O}_{4}$ determined by an $[\mathrm{M}+\mathrm{H}]^{+}$peak at $\mathrm{m} / \mathrm{z} 267.0186$. The same isotopic peak distribution observed for crytosporiopsin (16) indicative of two chlorine atoms was observed for 18. The NMR spectroscopic data for compound 18 and crytosporiopsin (16) were similar; however, subtle differences were observed. A COSY cross peak between $\delta 4.44(\mathrm{~d}, J=6.7, \mathrm{H}-4)$ and $4.17(\mathrm{~d}, J=6.7, \mathrm{H}-5)$ not observed for compounds 16-17 and the chemical shift of C-4 $(\delta 75.9)$ were notable differences compared to the previously elucidated structures. These spectroscopic data and the HRMS data indicated compound 18 possessed a hydroxyl group at C-4 instead of a ketone functionality. Comparison of the ${ }^{1} \mathrm{H}$ and ${ }^{13} \mathrm{C}$ data for compound $\mathbf{1 8}$ reported in Table 3.11 were in accordance with cryptosporiopsinol (Giles \& Turner, 1969; Holker \& Young, 1975). However, comparison of the experimentally determined optical rotation of 18, $[\alpha]_{\mathrm{D}} 23.6(\mathrm{c} 0.16, \mathrm{MeOH})$, had the opposite sign, $[\alpha]_{\mathrm{D}}-90$ (c 0.56, MeOH; Giles \& Turner, 1969) compared to cryptosporiopsinol isolated from a Periconia species. The absolute stereochemistry of (-)-cryptosporiopsinol was determined to be $1 S, 4 S$ and $5 R$ by X-ray crystallography (Giles \& Turner 1969; Holker \& Young, 1975). For compound 18, an NOE between $\mathrm{H}-4$ and $\mathrm{H}-5$ indicated these protons were in the same plane. This observation was consistent with (-)-cryptosporiopsinol (Giles \& Turner, 1969). The absolute 
configuration of positions 1, 4 and 5 could not be determined for compound $\mathbf{1 8}$ and is reported here as (+)-cryptosporiopsinol.

Using a chemical standard of (-)-(R)-mellein (19) previously isolated from CBS 120379 (Sumarah et al., 2008b), the simple isocoumarin was detected from the crude culture filtrate extract of $P$. sporulosa DAOM 250862 by LC-HRMS. At the appropriate retention index, an $[\mathrm{M}+\mathrm{H}]^{+}$ion was observed at $\mathrm{m} / \mathrm{z}$ 179.0702, indicative of a metabolite with the molecular formula $\mathrm{C}_{10} \mathrm{H}_{10} \mathrm{O}_{3}$.

Table 3.11: ${ }^{1} \mathrm{H}$ and ${ }^{13} \mathrm{C}$ NMR data for cryptosporiopsin related metabolites 16-18 in $\mathrm{CD}_{3} \mathrm{OD}$.

\begin{tabular}{|c|c|c|c|c|c|c|}
\hline \multirow[b]{2}{*}{ Position } & \multicolumn{2}{|c|}{16} & \multicolumn{2}{|c|}{17} & \multicolumn{2}{|c|}{18} \\
\hline & $\delta \mathrm{c}$, type & $\delta_{\mathbf{H}}(J, \mathbf{H z})$ & $\delta \mathrm{c}$, type & $\delta_{\mathrm{H}}(J, \mathbf{H z})$ & $\delta$, type & $\delta_{\mathrm{H}}(J, \mathbf{H z})$ \\
\hline 1 & 84.5 & & 84.4 & & 88.6 & \\
\hline 2 & 159.7 & & 158.4 & & 138.6 & \\
\hline 3 & 130.1 & & 130.0 & & 133.9 & \\
\hline 4 & 190.0 & & 196.5 & & 75.9, $\mathrm{CH}$ & $4.44, \mathrm{~d}(6.7)$ \\
\hline 5 & $67.0, \mathrm{CH}$ & $4.79, \mathrm{~s}$ & $83.1, \mathrm{CH}$ & $4.37, \mathrm{~s}$ & $80.5, \mathrm{CH}$ & $4.17, \mathrm{~d}(6.7)$ \\
\hline $1^{\prime}$ & 122.4, CH & $\begin{array}{c}6.52, \mathrm{dq} \\
(16.0,1.7)\end{array}$ & $122.6, \mathrm{CH}$ & $\begin{array}{c}6.49, \mathrm{dq} \\
(16.0,1.7)\end{array}$ & $\begin{array}{c}122.3 \\
\mathrm{CH}\end{array}$ & $6.19, \mathrm{o}$ \\
\hline $2^{\prime}$ & $145.5, \mathrm{CH}$ & $\begin{array}{c}6.96, \mathrm{dq} \\
(16.0,7.0)\end{array}$ & $144.2, \mathrm{CH}$ & $\begin{array}{c}6.90, \mathrm{dq} \\
(16.0,6.9)\end{array}$ & $\begin{array}{c}134.3 \\
\mathrm{CH}\end{array}$ & $6.15, \mathrm{o}$ \\
\hline $3^{\prime}$ & $20.2, \mathrm{CH}_{3}$ & $\begin{array}{c}1.96, \mathrm{dd} \\
(7.0,1.7)\end{array}$ & $20.0, \mathrm{CH}_{3}$ & $\begin{array}{c}1.95, \mathrm{dd} \\
(6.9,1.7)\end{array}$ & $19.3, \mathrm{CH}_{3}$ & $1.8, \mathrm{~d}(5.3)$ \\
\hline $1 "$ & 171.0 & & 171.9 & & 174.3 & \\
\hline $2 "$ & $53.8, \mathrm{CH}_{3}$ & $3.73, \mathrm{~s}$ & $53.6, \mathrm{CH}_{3}$ & $3.70, \mathrm{~s}$ & $53.3, \mathrm{CH}_{3}$ & $3.76, \mathrm{~s}$ \\
\hline
\end{tabular}


Table 3.12: Physicochemical properties of compounds 16-18.

\begin{tabular}{c|ccc} 
Properties & $\mathbf{1 6}$ & $\mathbf{1 7}$ & $\mathbf{1 8}$ \\
\hline Appearance & light yellow solid & yellow solid & clear solid \\
& & & \\
Empirical formula & $\mathrm{C}_{10} \mathrm{H}_{10} \mathrm{Cl}_{2} \mathrm{O}_{4}$ & $\mathrm{C}_{10} \mathrm{H}_{11} \mathrm{ClO}_{5}$ & $\mathrm{C}_{10} \mathrm{H}_{12} \mathrm{Cl}_{2} \mathrm{O}_{4}$ \\
HRMS $[\mathrm{M}+\mathrm{H}]^{+}$ & 265.0029 & & \\
& & 247.0368 & 267.0186 \\
Calculated $[\mathrm{M}+\mathrm{H}]^{+}$ & 265.0028 & 247.0367 & 267.0185 \\
& & & \\
OR $[\alpha]^{25}(\mathrm{MeOH})$ & $(\mathrm{c} 1.71)$ & $(\mathrm{c} 0.64)$ & $(\mathrm{c} 0.16)$ \\
$\mathrm{UV}(\mathrm{MeOH}) \lambda \mathrm{max}$ & $290(4.06)$ & $287(4.06)$ & $246(5.08)$ \\
nm $(\log \varepsilon)$ & & &
\end{tabular}

\section{Growth Inhibition Assays}

Compounds 1-19 (Figure 3.10) were tested for antimicrobial activity towards E. coli (ATCC 67878), B. subtilis (ATCC 23857), S. cerevisiae and M. violaceum. The bacterial and S. cerevisiae data at 8 hours and $M$. violaceum data at 60 hours was used for statistical analysis by an ANOVA followed by Tukey's test for significant differences (Systat V13) compared to the negative control (DMSO). P-values below 0.05 were considered significantly different. 
<smiles>C[C@@H]1OC(=O)C2=C(O)C[C@@H](O)C[C@H]2[C@H]1O</smiles>

1<smiles>C[C@H]1C[C@H]2C[C@H](O)CC(O)=C2C(=O)O1</smiles>

2<smiles>C[C@H]1OC(=O)c2c(O)cccc2[C@H]1O</smiles>

3<smiles>C[C@@H]1OC(=O)C2=C(O)C=CC[C@H]2[C@H]1O</smiles>

4<smiles>C[C@H]1OC(=O)C2=C(O)CCC[C@H]2[C@H]1O</smiles>

5<smiles>CCCCCCCC(=O)C1=C(O)C[C@@H](C(=O)O)OC1=O</smiles><smiles>CCCCCCCC(=O)C1=C(O)C[C@@H](C(=O)OC)OC1=O</smiles><smiles>[B]c1c(O)c(C)c(OC)c2c1COC2=O</smiles>

7<smiles>COc1cc(O)c2c(=O)oc(C)cc2c1</smiles>

10<smiles>CCC[C@H]1Cc2cc(OC)cc(O)c2C(=O)O1</smiles>

11<smiles>OCCc1ccc(O)cc1</smiles>

12<smiles>COc1c(C)c(O)c(CO)c2c1C(=O)OC2</smiles><smiles>C/C=C(\C)C(=O)O[C@H]1C=CC(=O)O[C@@H]1/C=C/C(=O)[C@H](C)O</smiles>

13<smiles>C/C=C(\C)C(=O)O[C@H]1C=CC(=O)O[C@@H]1/C=C/[C@@H](O)[C@@H](C)O</smiles>

14<smiles>C/C=C(\C)C(=O)O[C@H]1C=CC(=O)O[C@@H]1/C=C/C(=O)[C@@H](C)O</smiles>

15<smiles>C/C=C/C1=C(Cl)C(=O)[C@H](Cl)[C@]1(O)C(=O)OC</smiles>

16<smiles>C/C=C/C1=C(Cl)C(=O)[C@H](O)[C@]1(O)C(=O)OC</smiles>

17<smiles>C/C=C/C1=C(Cl)C(O)C(Cl)C1(O)C(=O)OC</smiles>

18

Figure 3.10: Secondary metabolites (1-19) characterized from foliar endophytes as part of this thesis. 
Antibacterial activity towards the Gram-negative bacterium E. coli was observed in 8 of the isolated metabolites (Table 3.13). The isocoumarin (11) from the undescribed Rhytismatales species showed the greatest potency out of all of the metabolites tested, where it continued to inhibit $E$. coli growth at a concentration of $2.5 \mu \mathrm{M}$. This activity was not conserved in the isocoumarin structures as compounds $\mathbf{1}$ and $\mathbf{2}$ were the only other isocoumarins showing activity, and were only active at $250 \mu \mathrm{M}$. In addition 11 , the two new pyrone structures $(6,7)$, one of the phthalides (9) and the tyrosol (12) metabolites isolated from the undescribed Rhytismatales endophyte all inhibited E. coli growth at $250 \mu \mathrm{M}$. The P. sporulosa endophyte compound cryptosporiopsin (16) was the only metabolite that reduced E. coli growth, but showed activity at $25 \mu \mathrm{M}$.

Table 3.13: Antibacterial activity of isolated metabolites towards E. coli $(p \leq 0.05)$.

\begin{tabular}{|c|c|c|c|}
\hline \multirow[b]{2}{*}{ Compounds } & \multicolumn{3}{|c|}{ Concentrations } \\
\hline & $250 \mu \mathrm{M}$ & $25 \mu \mathrm{M}$ & $2.5 \mu \mathrm{M}$ \\
\hline 1 & + & & \\
\hline 2 & + & & \\
\hline 6 & + & & \\
\hline 7 & + & & \\
\hline 9 & + & & \\
\hline 11 & + & + & + \\
\hline 12 & + & & \\
\hline 16 & + & + & \\
\hline
\end{tabular}


The metabolites isolated in this study showed limited bioactivity towards the Gram-negative bacterium B. subtilis (Table 3.14). Phomopsolide A (13) from was the most potent metabolite isolated, where it inhibited B. subtilis growth even at the lowest tested concentration $(2.5 \mu \mathrm{M})$. The new pyrone metabolite (6) from the undescribed Rhytismatales species and cryptosporiopsin (16) from the P. sporulosa endophyte both displayed antibacterial activity towards B. subtilis at $250 \mu \mathrm{M}$. None of the isocoumarins (1-5) isolated from the $P$. cf. gaeumannii endophyte reduced the growth of $B$. subtilis. Additionally, the potent activity of compound $\mathbf{1 1}$ towards inhibiting E. coli was not observed when testing against $B$. subtilis.

Table 3.14: Antibacterial activity of isolated metabolites towards B. subtilis $(p \leq 0.05)$.

\begin{tabular}{c|ccc} 
& \multicolumn{3}{|c}{ Concentrations } \\
Compounds & $250 \mu \mathrm{M}$ & $25 \mu \mathrm{M}$ & $2.5 \mu \mathrm{M}$ \\
\hline $\mathbf{6}$ & + & & \\
$\mathbf{1 3}$ & + & + & + \\
$\mathbf{1 6}$ & + & &
\end{tabular}

Antifungal activity towards the Ascomycete S. cerevisiae was observed in 8 of the isolated metabolites (Table 3.15). The metabolites originating from the undescribed Rhytismatales endophyte illustrated the highest potency. The new pyrone structure (7) inhibited S. cerevisiae growth even at the lowest tested concentration $(2.5 \mu \mathrm{M})$. The two isocoumarins $(\mathbf{1 0}, \mathbf{1 1})$ reduced S. cerevisiae growth at 250 and $25 \mu \mathrm{M}$, respectively. One of the isolated phthalides (9) also showed activity at $250 \mu \mathrm{M}$. Phomopsolides A (13) and B (14) from D. maritima showed antifungal activity 
towards $S$. cerevisiae at $250 \mu \mathrm{M}$. Lastly, one of the isocoumarins (3) from $P$. cf. gaeumannii and cryptosporiopsin (16) from $P$. sporulosa possessed antifungal activity towards $S$. cerevisiae at $250 \mu \mathrm{M}$.

Table 3.15: Antifungal activity of isolated metabolites towards $S$. cerevisiae $(p \leq 0.05)$.

\begin{tabular}{c|ccc} 
& \multicolumn{3}{|c}{ Concentrations } \\
Compounds & $250 \mu \mathrm{M}$ & $25 \mu \mathrm{M}$ & $2.5 \mu \mathrm{M}$ \\
\hline 3 & + & & \\
7 & + & & \\
9 & + & & \\
10 & + & + \\
11 & + & \\
13 & + & \\
14 & + &
\end{tabular}

Antifungal activity towards the Basidiomycete $M$. violaceum was observed in 7 of the isolated metabolites (Table 3.16). This activity was isolated to the undescribed Rhytismatales endophyte and the D. maritima endophyte. From the undescribed Rhytismatales species the two phthalides $(\mathbf{8}, \mathbf{9})$, two isocoumarins $(\mathbf{1 0}, \mathbf{1 1})$ and tyrosol (12) metabolites all showed antifungal activity towards M. violaceum at $250 \mu \mathrm{M}$. Phomopsolide A (13) was the most potent metabolite tested, where it reduced the growth of $M$. violaceum at $25 \mu \mathrm{M}$. Phomopsolide B (14) also reduced growth at $250 \mu \mathrm{M}$. 
Table 3.16: Antifungal activity of isolated metabolites towards $M$. violaceum $(p \leq 0.05)$.

\begin{tabular}{|c|c|c|c|}
\hline \multirow[b]{2}{*}{ Compounds } & \multicolumn{3}{|c|}{ Concentrations } \\
\hline & $250 \mu \mathrm{M}$ & $25 \mu \mathrm{M}$ & $2.5 \mu \mathrm{M}$ \\
\hline 8 & + & & \\
\hline 9 & + & & \\
\hline 10 & + & & \\
\hline 11 & + & & \\
\hline 12 & + & & \\
\hline 13 & + & + & \\
\hline 14 & + & & \\
\hline
\end{tabular}




\section{Discussion}

Our current understanding of the endophytes present in conifer trees of the Acadian forest is still very limited. To date, all needles collected from conifer tree species of the Acadian forest have possessed endophytes. Initial screens of these endophytes revealed a modest proportion of toxigenic endophytes $(\sim 5 \%)$. Over the past 25 years, screening of old forestry stands in protected areas has shown that the proportion of toxigenic endophytes in the Acadian forest to be much larger than the original 5\% estimate. Further, their ecological function has proven to be crucial to their conifer host. The $P$. scopiformis endophyte has been shown to produce, in planta, rugulosin above the effective concentration necessary to reduce $C$. fumiferana (Eastern spruce budworm) growth and herbivory (Miller et al., 2008; Frasz et al., 2014). By monitoring white spruce seedlings inoculated with $P$. scopiformis it was discovered that $P$. scopiformis can persist in the host tree for over 10 years, still producing rugulosin to deter herbivory by the cyclical spruce budworm pest (Miller et al., 2008; Miller, 2011, Frasz et al., 2014). Additionally, P. scopiformis was discovered to naturally infect other white spruce seedlings in close proximity of the original inoculated test tree. This horizontal transfer is why we are noticing high endophyte diversity throughout the undisturbed Acadian forest, yet low diversity in nursery conifers intended for reforestation projects (Sumarah et al., 2008a).

This thesis is part of a much larger project that is investigating the endophytes producing biologically active metabolites that are hiding throughout the Acadian forest. There are many important aspects to this work. Investigating these cryptic fungal species is providing information about their biodiversity and their ecological importance to the host tree as well as in forest 
dynamics. While describing these new fungal endophytes, novel metabolites with various antibiotic, antifungal and antiinsectan properties are being characterized. By inoculating nursery seedlings with these toxigenic endophytes we are increasing the fitness of replanted stands towards common pests and pathogens and we are restoring some endophyte diversity. Another important aspect of this research is in finding various, phylogenetically distinct endophytes, the risk imposed by common pests and pathogens developing tolerance to this increased diversity of endophyte toxins is reduced.

While sampling the Acadian forest, conifer needles are obtained from multiple trees in various regions in order to get a proper representation of the endophyte diversity. This generates a large collection of endophytes that are studied by our taxonomist collaborators for morphological features and ITS sequences in order to get a phylogenetic understanding of the fungal endophyte community. Doing so allows the selection of undescribed endophytes for metabolite screening. In this thesis, 61 endophytes were selected for screening, in which the crude extracts produced by one litre fermentations were tested for antifungal activity towards $S$. cerevisiae and $M$. violaceum (see appendix II) and analyzed by LC-UV-MS for complexity of the metabolite profiles. Based on LC-UV-MS chromatograms, bioassay result and phylogenetic analysis two $P$. rubens (red spruce) and two P. mariana (black spruce) endophytes were selected for secondary metabolite characterization studies.

A currently undescribed Phaeocryptopus cf. gaeumannii (DAOM 250863) was isolated as an endophyte of $P$. mariana (black spruce). Unlike many of the fungal endophytes studied here for natural products, the crude extract obtained from its one litre screening fermentation was adequate 
for metabolite isolations, particularly since the LC-UV-MS chromatogram only displayed six major metabolites. Endophytes of black spruce had not received extensive metabolite attention in the Miller group compared to white spruce and red spruce endophytes, prompting their investigation (Sumarah et al., 2008b; 2010). The crude extract of DAOM 250863 inhibited the growth of M. violaceum and afforded five structurally similar isocoumarins (1-5; Figure 3.1) including a new metabolite (1). The ramulosin related isocoumarins 2-5 were previously characterized from an undescribed endophyte of black spruce called Canoplea elagantula (Cooke) along with several structural analogs (Findlay et al., 1995b). This black spruce endophyte is most likely closely related or the same species as DAOM 250863 studied here; however, it was not deposited in a culture collection, thus preventing direct comparison. Based on sequencing of a portion of the ITS region, DAOM 250863 is $100 \%$ identical to the red spruce endophytes CBS 121943 and DAOM 239830 (Sumarah \& Miller, 2009). Compound (4) and four other biosynthetically related metabolites characterized by Findlay et al. (1995b) were produced by these red spruce endophytes. The crude culture filtrate extracts of CBS 121943 and DAOM 239830 were toxic to spruce budworm in feeding assays (Sumarah \& Miller, 2009). The culture filtrate of the unidentified black spruce endophyte and several isocoumarins, including compound $\mathbf{4}$, showed toxicity towards spruce budworm larvae and cells (Findlay et al., 1995b). In this study, compounds 1 and $\mathbf{2}$ showed modest antibacterial activity towards E. coli at $250 \mu \mathrm{M}$ (Table 3.13) and compound 3 showed modest antifungal activity to S. cerevisiae at $250 \mu \mathrm{M}$ (Table 3.15). Despite this, in vitro spruce budworm assays is warranted to evaluate the toxicity of the new isocoumarin (1) as well as the extract itself. As mentioned previously, the low activity of individual compounds may not be truly representative as it is believed endophytes produce an array of toxic metabolites that have synergistic toxicity (Miller, 1986). 
The culture filtrate extract of an undescribed black spruce endophyte (NB236-1A) from the Order Rhytismatales yielded several different chemical classes (Figures 3.3, 3.5-3.7) including pyrones (6-7), phthalides (8-9), isocoumarins (10-11) and the amino acid derived tyrosol metabolite (12). The pyrones (6-7) characterized by HRMS, NMR and other spectroscopic methods are reported here as new structures. Their structures share the same 3-acyl-4-hydroxy-5,6-dihydro-2-pyrone core structure as alternaric acid originally isolated from Alternaria solani (Brian et al., 1949; Tabuchi et al., 1994) and podoblastins A-C obtained from the medicinal plant Podophyllum (Miyakado et al., 1982; Tanabe et al., 1982). The methylated pyrone (7) showed potent antifungal activity as it inhibited the growth of $S$. cerevisiae even at the lowest concentration tested, $2.5 \mu \mathrm{M}$ (Table 3.15). Alternaric acid is not appreciably antibiotic; however, is antifungal in the low $\mu \mathrm{g}$ $\mathrm{mL}^{-1}$ range (Brian et al., 1949). Podoblastins were identified as the antifungal constituents of a Podophyllum extract that inhibited the growth of Pyricularia oryzae, the causative agent of rice blast, in the low $\mu \mathrm{g} \mathrm{mL}^{-1}$ range (Miyakado et al., 1982).

The phthalide, 5-hydroxy-7-methoxy-4,6-dimethylphthalide (8), was previously characterized from Microsphaeropsis obtained from the foliage of Garcinia hombroniana (seashore mangosteen; Sommart et al., 2012) and a wood associated Lachnum papyraceum strain (Shan et al., 1997; Stadler et al., 1993). It was observed in this study to have modest (250 $\mu \mathrm{M})$ antifungal activity towards the rust fungus M. violaceum. Compound 9, 5-hydroxy-4-(hydroxymethyl)-7methoxy-6-methylphthalide, was prepared as a reduced derivative of cyclopaldic acid in a structure activity relationship study examining mosquito bite deterrent compounds (Cimmino et al., 2013). This phthalide (9) was active in the Aedes aegypti (dengue fever insect vector) bite deterrent assay. 
In this study, 9 showed modest $(250 \mu \mathrm{M})$ activity towards $E$. coli and both test fungal species (Tables 3.13, 3.15, 3.16).

8-hydroxy-6-methoxy-3-methyisocoumarin (10) was previously isolated as a fungal metabolite with a related isocoumarin, indole-3-acetic acid, tyrosol (12) and several other parahydroxyphenolic metabolites (Stossel, 1969) and from the bacterium Streptomyces mobaraensis (Eaton \& Hutchinson, 1971). Compound 10 inhibited the growth of a Fusarium species (minimum inhibitory concentration (MIC) of $200 \mu \mathrm{g} \mathrm{mL} \mathrm{m}^{-1}$ or $c a .970 \mu \mathrm{M}$ ) and was prepared during the synthesis of a related chlorinated isocoumarin produced by a Periconia species (Giles \& Turner, 1969). In this study, compound $\mathbf{1 0}$ showed antifungal activity at $250 \mu \mathrm{M}$ towards $S$. cerevisiae (Table 3.15) and M. violaceum (Table 3.16). (R)-8-hydroxy-6-methoxy-3-propylisochromanone (11) was identified as a fungal natural product from an unidentified white spruce endophyte also originating from the Order Rhytismatales (CBS 120380; Sumarah et al., 2008b). Although structurally similar to $\mathbf{1 0}$, this isocoumarin $(\mathbf{1 1})$ showed potent $(2.5 \mu \mathrm{M})$ antibacterial activity to $E$. coli as well as antifungal activity to $S$. cerevisiae at $250 \mu \mathrm{M}$ and $M$. violaceum at $25 \mu \mathrm{M}$.

The remaining secondary metabolite from the undescribed Rhytismatales species (NB236-1A) is tyrosol (12), which showed modest $(250 \mu \mathrm{M})$ antimicrobial activity to E. coli and M. violaceum. Tyrosol (12) was also identified from three white spruce endophytes (CBS 120379-120381) and has been reported from numerous fungal genera including Diaporthe, Xylaria and Epichlö̈ (Claydon et al., 1985; Koshino et al., 1988; Schneider et al., 1996; Sumarah et al., 2008b). The white spruce endophytes CBS 120379 and 120380 are closely related to an unidentified black spruce endophyte isolated in Quebec based on ITS sequence comparisons (Ganley \& Newcombe, 
2006). A phylogenetic analysis of Rhytismatales endophytes obtained from the Acadian forest determined that the undescribed Rhytismatales species (NB236-1A) studied here and CBS 120380 are two distinct species; however, closely related (Joey Tanney, personal communication). Their secondary metabolite profiles were also quite similar. An isocoumarin (11) and tyrosol (12) were isolated from both extracts and a phthalide, 5,7-dimethoxy-3-methylphthalide, structurally similar to compounds (8-9) were also characterized (Sumarah et al., 2008b). No dihydropyrones related to compounds (6-7) were identified from CBS 120380. Incorporation of the culture filtrate extracts of CBS 120380 significantly reduced the weight and head capsule size of spruce budworm larvae (Sumarah et al., 2008b). The similarity of their metabolite profiles suggests the undescribed Rhytismatales endophyte studied here (NB236-1A) synthesizes metabolites toxic to spruce budworm, warranting further investigation.

During this survey of endophyte of the Acadian forest, a fungus belonging to the Diaporthe eres species complex was frequently recovered from healthy surface-sterilized black and red spruce needles. In a complementary investigation, this abundant foliar endophyte was recently described as new species, Diaporthe maritima, using morphological characteristics and multiple gene phylogenetic analysis (Tanney et al., 2016b). The crude extract of D. maritima DAOM 628553 was shown to inhibit the growth of the biotrophic fungal pathogen M. violaceum. The culture filtrate extract of this strain afforded phomopsolides A (13), B (14) and C (15) (Figure 3.8). Phomopsolides A (13) and B (14) were originally isolated from Diaporthe eres (as Phomopsis oblonga), a fungal species commonly associated with the outer bark of healthy Ulmus (elm) trees (Grove, 1985). These strains have been shown to invade the phloem tissue of elm trees infected with the fungus Ophiostoma ulmi, the causative agent of Dutch elm disease (Webber, 1981). 
Phomopsolides A (13) and B (14) were shown to elicit anti-feedant and anti-boring activity against adult female bark beetles (Scolytus scolytus), an insect vector of $O$. ulmi (Claydon et al., 1985). It was hypothesized that these Diaporthe species naturally controlled Dutch elm disease as they deterred boring and in turn, the subsequent mating of bark beetles, insect vectors for this fungal pathogen (Webber, 1981; Webber \& Gibbs, 1984).

Subsequent to the original discovery of phomopsolides from species within the Diaporthe eres species complex, this class of secondary metabolites has been reported from related and phylogenetically distant fungi associated with various host species. Phomopsolide C (15), the trans isomer of 13, was originally isolated from a Penicillium species (NRRL 21208) obtained from the inner bark of Taxus brevifolia (Pacific yew). This Penicillium strain was shown to produce Phomopsolides A-E as well as a furanone structure, all of which had strong inhibitory activity towards Staphylococcus aureus with potencies comparable to the known antibiotics tetracycline and streptomycin (Stierle et al., 1997). Phomopsolide A (13) isolated from the D. maritima endophyte in this study had strong antimicrobial activity towards B. subtilis, where it remained effective at the lowest concentration of $2.5 \mu \mathrm{M}$ (Table 3.14). Phomopsolide A (13) was also observed to have antifungal activity towards $S$. cerevisiae at $250 \mu \mathrm{M}$ and $M$. violaceum at $25 \mu \mathrm{M}$ (Tables 3.15 and 3.16, respectively). Phomopsolide B (2) was recently characterized as the dominant metabolite from an undescribed Diaporthe species (GenBank DQ272498) isolated from surface sterilized twig tissue of Camptotheca acuminate in China (Yuan et al., 2009). Nine Diaporthe strains associated with grapevines growing in Switzerland synthesized several different mixtures of secondary metabolites. Characterized natural products included phomopsolide B, four furanones, the xanthones sydowinin A and sydowinol, and cytosporone (Goddard et al., 2014). A 
large proportion of North American and European Diaporthe endophytes of Silax (willow) trees produced phomopsolide B whereas phomodiol biosynthesis varied (Horn et al., 1996).

Diaporthe species associated with woody plants produce a diverse array of biologically active natural products. Several of these chemicals are directly implicated in host tree-pest chemical ecologies. From these chemical investigations, phomopsolide B appears as the most commonly reported metabolite from Diaporthe species (Claydon et al., 1985; Grove, 1985; Horn et al. 1996). The secondary metabolites of European isolates within the DESC associated with Fraxinus (Ash), Platanus, and Ulmus (Elm) trees were studied because of the known antiinsectan activity of their natural products such as the phomopsolides (Claydon et al. 1985; Grove, 1985). Chemical differences were observed between morphologically distinct elm-derived isolates. Diaporthe isolates from each of the host trees produced phomopsolide B (14) and oblongolide (Begley \& Grove, 1985; Claydon et al., 1985; Grove, 1985). The elm-derived Diaporthe species also synthesized various pyrones, orsellinic acids, aromatics, and isocoumarins including $(R)-5$ methylmellein, tyrosol, and mellein. Interestingly, several of these secondary metabolites were also reported from endophytes of white spruce in the Acadian forest of North America (Sumarah et al., 2008b). Culture filtrate extracts of these white spruce endophytes, when incorporated into the diets of spruce budworm larvae, significantly reduced both the weight and head capsule size (Sumarah et al., 2008b). Phomopsolides A (13) and B (14), (R)-5-methylmellein, tyrosol, and mellein all displayed in vitro antiinsectan activities, where $\mathbf{1 3}$ was the most active towards the elm bark beetle S. scolytus (Claydon et al., 1985). Of particular interest is the identification of the same biologically active natural products synthesized by different tree-associated fungi of different geographic origin having potentially very important ecological roles. These data further 
demonstrate the production of antagonistic mixtures of secondary metabolites by tree-associated and endophytic fungi toward host insect pests. Further investigations into the antiinsectan activity of the D. maritima (DAOM 628553) extract as well as the isolated phomopsolides (13-15) towards spruce budworm larvae is warranted.

From the fermentation broth of Pezicula sporulosa DAOM 250862, three chlorinated metabolites (16-18) were characterized and $(R)$-mellein (19) was detected using an in-house standard (Figure 4). (+)-Crytosporiopsin (16) and related chlorinated cyclopentenone analogs were originally isolated from a coprophilous Sporormia sp. (McGahren et al. 1969), a Periconia sp. (Giles \& Turner 1969) and Cryptosporiopsis sp. (Strunz et al. 1969) at approximately the same time. Several biosynthetically related chlorinated dihydroisocoumarins not isolated here or previously from Cryptosporiopsis were characterized from the other cryptosporiopsin producing fungi. The structure of $(+)$-crytosporiopsin (16) was confirmed by x-ray crystallography (McGahren et al. 1969) and has the $S$ configuration at positions 1 and 5. It is not surprising that (+)-crytosporiopsin (16) was isolated from a P. sporulosa endophyte since one of the original reports of this metabolite was from its anamorphic state, Cryptosporiopsis, isolated from decaying Betula alleghaniensis (yellow birch; Stillwell et al. 1969; Strunz et al. 1969). Interestingly, the $P$. sporulosa endophyte studied here was collected from as an endophyte of red spruce in a yellow birch and red maple stand. In a study of Pezicula endophytes isolated from asymptomatic deciduous and coniferous tree branches in Northern Germany, $(+)$-crytosporiopsin (16) was characterized from six of the eighty five strains studied (Schulz et al. 1995). This chlorinated natural product possesses antifungal activity against several other wood rot fungi and is antibiotic (Stillwell et al. 1969). The authors suggested this biologically active metabolite could be applied to prevent the deterioration 
of forest products or control diseases of agriculture and forests. This agrees with the findings in this study, where cryptosporiopsin (16) was antibacterial towards E. coli and B. subtilis at $25 \mu \mathrm{M}$ and $250 \mu \mathrm{M}$, respectively, as well as inhibited the growth of $S$. cerevisiae at $250 \mu \mathrm{M}$.

The 5-hydroxy cryptosporiopsin analog (17) was originally isolated from the fermentation broth of a wood derived Cryptosporiopsis along with cryptosporiopsin (16). Chemical derivatization and comparison of the spectroscopic data of compounds $\mathbf{1 6}$ and $\mathbf{1 7}$ determined that both metabolites were $5 S$; however, 17 was $1 R$ as opposed to 16, which was $1 S$ (Strunz et al. 1974). Compound 17 did not display any considerable in vitro antifungal activity when assayed by Strunz et al. (1974), nor in this present investigation. This suggests the C-5 chlorine is necessary for appreciable antifungal activity.

An in house standard of $(R)$-mellein (19) isolated from an undescribed Rhytismatales (Order) foliar endophyte of white spruce (Sumarah et al., 2008b) was utilized to confirm its production by $P$. sporulosa (DAOM 250862). At the appropriate retention index, an $[\mathrm{M}+\mathrm{H}]^{+}$ion at $\mathrm{m} / \mathrm{z} 179.0702$ was observed, identifying the simple isocoumarin within the culture filtrate extract. In a survey of the secondary metabolites produced by endophytic Pezicula species, $(R)$-mellein (19) was detected from all eighty five extracts (Schulz et al., 1995). While (R)-mellein (19) could be characteristic of the genus, the antifungal metabolites cryptosporiopsin (16), (-)-mycorrhizin A and 4-epiethiosolide appear to be more species specific (Schulz et al., 1995). Metabolite profiles were also influenced by culture conditions. Several other structurally related non-chlorinated isocoumarins have been characterized from endophytic Pezicula species (reported as Cryptosporiopsis; Krohn et al. 1997). This metabolite was originally reported from Aspergillus melleus (Nishikawa, 1933) 
and subsequently from several fungal genera, plants and insects (Nago \& Matsumoto, 1993; Sumarah et al., 2008b). (R)-mellein (19) possesses antifungal, herbicidal, algicidal and antiinsectan activities (Claydon et al., 1985; Schulz et al., 1995). As noted previously, this metabolite has been characterized from a white spruce endophyte extract that displayed antiinsectan activity towards the spruce budworm.

The $P$. sporulosa endophyte of red spruce examined here and the several Pezicula species investigated by Schulz et al. (1995) for natural products were all isolated from needles of healthy tree branches. The synthesis of antifungal metabolites such as cryptosporiopsin (16) that are active towards plant pathogens hints at a host-endophyte mutualistic relationship existing (Schulz et al., 1995; Stillwell et al., 1969). Since these Pezicula endophytes were reported to be recovered from a high percentage of healthy foliage, it is suspected that at the very least they have low virulence towards their host. A Xylaria species producing the potently antifungal metabolite was recovered as an endophyte of white pine needles and Vaccinium angustifolium (low bush blueberry) stems (Richardson et al., 2014). Interestingly, the same species was also recovered growing on decaying Acer saccharum (sugar maple) from the same environment. A similar observation was made for the Cryptosporiopsis sp. producing cryptosporiopsin (16) that was isolated from decaying yellow birch (Strunz et al., 1969; Stillwell et al., 1969). The cryptic life cycles of fungal endophytes are currently poorly understood despite their important ecological roles. It is conceivable that specific foliar endophytes complete a portion of their lifecycle as mutualistic symbionts which is supported by their energy expenditure synthesizing metabolites toxic to host pests in planta (Miller et al. 2008). During this latency period, they maintain an equilibrium with their host. The production of herbicidal metabolites (19) or low pathogenicity towards their host 
may represent a dispersal technique whereby the foliage provides a vector enabling endophytes to colonize new microclimates not accessible by typical spore dispersion. This notion was proposed and termed the foraging ascomycete hypothesis by Prof. George C. Carroll (Thomas et al., 2016). This notion is additionally supported by the discovery of foliar endophytes infecting tress close in proximity by horizontal transmission (Miller et al. 2009). Decaying yellow birch may represent a secondary host for Pezicula species as sugar maple does for the griseofulvin producing Xylaria. Continuing to investigate the in planta production of metabolites of taxonomically distant endophytes would contribute to a better understanding of plant-endophytes relationships, their biodiversity, cryptic lifecycles and ecological roles.

\section{Conclusion}

The cyclical pest Eastern spruce budworm defoliates millions of hectares of coniferous forest during each outbreak. One of the only available options to mitigate this damage is to spray the naturally occurring bacterium Bacillus thuringiensis var. Kurstaki (Btk). This bacterium produces a toxic crystal that is activated by the alkaline intestines of insect pests. The problem with spraying Btk is that it is expensive, and the total forestry region affected during spruce budworm outbreaks is vast. Our research group aims to improve the fitness of reforested stands by inoculating them with toxigenic endophytes.

The basis of this research was demonstrated with the white spruce endophyte P. scopiformis. After inoculating this toxigenic endophyte into white spruce seedlings it was monitored for over 10 years. Despite natural needle shedding, this endophyte remained present in the inoculated white spruce. Additionally, it continued to produce its major toxin rugulosin at concentrations that were 
effective to reduce spruce budworm growth. This was demonstrated by white spruce inoculated with P. scopiformis having more tolerance towards spruce budworm herbivory compared to uninoculated white spruce. The ongoing effort of our group is to expand the number of toxigenic endophytes that can be inoculated into conifer trees as this will allow the endophyte diversity in replanted forests to be restored. Additionally, the phylogenetically diversity of these endophytes translates to the production of unique arrays of secondary metabolites. By inoculating conifers with genetically distinct toxigenic endophytes, we may also be limiting the risk of spruce budworm developing a tolerance.

This thesis focused on four conifer needle endophytes, two isolated from red spruce and two from black spruce. From the Phaeocryptopus cf. gaeumannii endophyte of black spruce 5 isocoumarin structures were characterized, where compound $\mathbf{1}$ was a new structure. Although the antibiotic and antifungal activity of these isocoumarins was modest, previous reports have shown some of these isocoumarins are toxic towards spruce budworm larvae and cells (Findlay et al., 1995b). From an undescribed Rhytismatales endophyte also from black spruce, two new pyrones $(6,7)$ structures were elucidated together with two phthalides $(\mathbf{8}, \mathbf{9})$, two isocoumarins $(\mathbf{1 0}, \mathbf{1 1})$ and the amino acid derived metabolite tyrosol (12). These metabolites represent an array of structural variability. Additionally, a number of these metabolites and related structures have documented antiinsectan activity towards spruce budworm larvae and mosquitos (Cimmino et al., 2013; Sumarah et al., 2008b). From the red spruce endophyte D. maritima, phomopsolides A-C (13-15) were characterized. In addition to the potent antimicrobial activity observed for $\mathbf{1 3}$ and $\mathbf{1 4}$ in this study, these phomopsolides disrupt the insect vector of Dutch elm disease (Claydon et al., 1985). Lastly, from a $P$. sporulosa endophyte of red spruce, cryptosporiopsinol (16), 5-hydroxyl cryptosporiopsin 
(17), cryptosporiopsinol (18) and mellein (19) were identified. Cryptosporiopsin and mellein are metabolites known for their broad spectrum biological activities (Schulz et al., 1995). Taken together, the experimentally observed antimicrobial activities and the literature reports on the antiinsectan activities of these metabolites warrants further testing towards spruce budworm in vitro and potentially in planta thereafter by inoculating these toxigenic endophytes into spruce trees. 


\section{References}

Amos-Binks LJ, Maclean DA, Wilson JS, Wagner RG (2010) Temporal changes in species composition of mixed wood stands in northwest New Brunswick: 1946-2008. Can. J. For. Res. 40: $1-12$.

Arnold AE, Lutzoni F (2007) Diversity and host range of foliar fungal endophytes: are tropical leaves biodiversity hotspots? Ecol. Soc. Am. 88: 541-549.

Bacon CW, Porter JK, Robbins JD, Luttrell ES (1977) Epichloë typhina from toxic tall fescue grasses. Appl. Environ. Microbiol. 34: 576-81.

Begley MJ, Grove JF (1985) Metabolic products of Phomopsis oblonga. part 1. 3a, 5a, 6, 7, 8, 9, 9a, 9b-octahydro-7,9b-dimethylnaphtho[1,2-c]furan-1(3H)-one (oblongolide). J. Chem. Soc.

Perkin Trans. 1: 861-863.

Blais JR (1983) Trends in the frequency, extent and severity of spruce budworm outbreaks in eastern Canada. Can. J. For. Res. 13: 539-545.

Boysen ME, Jacobsson KG, Schnürer J (2000) Molecular identification of species from the Penicillium roqueforti group associated with spoiled animal feed. Appl. Environ. Microbiol 66: 1523-1526.

Brenna E, Fronza G, Fuganti C, Pinciroli M (2003) Differentiation of natural and synthetic phenylalanine and tyrosine through natural abundance $2 \mathrm{H}$ nuclear magnetic resonance. J. Agric. Food Chem. 51: 4866-4872.

Brian PW, Curtis PJ, Hemming HG, Unwin CH, Wright JM (1949) Alternaric acid, a biologically active metabolic product of the fungus Alternaria solani. Nature 164: 534.

Bush LP, Wilkinson HH, Shardl CL (1997) Bioprotective alkaloids of grass-fungal endophyte symbioses. Plant Physiol. 144: 1-7.

Calhoun LA, Findlay JA, Miller JD, Whitney NJ (1992) Metabolites toxic to spruce budworm from balsam fir needle endophytes. Mycol. Res. 96: 281-286.

Carroll GC, (1986) The biology of endophytism in plants with particular reference to woody perennials. In: Fokkema NJ, Van den Heuvel J (eds.) Microbiology of the phyllosphere.

Cambridge University Press, Cambridge, pp 205-222.

Carroll GC, Carroll FE (1978) Studies on the incidence of coniferous needle endophytes in the Pacific Northwest. Can. J. Bot. 56: 3034-3043.

Cimmino A, Andolfi A, Avolio F, Ali A, Tabanca N, Khan IA, Evidente A (2013) Cyclopaldic acid, seiridin, and sphaeropsidin $\mathrm{A}$ as fungal phytotoxins, and larvicidal and biting deterrents 
against Aedes aegypti (Diptera: Culicidae): structure-activity relationships. Chem. Biodivers. 10: 1239-1251.

Clay K (1997) Fungal endophytes, herbivores and the structure of grassland communities. In: Gange AC, Brown VK (eds.) Multitrophic interactions in terrestrial systems. Blackwell, Oxford, pp. 151-169.

Clay K, Schardl C (2002) Evolutionary origins and ecological consequences of endophyte symbiosis with grasses. Am. Nat. 160: 99-127.

Claydon N, Grove JF, Pople M (1985) Elm bark beetle boring and feeding deterrents from Phomopsis oblonga. Phytochemistry 24: 937-943.

Connell JH (1961) The influence of interspecific competition and other factors on the distribution of the barnacle Chthamalus stellatus. Ecology 42: 710-723.

Deacon JW (2005) Fungal metabolism and fungal products. In: Fungal biology, 4th edition. Blackwell Publishing Ltd., Malden, pp. 122-141.

Dewick, PM (1997). Medicinal natural products: a biosynthetic approach. John Wiley \& Sons, New York, pp. 9, 121-147.

Dörge T, Carstensen JM, Frisvad JC (2000) Direct identification of pure Penicillium species using image analysis. J. Microbiol. Methods 41:121-133.

Dowd PF (1988) Synergism of aflatoxin B toxicity with the co-occuring fungal metabolite kojic acid to two caterpillars. Entomol. Exp. Appl. 47: 69-71.

Dowd PF, Miller JD Greenhalgh R (1989) Toxicity and interactions of some Fusarium graminearum metabolites to caterpillars. Mycologia 81: 646-650.

Eaton MAW, Hutchinson DW (1971) Isocoumarins from Streptomyces mobaraensis. Tet. Lett. 18: 1337-1340.

Etheridge DA, Maclean DA, Wagner RG, Wilson JS (2005) Changes in landscape composition and stand structure from 1945-2002 on an industrial forest in New Brunswick, Canada. Can. J. For. Res. 35: 1965-1977.

Etheridge DA, Maclean DA, Wagner RG, Wilson JS (2006) Effects of intensive forest management on stand and landscape characteristics in northern New Brunswick, Canada (19452027). Landscape Ecol. 21: 509-524.

Ferreira RB, Monteiro S, Freitas R, Santos CN, Chen Z, Batista LM, Duarte J, Borges A, Teixeteira AR (2006) Fungal pathogens: the battle for plant infection. Crit. Rev. Plant Sci. 25: 505-524. 
Findlay JA, Buthelezi S, Lavoie R, Pena-Rodriguez L, Miller JD (1995b) Bioactive isocoumarins and related metabolites from conifer endophytes. J. Nat. Prod. 58: 1759-1766.

Findlay JA, Li G, Miller JD, Womiloju TO (2003) Insect toxins from spruce endophytes. Can. J. Chem. 81: 284-292.

Findlay JA, Li G, Penner PE (1995a) Novel diterpenoid insect toxins from a conifer endophyte. J. Nat. Prod. 58: 197-200.

Forbes G, Veen H, Loo J, Zelazny V, Woodley S (1998) Ecological change in the greater Fundy ecosystem. In: Woodley S, Forbes G, Skibicki A (eds.) State of the Greater Fundy Ecosystem. Canadian Forest Services Publications, Fredericton, pp. 55-74.

Frasz SL, Walker AK, Nsiama TK, Adams GW, Miller JD (2014) Distribution of the foliar fungal endophyte Phialocephala scopiformis and its toxin in the crown of a mature white spruce tree as revealed by chemical and qPCR analyses. Can. J. For. Res. 44: 1138-1143.

Ganley RJ, Newcombe G (2006) Fungal endophytes in seeds and needles of Pinus monticola. Mycol. Res. 110: 318-327.

Garbary DJ (2009) Why is Ascophyllum nodosum not a lichen? Int. Lichen News 41: 34-35.

Garbary DJ, London JF (1995) The Ascophyllum/Polysiphonial/Mycosphaerella symbiosis. 5. fungal infection protects A. nosodum from desiccation. Bot. Mar. 38: 529-533.

Giles D, Turner WB (1969) Chlorine-containing metabolites of Periconia macrospinosa. J. Chem. Soc., 2187-2189.

Goddard ML, Mottier N, Jeanneret-Gris J, Christen D, Tabacchi R, Abou-Mansour E (2014) Differential production of phytotoxins from Phomopsis sp. from grapevine plants showing esca Symptoms. J. Agric. Food Chem. 62: 8602-8607.

Grove JF (1985) Metabolic products of Phomopsis oblonga. part 2. phomopsolide A and B, tiglic esters of two 6-substituted 56-dihydro-5-hydroxypyran-2-ones. J. Chem. Soc., Perkin Trans. 1: 865-869.

Haslam E (1974) The shikimate pathway. Butterworth and Co Ltd., London, pp. 1-48.

Hennigar CR, Maclean DA, Quiring DT, Kershaw JA (2008) Differences in spruce budworm defoliation among balsam fir and white, red and black spruce. Forest Sci. 54: 158-166.

Herrmann KM (1995) The shikimate pathway: early steps in the biosynthesis of aromatic compounds. The Plant Cell 7: 907-919.

Hoffmeister D, Keller NP (2007) Natural products of filamentous fungi: enzymes, genes, and their regulation. Nat. Prod. Rep. 24: 393-416. 
Holker JSE, Young K (1975) Biosynthesis of metabolites of Periconia macrospinosa from [1$\left.{ }^{13} \mathrm{C}\right]-,\left[2-{ }^{13} \mathrm{C}\right]$-, and $\left[1,2-{ }^{13} \mathrm{C}\right]$-acetate. J.C.S. Chem. Comm., 525-526.

Horn WS, Simmonds MSJ, Schwartz RE, Blaney WM (1996) Variation in production of phomodiol and phomopsolide B by Phomopsis spp. Mycologia 88: 588-595.

Hunt RS, Rudloff EV (1977) Leaf oil terpene variation in western white pine populations of the Pacific Northwest. Forest Sci. 23: 507-516.

Ichimoto I, Machiya K, Kirihata M, Ueda H (1988) Stereoselective synthesis of podoblastins and their antiblast activity. J. Pesticide Sci. 13: 605-613.

Irland LC (1980) Pulpwood, pesticides, and people. controlling spruce budworm in northeastern North America. Environ. Manage. 4: 381-389.

Johnson JA, Whitney NJ (1989) A study of fungal endophytes of needles of balsam fir (Abies balsamea) and red spruce (Piceae rubens) in New Brunswick, Canada, using cultural and electron microscope techniques. Can. J. Bot. 67: 3513-3516.

Katoh N, Nakahata T, Kuwahara S (2008) Synthesis of novel antifungal phthalides produced by a wheat rhizosphere fungus. Tetrahedron 64: 9073-9077.

Keller NP, Turner G, Bennett JW (2005) Fungal secondary metabolism-from biochemistry to genomics. Natural Rev. Microbiol. 3: 937-947.

Koshino H, Terada S, Yoshihara T, Sakamura S, Shimanuki T, Sato T, Tajimi A (1988) Three phenolic acid derivatives from stromata from Epichloe typhina on Phleum pretense. Phytochemistry 27: 1333-1338.

Krohn K, Bahramsari R, Florke U, Ludewig K, Kliche-Spory C, Michel A, Aust HJ, Draeger S, Schulz B, Antus S (1997) Dihydroisocoumarins from fungi: isolation, structure elucidation, circular dichroism and biological activity. Phytochemistry 45: 313-320.

Loo J, Ives N (2003) The Acadian forest: historical condition and human impacts. For. Chron. 79: 462-474.

Lorimer GG (2008) Eastern white pine abundance in $19^{\text {th }}$ century forests: a re-examination of evidence from land surveys and lumber statistics. J. For. 106: 253-260.

Lousberg RJJ, Moreau TM (1976) Isolation of (-)-cryptosporiopsin, a chlorinated cyclopentenone fungitoxic metabolite from Phialophora asteris f. sp. helianthi. Experientia 32: 331-332.

Lysyk TJ (1990) Relationships between spruce budworm (Lepidoptera, Tortricidae) egg mass density and resultant defoliation of balsam fir and white spruce. Can. Entomol. 122: 253-262. 
MacLean DA, Beaton KP, Porter KB, MacKinnon WB, Budd WB (2002) Potential wood supply losses to spruce budworm in New Brunswick estimated using the spruce budworm decision support system. Forestry Chron. 78: 739-750.

Manitto P (1981) Primary and secondary metabolism. In: Sammes PG (ed.) Biosynthesis of natural products. Ellis Horwood Ltd., New York, pp. 9-50.

McGahren WJ, van den Hende JH, Mitscher LA (1969) Chlorinated cyclopentenone fungitoxic metabolites from the fungus, Sporomia affinis. J. Amer. Chem. Soc. 91: 157-162.

McGee DI, Mallais TC, Mayo PDM, Strunz GM (2006) Studies in stereoselective [2+2]cycloadditions with dichloroketene. Tetrahedron 62: 4153-4161.

Miller JD (1986) Toxic metabolites of epiphytic and endophytic fungi of conifer needles. In: Fokkema NJ, Van den Heuvel J (eds.) Microbiology of the phyllosphere. Cambridge University Press, Cambridge, pp. 223-231.

Miller JD (2011) Foliar endophytes of spruce species found in the Acadian Forest: basis and potential for improving the tolerance of the forest to spruce budworm. In: Pirttilä AM, Frank AC (eds.) Endophytes of forest trees: biology and applications. Springer Science+Business Media LLC, New York, pp. 238-249.

Miller JD, Cherid H, Sumarah MW, Adams GW (2009) Horizontal transmission of the Picea glauca foliar endophyte Phialocephala scopiformis CBS 120377. Fungal Ecol. 2: 98-101.

Miller JD, Mackenzie S, Foto M, Adams GW, Findlay JA (2002) Needles of white spruce inoculated with rugulosin-producing endophytes contain rugulosin reducing spruce budworm growth rate. Mycol. Res. 106: 471-479.

Miller JD, Strongman D, Whitney NJ (1985) Observations on fungi associated with spruce budworm infested balsam fir needles. Can. J. For. Res. 15: 896-901.

Miller JD, Sumarah MW, Adams GW (2008) Effect of a rugulosin-producing endophyte in Picea glauca on Choristoneura fumiferana. J. Chem. Ecol. 34: 362-368.

Miyakado M, Inoue S, Tanabe Y, Watanabe K, Ohno N, Yoshioka H, Mabry TJ (1982) Studies on podoblastin I, podoblastin-A, podoblastin-B and podoblastin-C - new antifungal 3-acyl-4hydroxy-5,6-dihydro-2-pyrones obtained from Podophyllum peltatum L. Chemistry Lett. 10: 1539-1542.

Mortimer PH, Fletcher LR, di Menna ME (1982) Recent advances in ryegrass staggers research - an overview. Proc. New Zeal. Soc. An. 44: 181-184.

Nago H, Matsumoto M (1993) An ecological role of volatiles produced by Lasiodiplodia theobromae. Biosci. Biotechnol. Biochem. 58: 1267-1272. 
Natural Resources Canada (2016) Top forest insects and diseases in Canada: spruce budworm. Retrieved on 21-07-2016 <www.nrcan.gc.ca/forests/fire-insects-disturbances/topinsects/13383>.

Nishikawa H (1933) Biochemistry of filamentous fungi. II. B. Agr. Chem. Soc. Japan, 9: 107109.

Nozawa K, Nakajima S, Yamada M, Kawai K (1980) Syntheses of two microbial metabolites, 5chloro-3,4-dihydro-8-hydroxy-6-methoxy-3-methylisocoumarin and 8-hydroxy-6-methoxy-3methylisocoumarin. Chem. Pharm. Bull. 28: 1622-1625.

Pelaez F (2005) Biological activities of fungal metabolites. In: An Z (ed.) Handbook of industrial mycology. Marcel Dekker Inc, New York, pp. 49-92.

Petrini O (1991) Fungal endophytes of tree leaves. In: Andrews JH, Hirano SS (eds.) Microbial ecology of leaves part 3. Springer New York, New York, pp. 179-197.

Richardson SN, Walker AK, Nsiama TK, McFarlane J, Sumarah MW, Ibrahim A, Miller JD (2014) Griseofulvin-producing Xylaria endophytes of Pinus strobus and Vaccinium angustifolium: evidence for a conifer-understory species endophyte ecology. Fungal Ecol. 11: 107-113.

Rodriguez RJ, White Jr JF, Arnold AE, Redman RS (2009) Fungal endophytes: diversity and functional role. New Phytol. 182: 314-30.

Royama T (1984) Population dynamics of the spruce budworm. Ecol. Monogr. 54: 429-462.

Saikkonen K, Saari S, Helander M (2010) Defensive mutualism between plants and endophytic fungi? Fungal Divers. 41: 101-113.

Schmidt JP, Lodge DJ (2004) Classical methods and modern analysis for studying fungal diversity. In: Dighton J, White JF, Oudemans P (eds.) The fungal community, its organization and role in the ecosystem $3^{\text {rd }}$ edition. CRC Press, USA, pp. 193-214.

Schmit JP, Mueller GM (2007) An estimate of the lower limit of global fungal diversity. Biodivers. Conserv. 16: 99-111.

Schneider G, Anke H, Sterner O (1996) Xylaramide, a new antifungal compound, and other secondary metabolites from Xylaria longipes. Z. Naturforsch. C. 51: 802-806.

Schoch CL, Seifert KA, Huhndorf S, Robert V, Spouge JL, Levesque CA, Chen W (2012) Nuclear ribosomal internal transcribed spacer (ITS) region as a universal DNA barcode marker for fungi. PNAS 109: 6241-6246.

Schulz B, Sucker J, Aust HJ, Krohn K, Ludewig K, Jones PG, Doring D (1995) Biologically active secondary metabolites of endophytic Pezicula species. Mycol. Res. 99: 1007-1015. 
Shan R, Stadler M, Anke H, Sterner O (1997) Naphthalenone and phthalide metabolites from Lachnum papyraceum. J. Nat. Prod. 60: 804-805.

Sherwood-Pike M, Stone JK, Carroll GC (1986) Rhabdocline parkeri, a ubiquitous foliar endophyte of douglas fir. Can. J. Bot. 64: 1849-1855.

Sieber TN (2007) Endophytic fungi in forest trees: are they mutualists? Fungal Biol. Rev. 21: 7589.

Sommart U, Rukachaisirikul V, Tadpetch K, Sukpondma Y, Phongpaichit S, HutadilokTowatana N, Sakayaroj J (2012) Modiolin and phthalide derivatives from the endophytic fungus Microsphaeropsis arundinis PSU-G18. Tetrahedron 68: 10005-10010.

Stadler M, Anke H (1993) Lachnumon and lachnumol A, new metabolites with nematicidal and antimicrobial activities from the Ascomycete Lachnum papyraceum (KARST.) Karst. J. Antibiotics 46: 961-967.

Stierle DB, Stierle AA, Ganser B (1997) New phomopsolides from a Penicillium sp. J. Nat. Prod. 60: 1207-1209.

Stillwell MA, Wood FA, Strunz GM (1969) A broad-spectrum antibiotic produced by a species of Cryptosporiopsis. Can. J. Microbiol. 15: 501-507.

Stossel A (1969) 8-hydroxy-6-methoxy-3-methylisocoumarin and other metabolites of Ceratocystis fimbriata. Bioc. Biophys. Res. Comm. 35: 186-191.

Strunz GM, Court AS, Komlossy J, Stillwell MA (1969) Addendum: cryptosporiopsin, an amended structure. Can. J. Chem. 47: 3700.

Strunz GM, Court AS, Komlossy J, Stillwell MA (1969) Structure of cryptosporiopsin: a new antibiotic substance produced by a species of Cryptosporiopsis. Can. J. Chem. 47: 2087-2094.

Strunz GM, Kazinoti PI, Stillwell MA (1974) A new chlorinated cyclopentenone produced by a Cryptosporiopsis species. Can. J. Chem. 52: 3623-3625.

Sumarah MW, Adams GW, Berghout J, Slack GJ, Wilson AM, Miller, JD (2008a). Spread and persistence of a rugulosin-producing endophyte in Picea glauca seedlings. Mycol. Res. 112: 731-736.

Sumarah MW, Kesting JR, Sorensen D, Miller JD (2011) Antifungal metabolites from fungal endophytes of Pinus strobus. Phytochemistry 72: 1833-1837.

Sumarah MW, Miller JD (2009) Anti-insect secondary metabolites from fungal endophytes of conifer trees. Nat. Prod. Commun. 4: 1497-1504. 
Sumarah MW, Puniani E, Blackwell BA, Miller JD (2008b) Characterization of polyketide metabolites from foliar endophytes of Picea glauca. J. Nat. Prod. 71: 1393-1398.

Sumarah MW, Puniani E, Sørensen D, Blackwell BA, Miller JD (2010) Secondary metabolites from anti-insect extracts of endophytic fungi isolated from Picea rubens. Phytochemistry 71: 760-765.

Tabuchi H, Hamamoto T, Miki S, Tejima T, Ichihara A (1994) Total synthesis and stereochemistry of alternaric acid. J. Org. Chem. 59: 4749-4759.

Takaya Y, Furukawa T, Miura S, Akutagawa T, Hotta Y, Ishikawa N, Niwa M (2007) Antioxidant constituents in distillation residue of awamori spirits. J. Agric. Food Chem. 55: 7579.

Takaya Y, Kikuchi H, Terui Y, Komiya J, Furukawa K, Seya K, Motomura S, Ito A, Oshima Y (2000) Novel acyl-alpha-pyronoids, dictyopyrone A, B, and C, from Dictyostelium cellular slime Molds. J. Org. Chem. 65: 985-989.

Tanabe Y, Miyakado M, Ohno N, Yoshioka H (1982) A new 3-Acyl-4-hydroxy-2-pyrone synthesis and its application to total synthesis of (+/-) podoblastin A, B and C. Chem. Lett. 10: 1543-1546.

Tanney JB, Douglas B, Seifert KA (2016a) Sexual and asexual states of some endophytic Phialocephala species of Picea. Mycologia 108: 255-280.

Tanney JB, McMullin DR, Green BD, Miller JD, Seifert KA (2016b) Production of antifungal and antisectan metabolites by the Picea endophyte Diaporthe maritima sp. nov. Fungal Biol. In Press.

Thomas DC, Vandegrift R, Ludden A, Carroll GC, Roy BA (2016) Spatial ecology of the fungal genus Xylaria in a tropical cloud forest. Biotropica 48: 381-393.

Uchida K, Watanabe H, Kitahara T (1998) Synthesis of both enantiomers of hiburipyranone. Tetrahedron 54: 8975-8984.

Vincent JG, Vincent HW (1944) Filter paper disc modification of the oxford cup penicillin determination. Proc. Soc. for Exp. Biol. Med. 55: 162-164.

Webber J (1981) A natural biological control of Dutch elm disease. Nature 292: 449-451.

Webber JF, Gibbs JN (1984) Colonization of elm bark by Phomopsis oblonga. Trans. Br. Mycol. Soc. 82: 348-352.

Wicklow DT (1981) The fungal community. Its organization and role in the ecosystem. Marcel Dekker Inc, New York. 
Wilson R, Wheatcroft R, Miller JD, Whitney NJ (1994). Genetic diversity among natural populations of endophytic Lophodermium pinastri from Pinus resinosa. Mycol. Res. 98: 740744.

Yuan L, Lin X, Zhao PJ, Ma J, Huang YJ, Shen YM (2009) New polyketides from endophytic Diaporthe sp. XZ-07. Helv. Chim. Acta 92: 1184-1190. 
Appendix I $-{ }^{1} \mathrm{H}$ and ${ }^{13} \mathrm{C}$ NMR spectra of isolated endophyte metabolites<smiles>C[C@H]1OC(=O)C2=C(O)C[C@@H](O)C[C@H]2[C@H]1O</smiles>

${ }^{1} \mathrm{H}$ NMR spectrum of compound 1 (400MHz, CD $3 \mathrm{OD}$ )
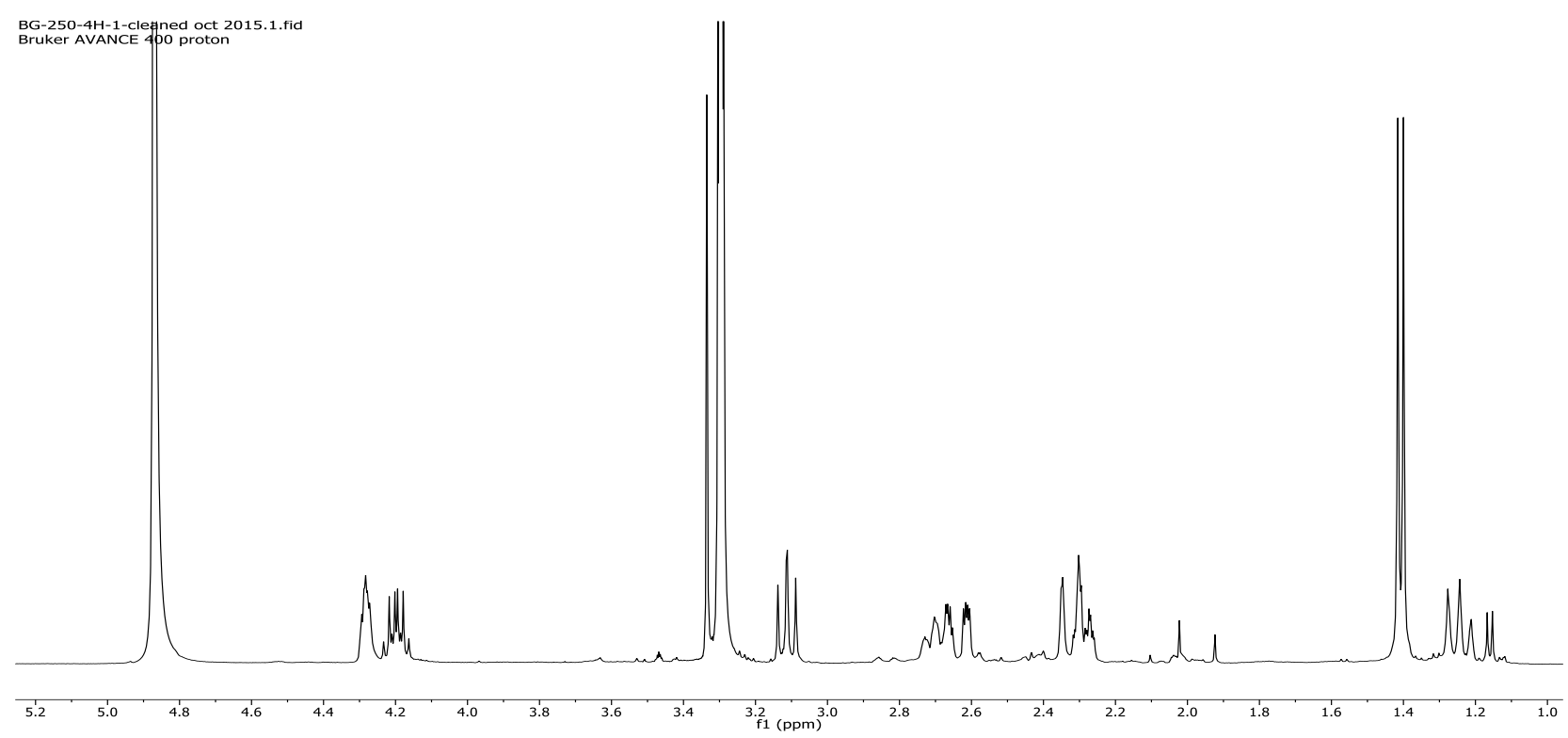

${ }^{13} \mathrm{C}$ NMR spectrum of compound 1 (100 MHz, CD $\left.3 \mathrm{OD}\right)$

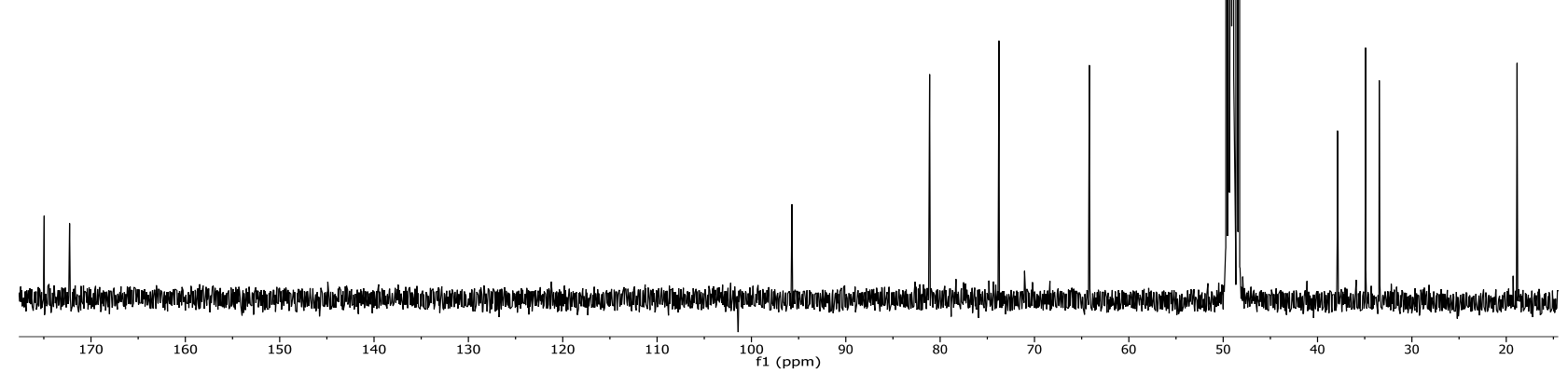


<smiles>C[C@H]1C[C@H]2C[C@H](O)CC(O)=C2C(=O)O1</smiles>

${ }^{1} \mathrm{H}$ NMR spectrum of compound $2\left(400 \mathrm{MHz}, \mathrm{CD}_{3} \mathrm{OD}\right)$

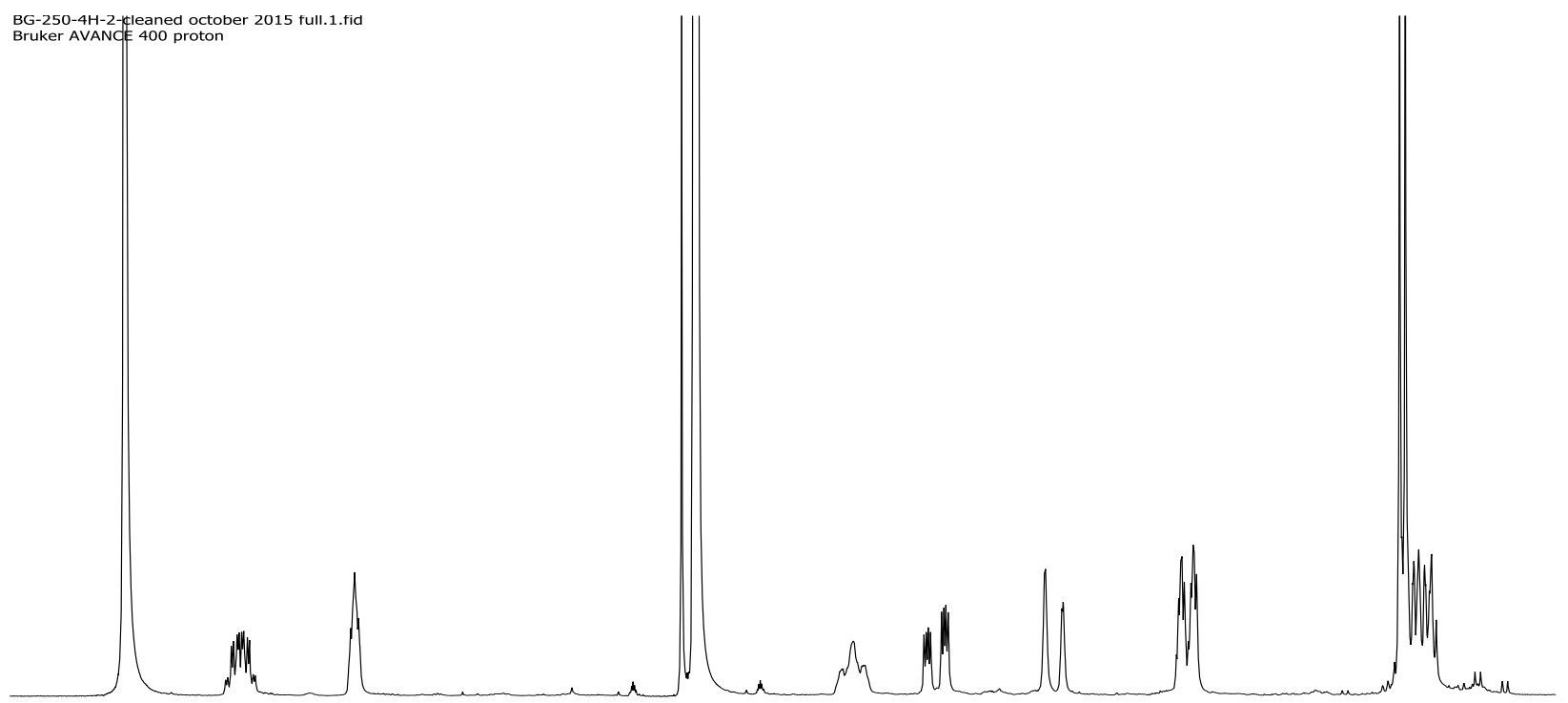

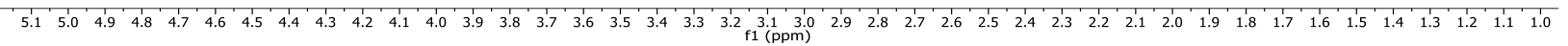

${ }^{13} \mathrm{C}$ NMR spectrum of compound $2\left(100 \mathrm{MHz}, \mathrm{CD}_{3} \mathrm{OD}\right)$

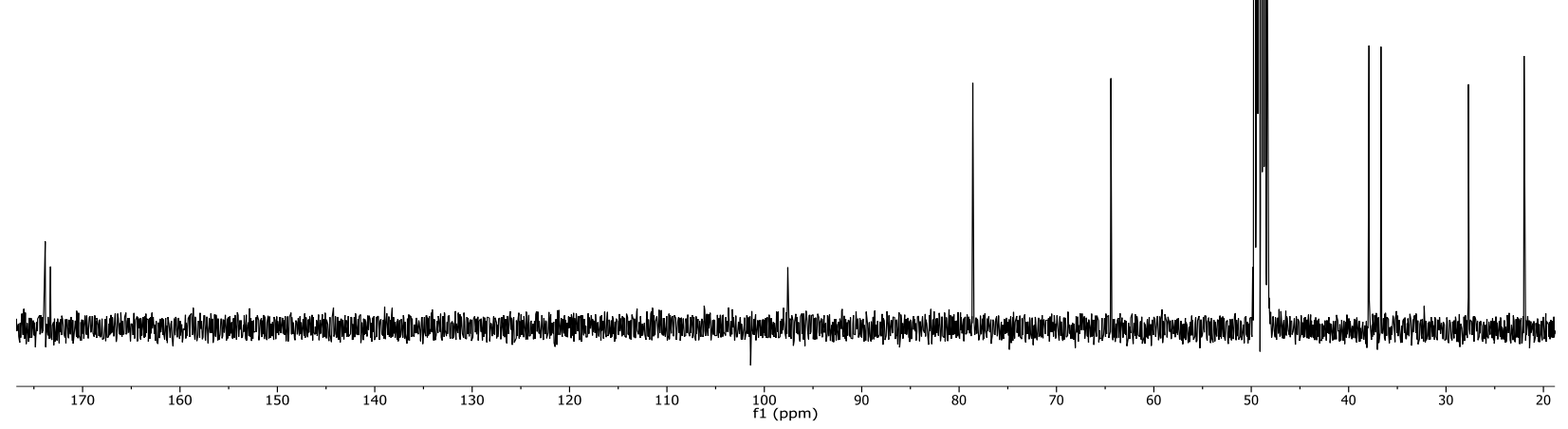


<smiles>C[C@H]1OC(=O)c2c(O)cccc2[C@H]1O</smiles>

${ }^{1} \mathrm{H}$ NMR spectrum of compound 3 (400MHz, CD $\left.3 \mathrm{OD}\right)$

BG-250-4H-5-cleaned oct 2015.1.fid
Bruker AVANCE 400 proton

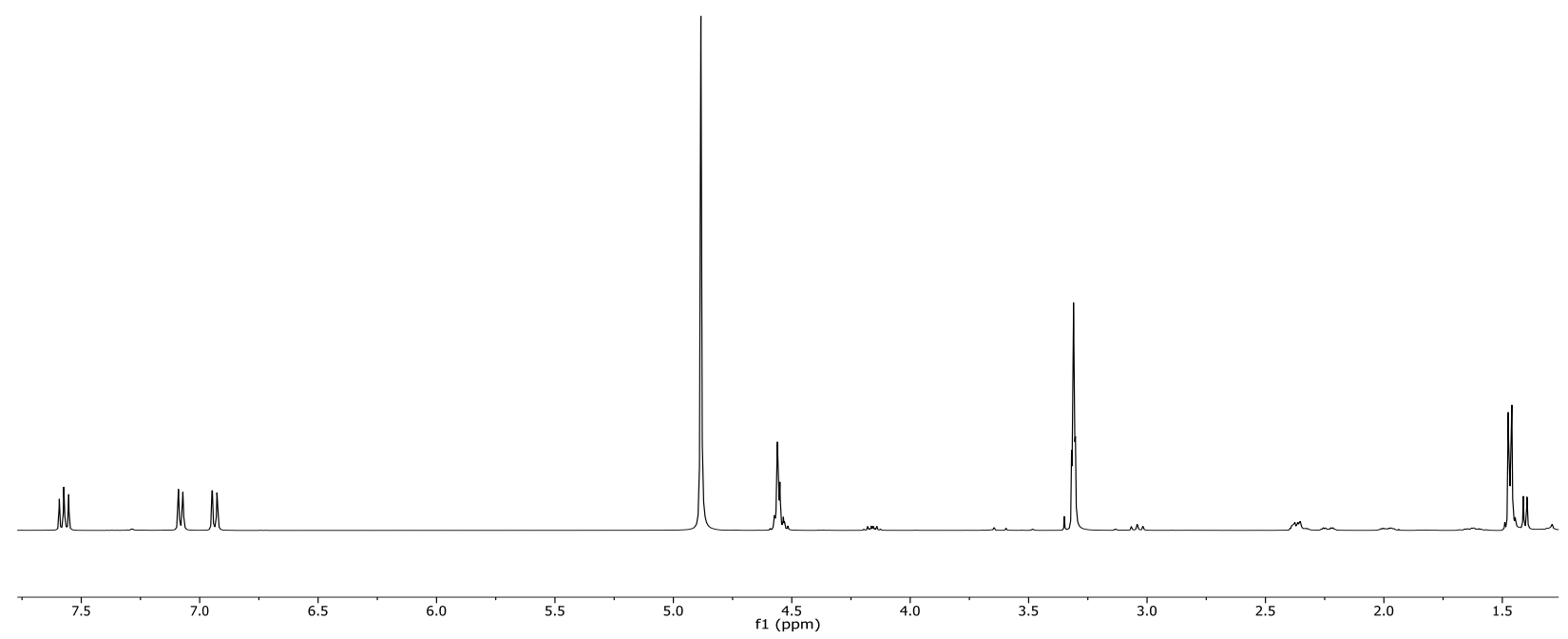

${ }^{13} \mathrm{C}$ NMR spectrum of compound $3\left(100 \mathrm{MHz}, \mathrm{CD}_{3} \mathrm{OD}\right)$

BG-250-4H-5-cleaned oct 2015.3.fid

Bruker AVANCE 400 carbon

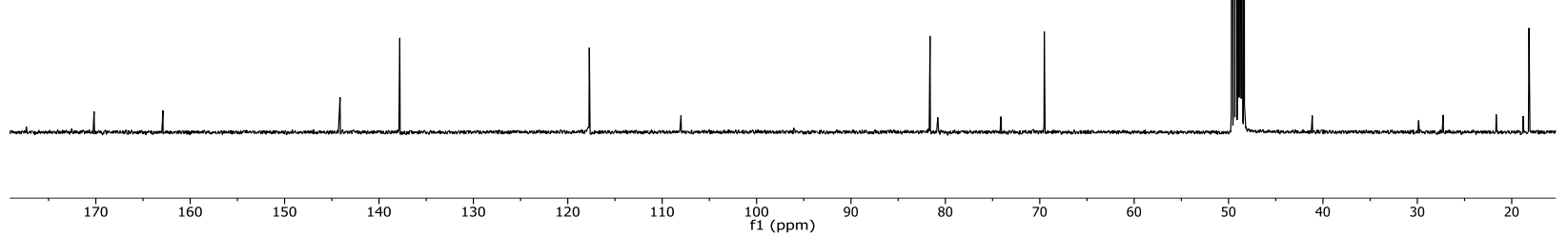


<smiles>C[C@H]1OC(=O)C2=C(O)C=CC[C@H]2[C@H]1O</smiles>

${ }^{1} \mathrm{H}$ NMR spectrum of compound 4 (400 MHz, $\left.\mathrm{CD}_{3} \mathrm{OD}\right)$

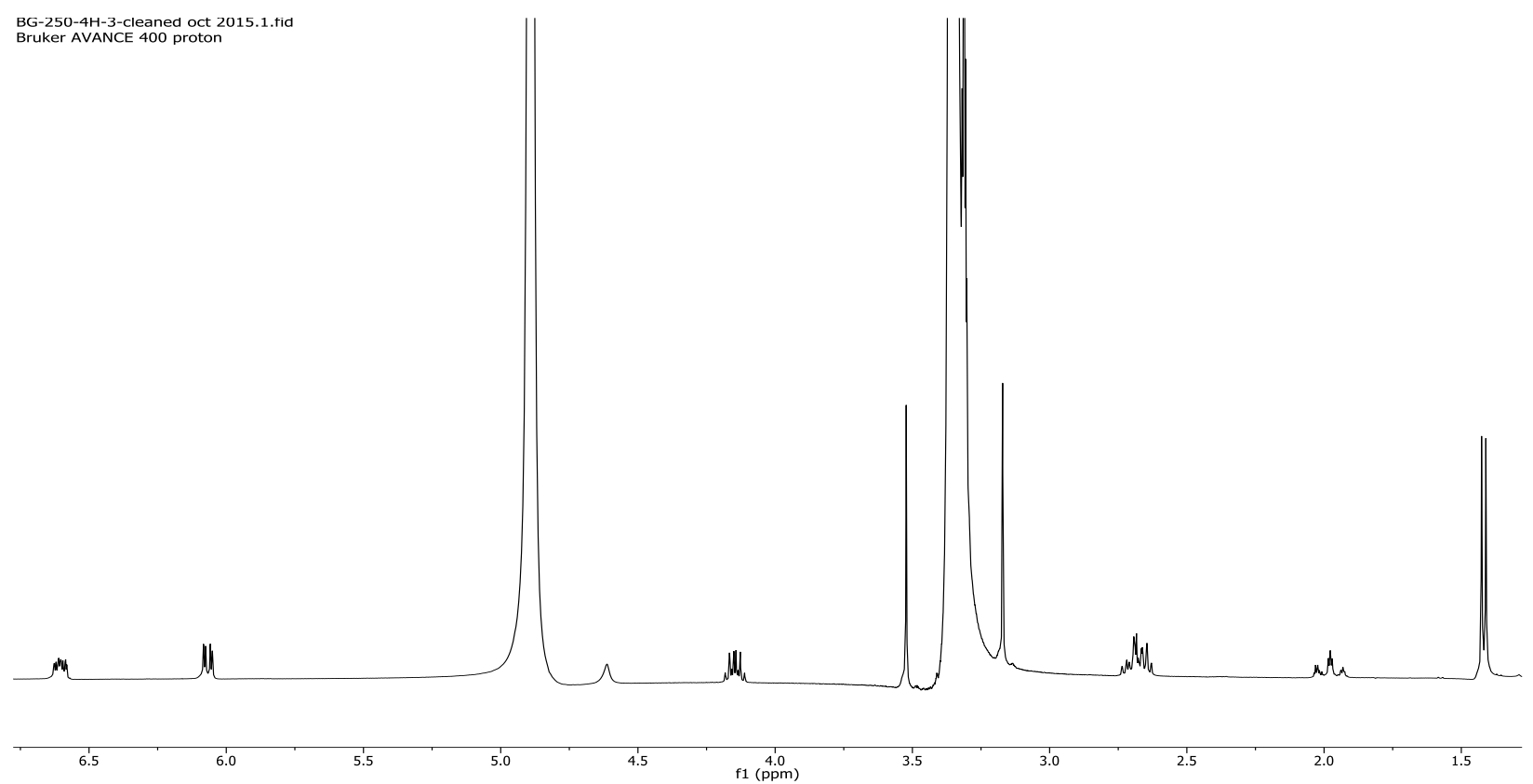

${ }^{13} \mathrm{C}$ NMR spectrum of compound $4\left(100 \mathrm{MHz}, \mathrm{CD}_{3} \mathrm{OD}\right)$

BG-250-4H-3-cleaned oct 2015.3.fid
Bruker AVANCE 400 carbon 
<smiles>C[C@H]1OC(=O)C2=C(O)CCC[C@H]2[C@H]1O</smiles>

${ }^{1} \mathrm{H}$ NMR spectrum of compound 5 (400 MHz, CD $\left.3 \mathrm{OD}\right)$

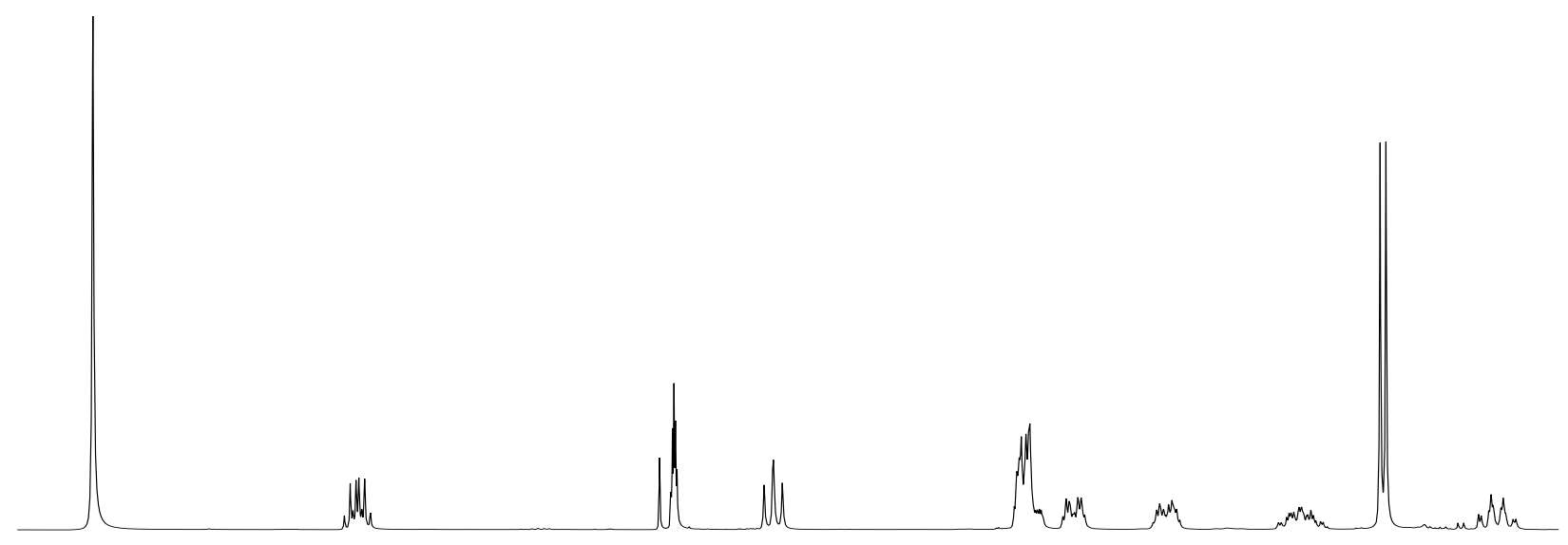

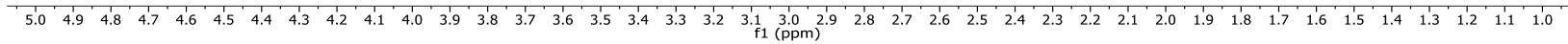

${ }^{13} \mathrm{C}$ NMR spectrum of compound $5\left(100 \mathrm{MHz}, \mathrm{CD}_{3} \mathrm{OD}\right)$
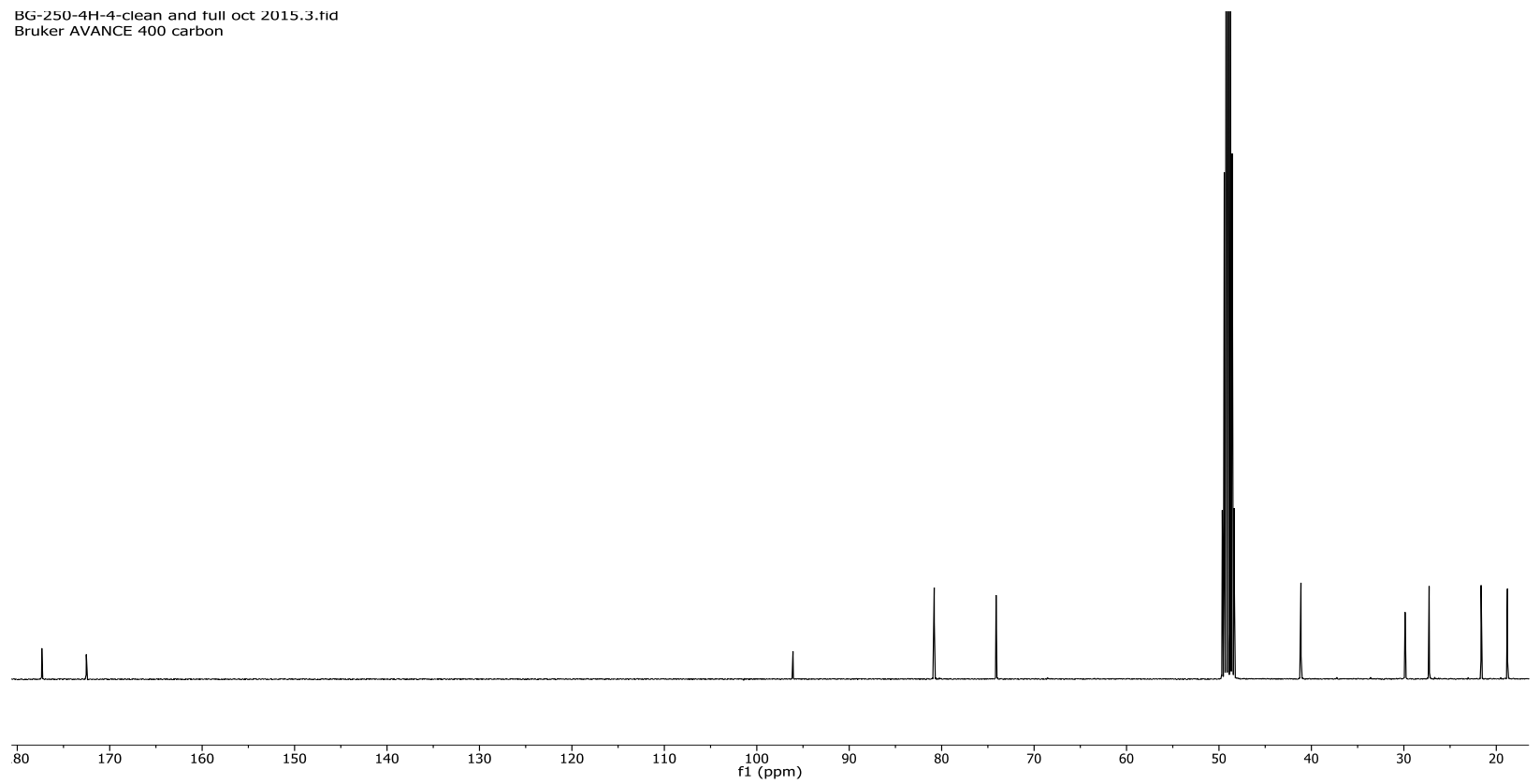


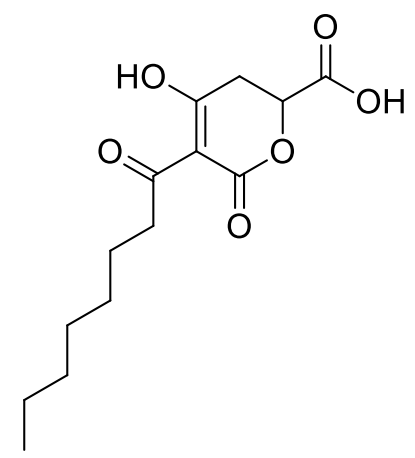

${ }^{1} \mathrm{H}$ NMR spectrum of compound 6 (400 MHz, $\left.\mathrm{CD}_{3} \mathrm{OD}\right)$
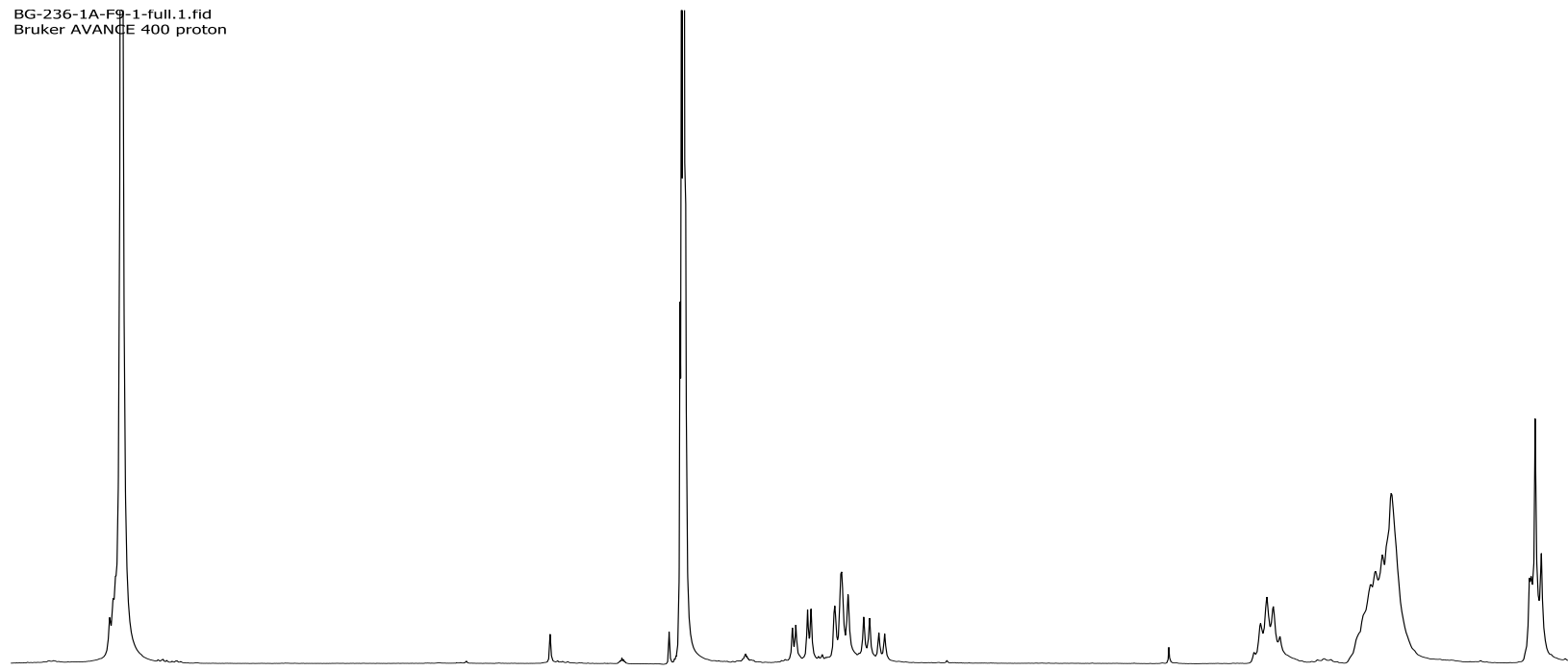

$.2 \cdot$
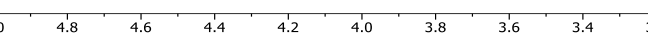

$2 \stackrel{3.0}{1.0}$

${ }^{13} \mathrm{C}$ NMR spectrum of compound $6\left(100 \mathrm{MHz}, \mathrm{CD}_{3} \mathrm{OD}\right)$ BG-236-1A-F9-1-full.3.fid
1D C13 Experiment 


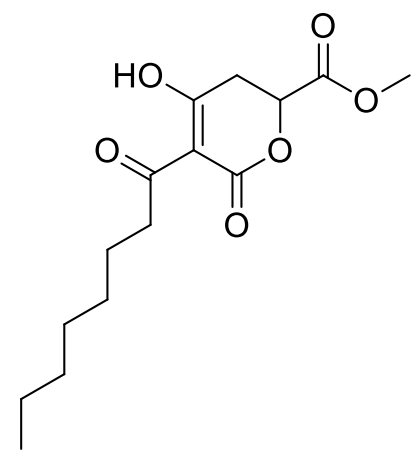

${ }^{1} \mathrm{H}$ NMR spectrum of compound 7 (400 MHz, $\left.\mathrm{CD}_{3} \mathrm{OD}\right)$
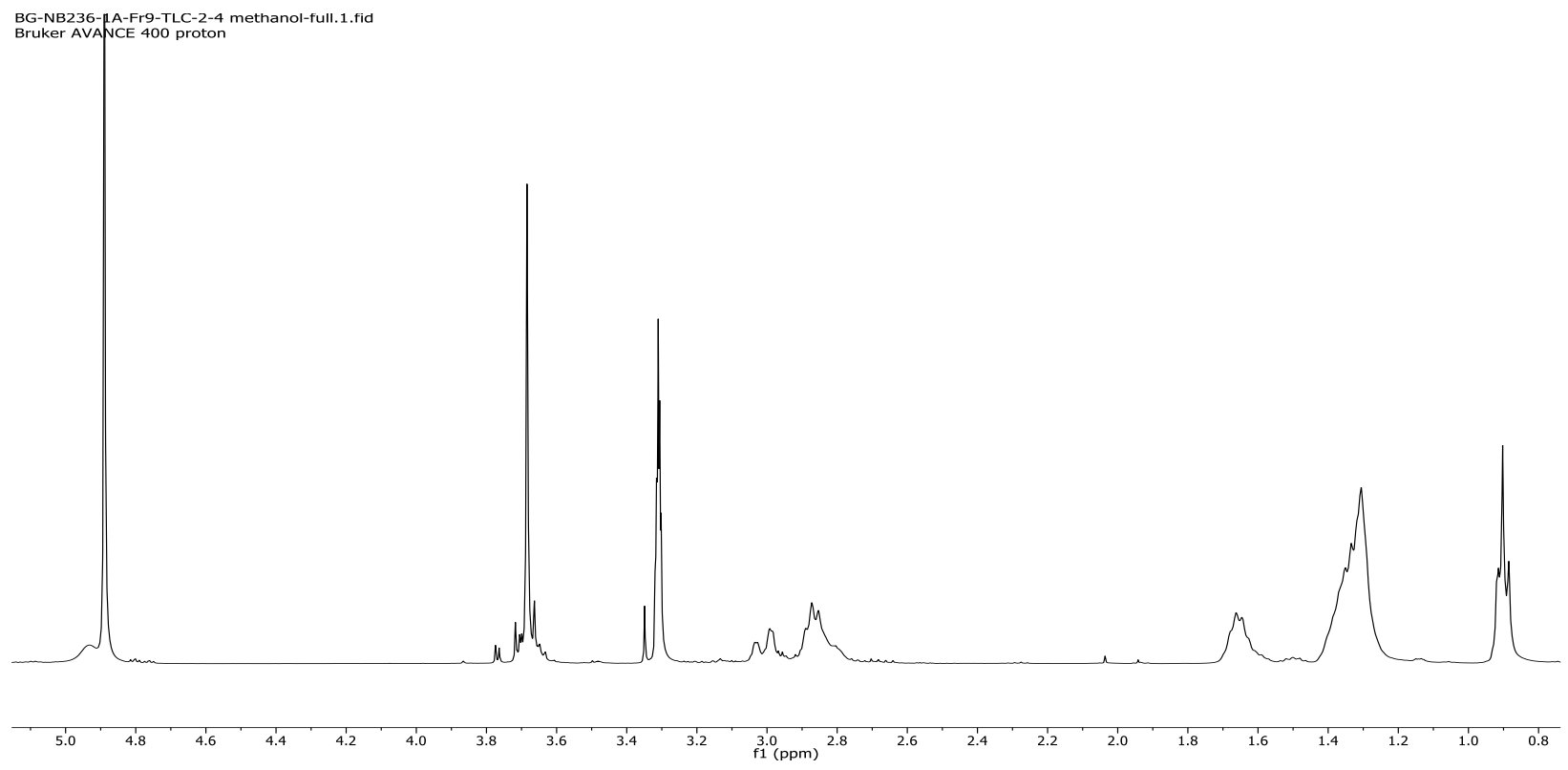

${ }^{13} \mathrm{C}$ NMR spectrum of compound $7\left(100 \mathrm{MHz}, \mathrm{CD}_{3} \mathrm{OD}\right)$

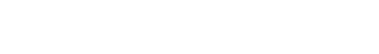


<smiles>COc1c(C)c(O)c(C)c2c1C(=O)OC2</smiles>

${ }^{1} \mathrm{H}$ NMR spectrum of compound 8 (400 MHz, CD $\left.3 \mathrm{OD}\right)$
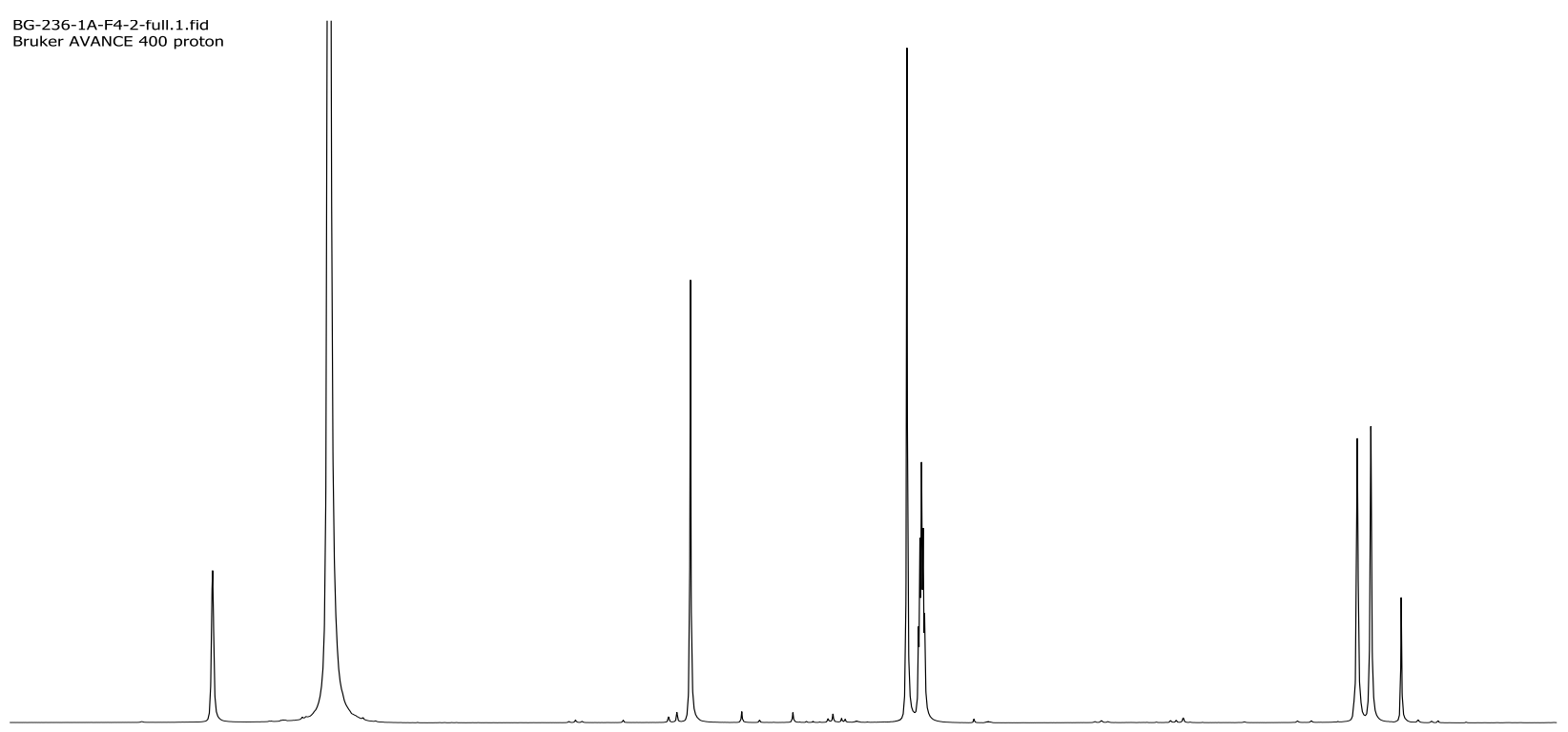

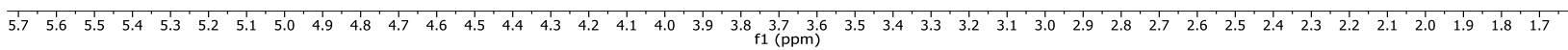

${ }^{13} \mathrm{C}$ NMR spectrum of compound $8\left(100 \mathrm{MHz}, \mathrm{CD}_{3} \mathrm{OD}\right)$ BG-236-1A-F4-2-full.3.fid
1D C13 Experiment

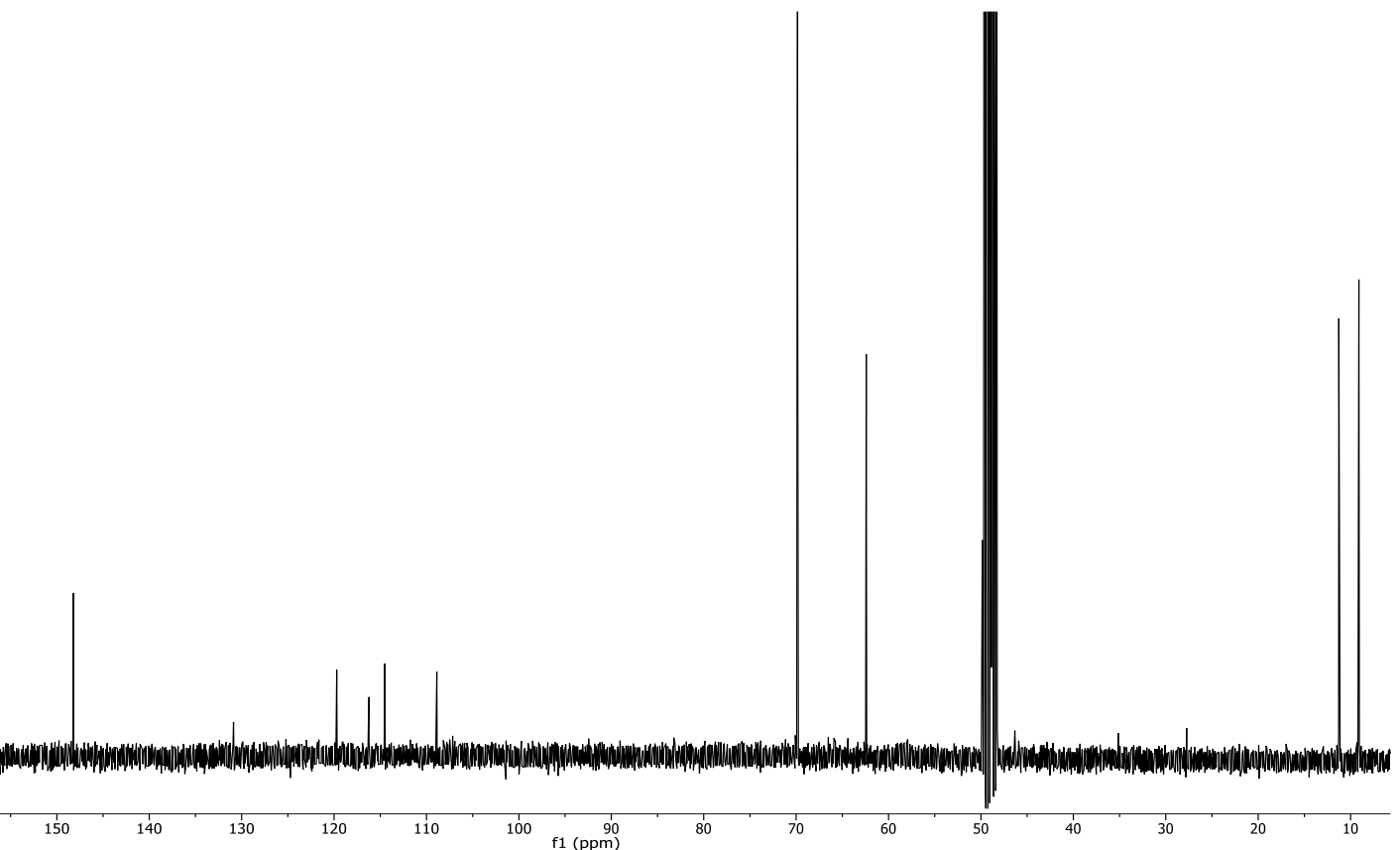


<smiles>COc1c(C)c(O)c(CO)c2c1C(=O)OC2</smiles>

${ }^{1} \mathrm{H}$ NMR spectrum of compound 9 (400 MHz, CD 3 OD)

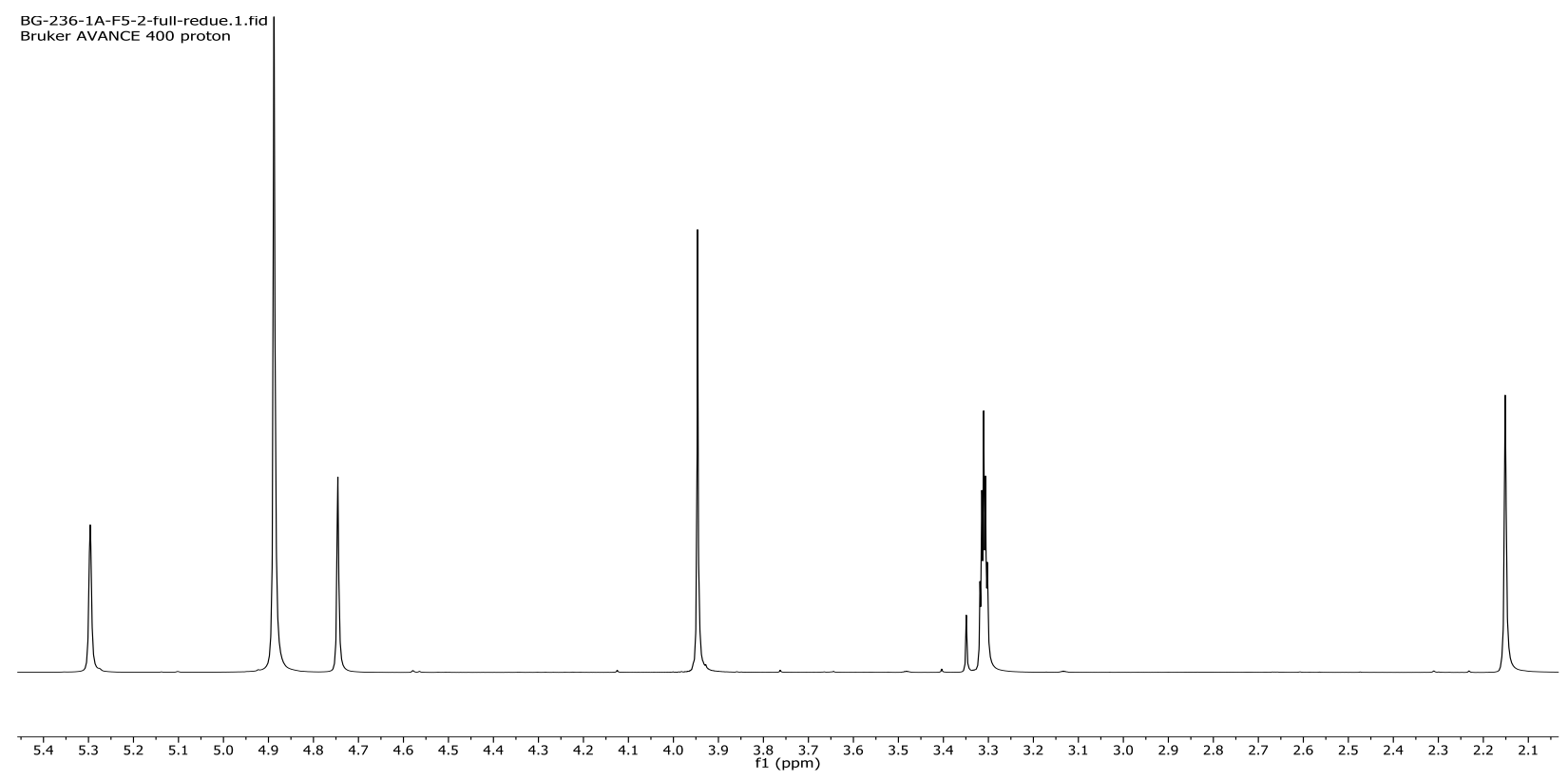

${ }^{13} \mathrm{C}$ NMR spectrum of compound 9 (100 MHz, CD $\left.3 \mathrm{OD}\right)$

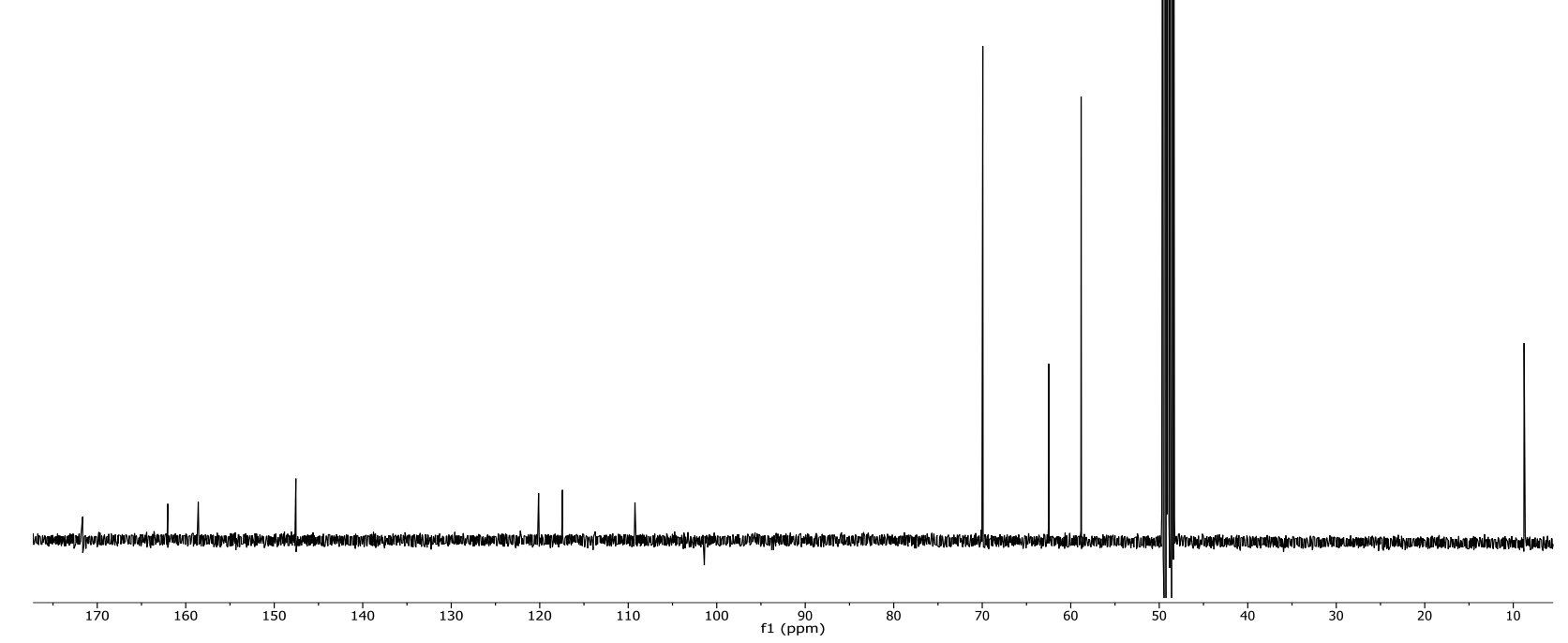


<smiles>COc1cc(O)c2c(=O)oc(C)cc2c1</smiles>

${ }^{1} \mathrm{H}$ NMR spectrum of compound 10 (400 MHz, CD $\left.3 \mathrm{OD}\right)$

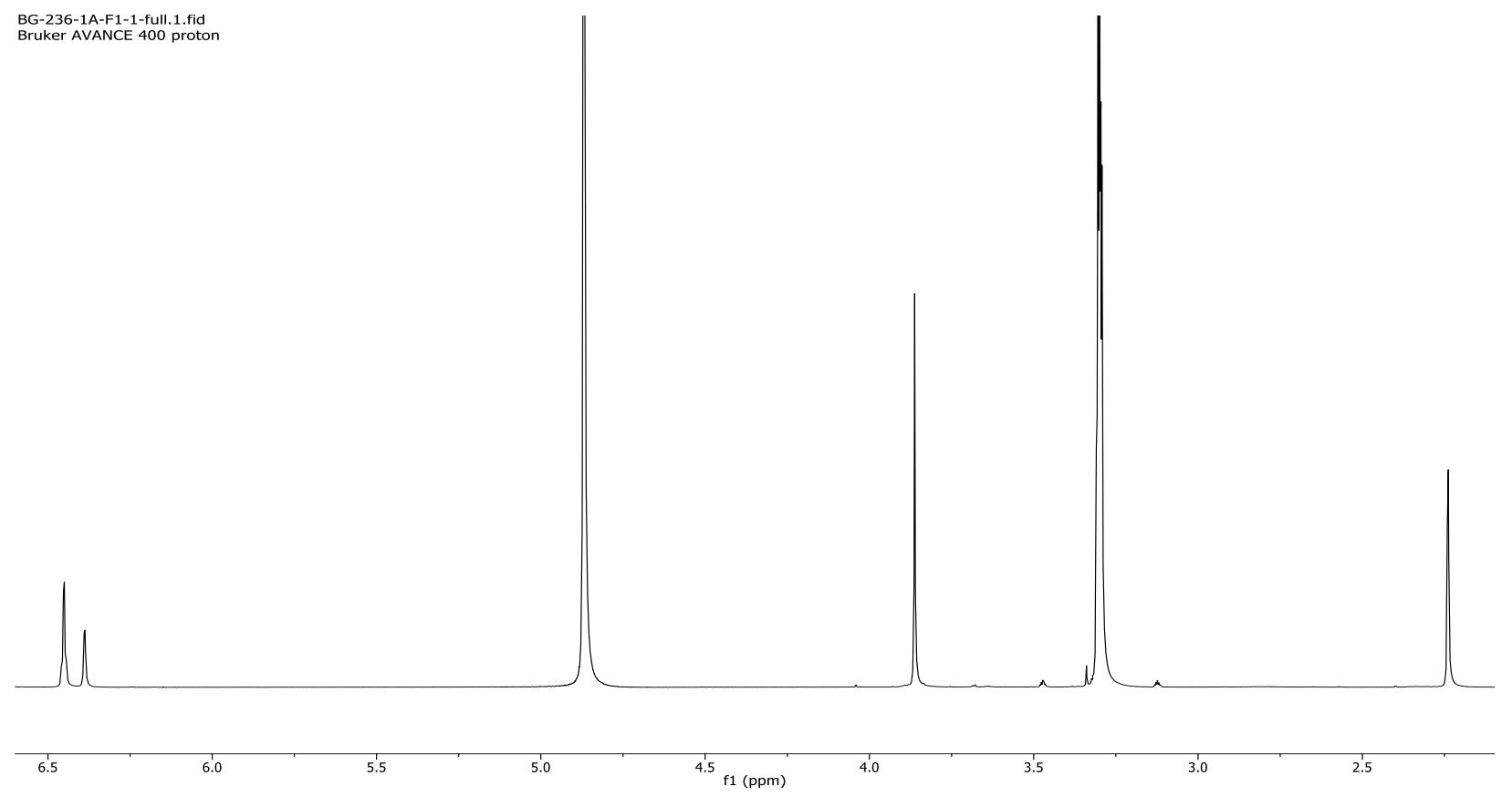

${ }^{13} \mathrm{C}$ NMR spectrum of compound $10\left(100 \mathrm{MHz}, \mathrm{CD}_{3} \mathrm{OD}\right)$ BG-236-1A-F1-1-full.3.fid
1D C13 Experiment

1D C13 Exp 
<smiles>CCCC1Cc2cc(OC)cc(O)c2C(=O)O1</smiles>

${ }^{1} \mathrm{H}$ NMR spectrum of compound $11\left(400 \mathrm{MHz}, \mathrm{CD}_{3} \mathrm{OD}\right)$

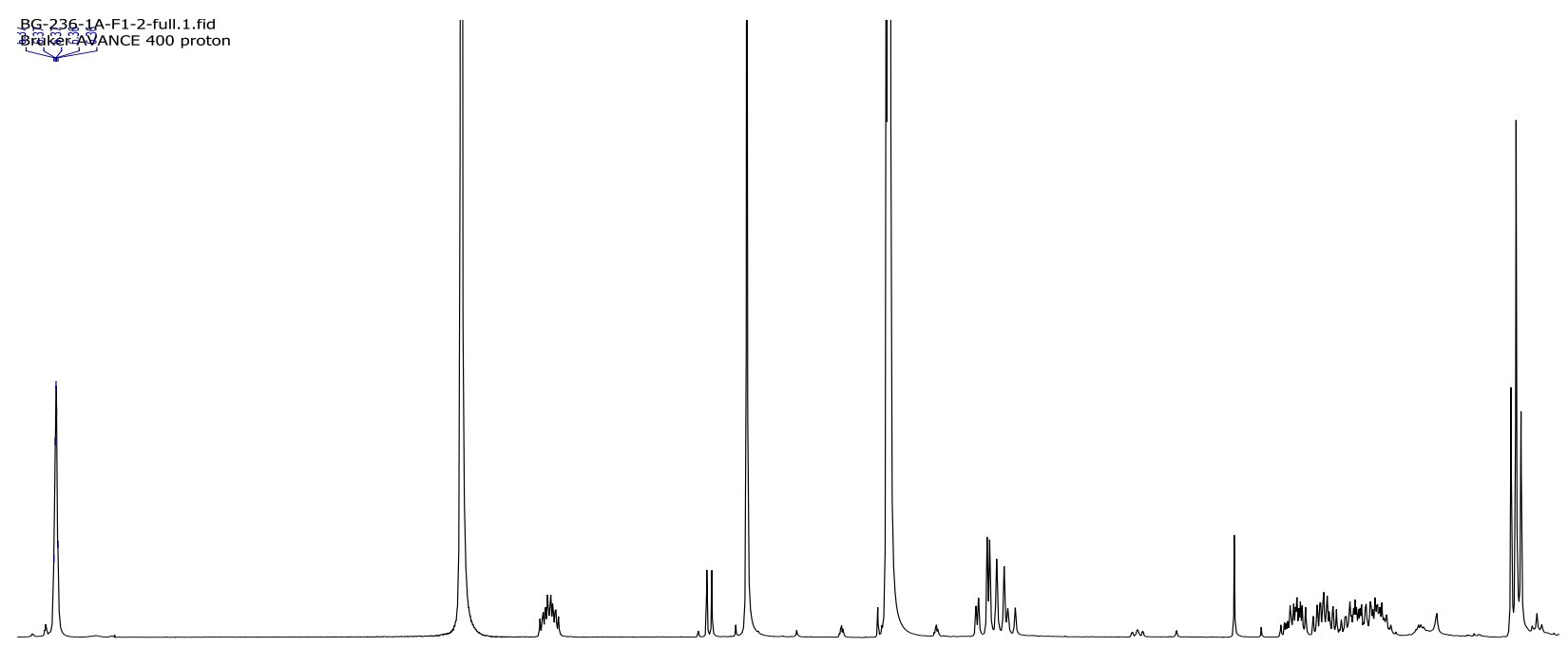

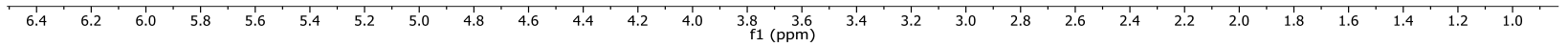

${ }^{13} \mathrm{C}$ NMR spectrum of compound $11\left(100 \mathrm{MHz}, \mathrm{CD}_{3} \mathrm{OD}\right)$

BG-236-1A-F1-2-full.3.fid
1D C13 Experiment

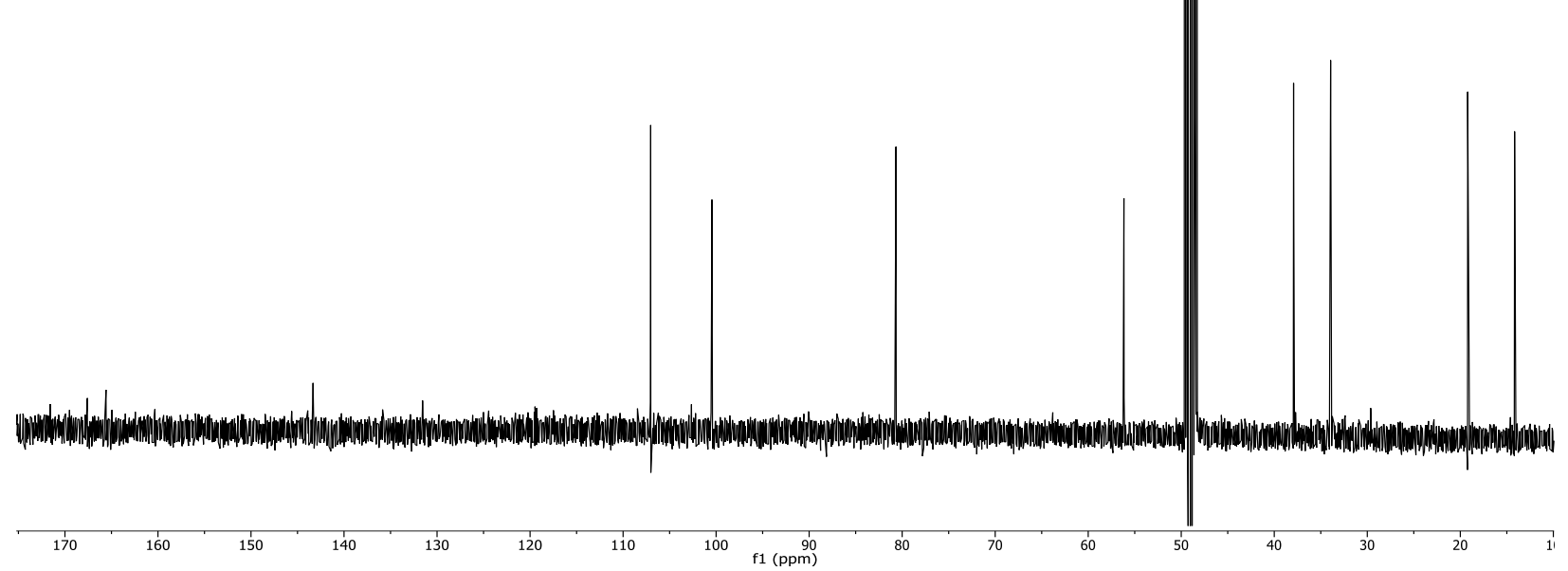




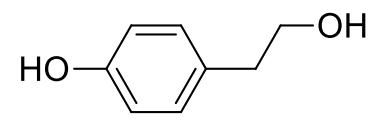

${ }^{1} \mathrm{H}$ NMR spectrum of compound 12 (400 MHz, CD $\left.3 \mathrm{OD}\right)$

BG-236-1A-F4-1-full.1.fid
Bruker AVANCE 400 proton
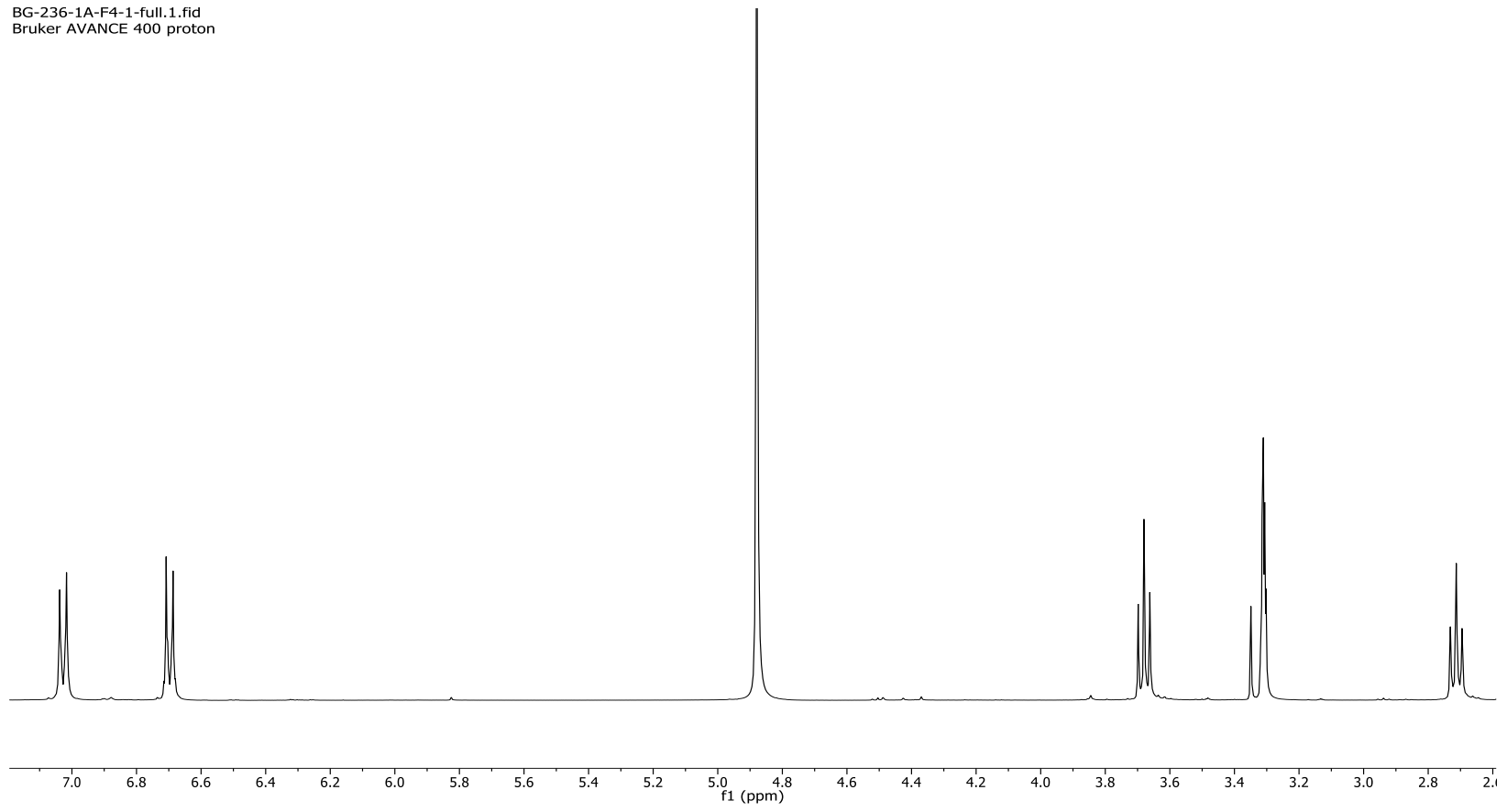

${ }^{13} \mathrm{C}$ NMR spectrum of compound $12\left(100 \mathrm{MHz}, \mathrm{CD}_{3} \mathrm{OD}\right)$

BG-236-1A-F4-1-full.3.fid
1D C13 Experiment

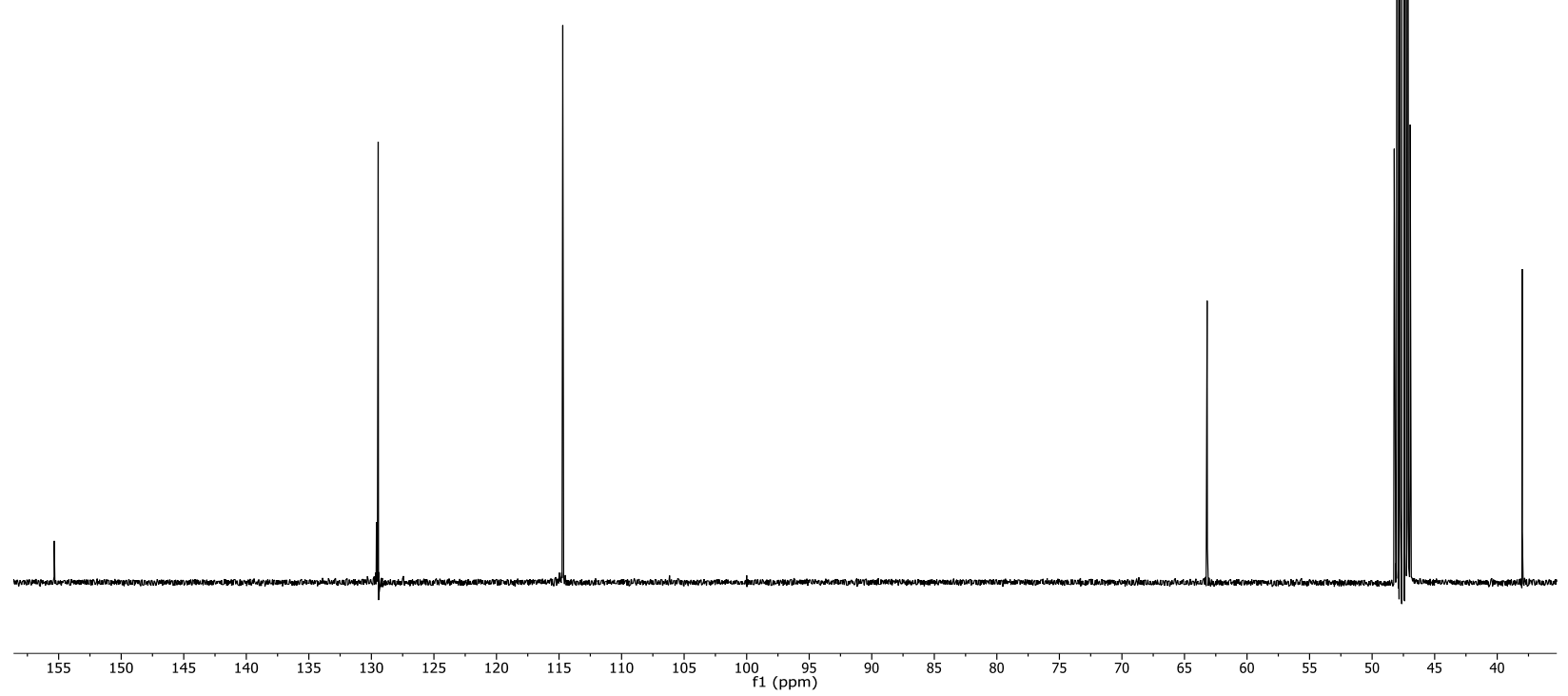


<smiles>C/C=C(\C)C(=O)O[C@H]1C=CC(=O)O[C@@H]1/C=C/C(=O)[C@H](C)O</smiles>

${ }^{1} \mathrm{H}$ NMR spectrum of compound 13 (400 MHz, $\left.\mathrm{CD}_{3} \mathrm{OD}\right)$

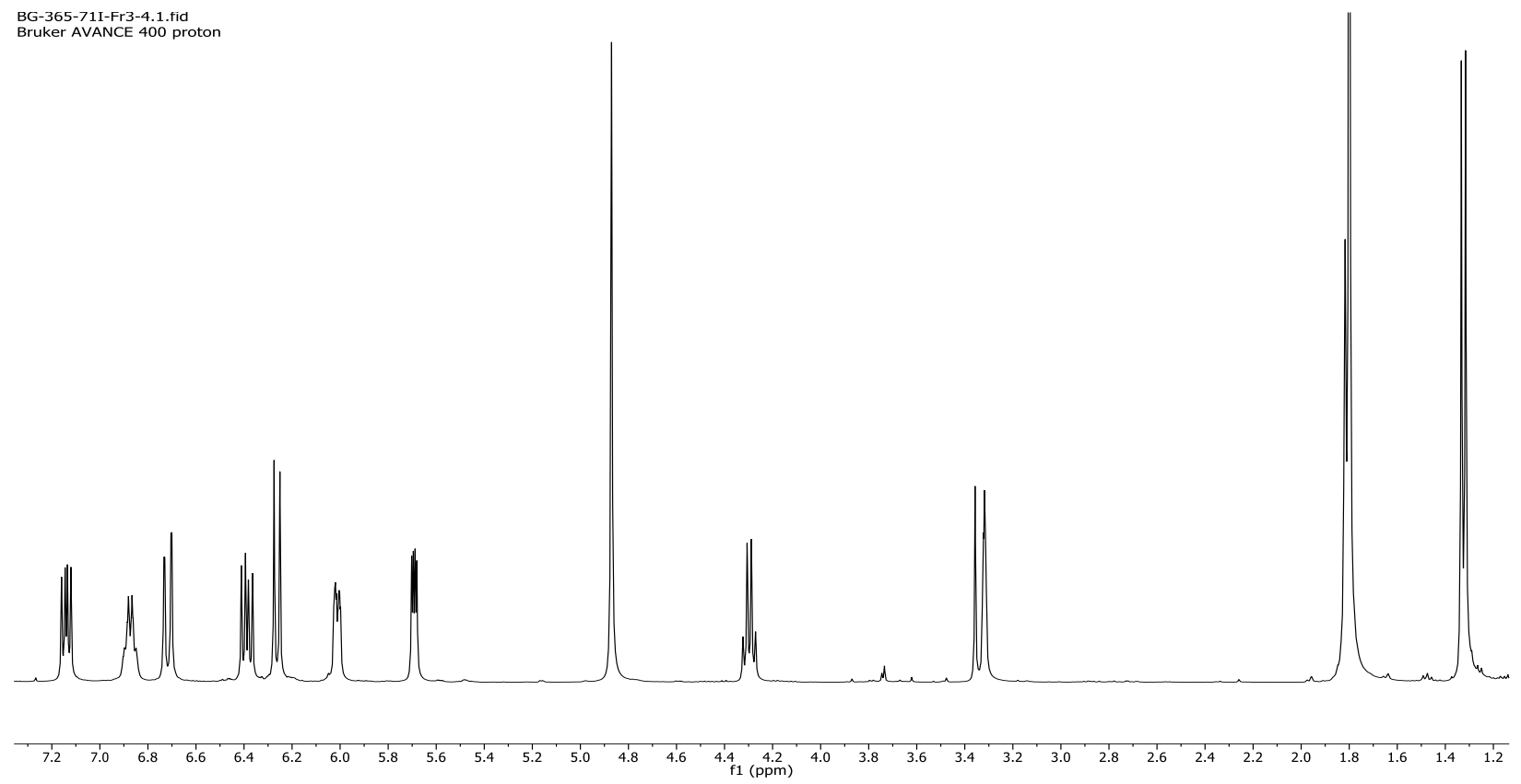

${ }^{13} \mathrm{C}$ NMR spectrum of compound $13\left(100 \mathrm{MHz}, \mathrm{CD}_{3} \mathrm{OD}\right)$ BG-365-71-Fr-3-4.2.fid
Bruker AVANCE 400 carbon

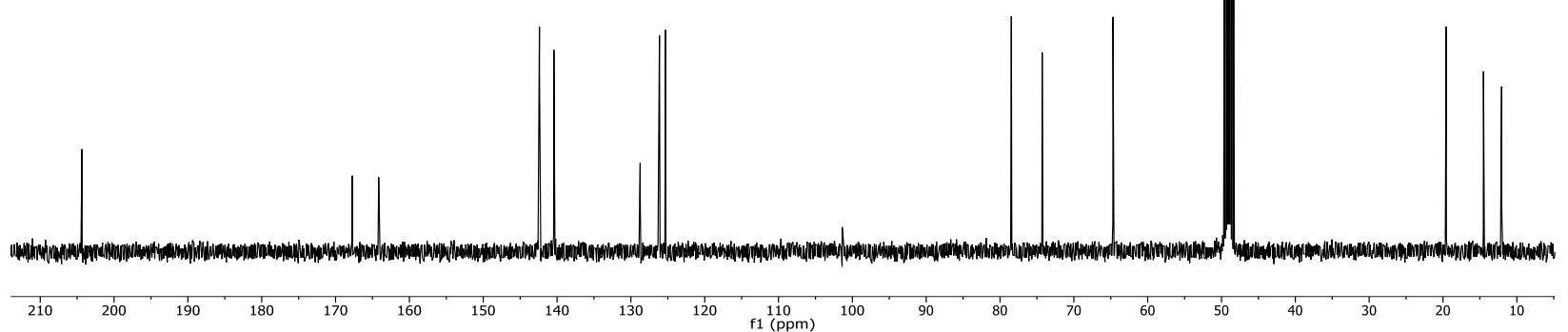


<smiles>C/C=C(\C)C(=O)O[C@H]1C=CC(=O)O[C@@H]1/C=C/[C@@H](O)[C@H](C)O</smiles>

${ }^{1} \mathrm{H}$ NMR spectrum of compound $14\left(400 \mathrm{MHz}, \mathrm{CD}_{3} \mathrm{OD}\right)$
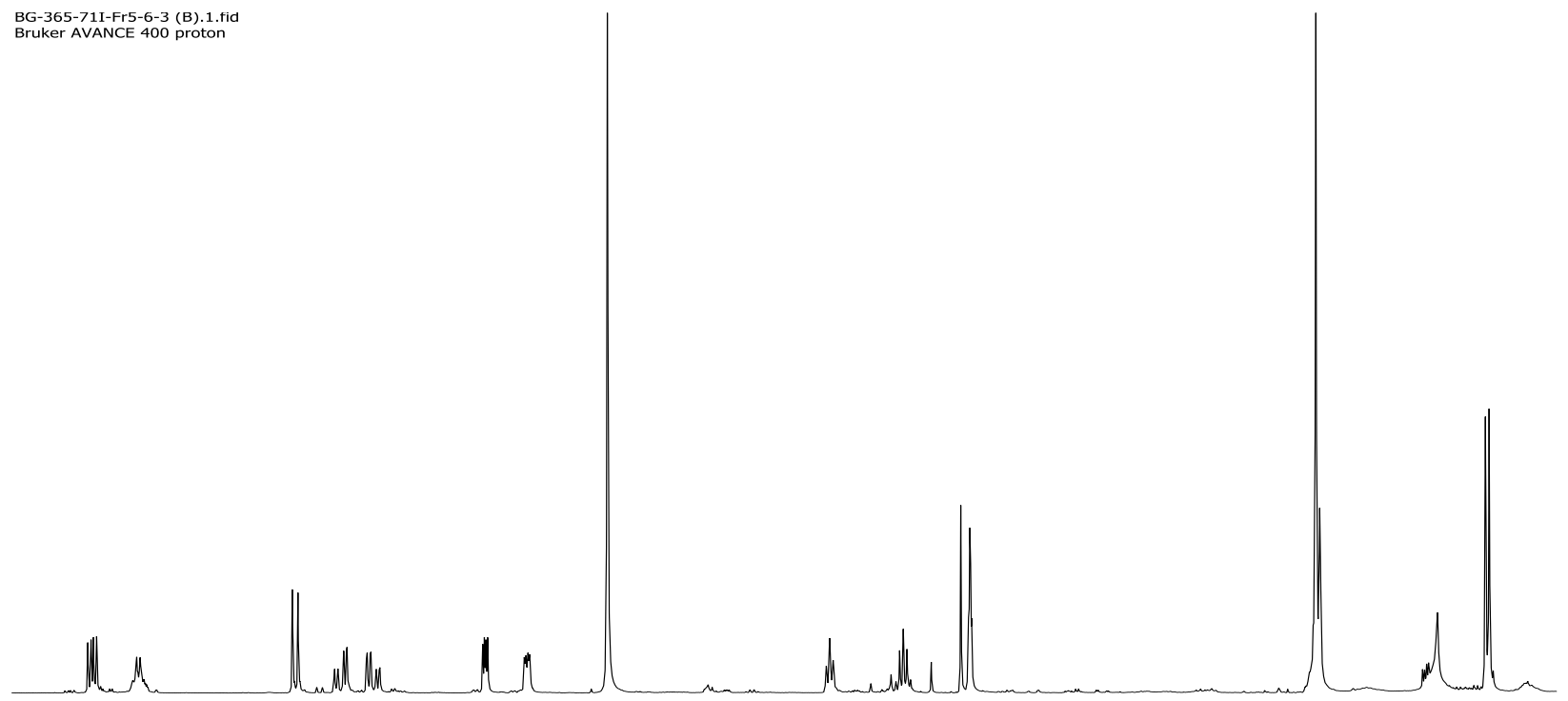

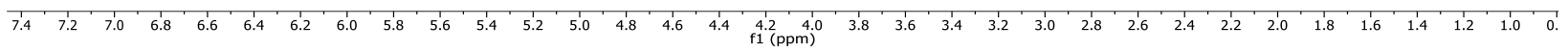

${ }^{13} \mathrm{C}$ NMR spectrum of compound $14\left(100 \mathrm{MHz}, \mathrm{CD}_{3} \mathrm{OD}\right)$

BG-365-711-Fr5-6-3 (B).3.fid
Bruker AVANCE 400 carbon

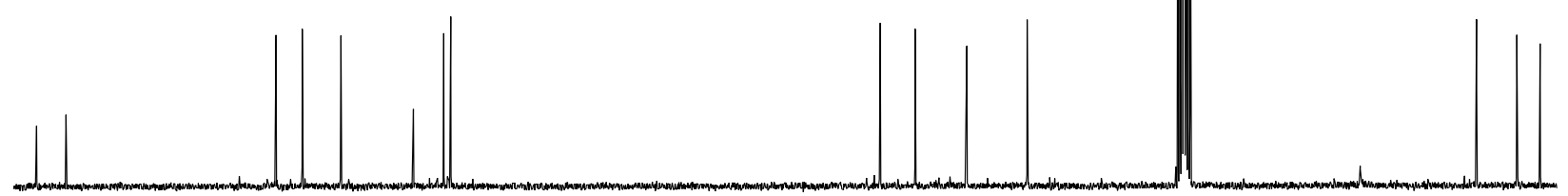

f1 90 (ppm) 
<smiles>C/C=C(\C)C(=O)O[C@H]1C=CC(=O)O[C@H]1/C=C/C(=O)[C@@H](C)O</smiles>

${ }^{1} \mathrm{H}$ NMR spectrum of compound 15 (400 MHz, CD 3 OD)

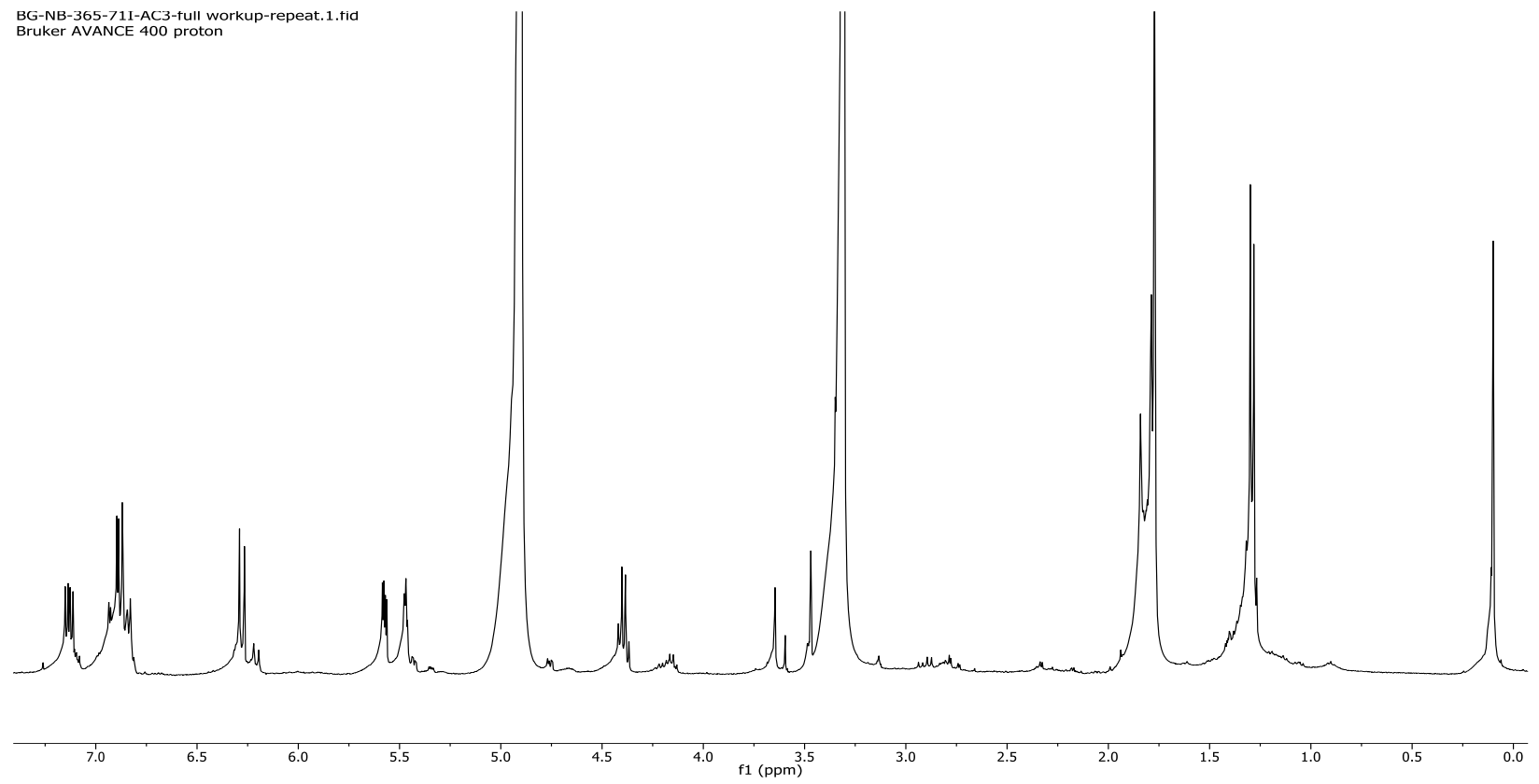

${ }^{13} \mathrm{C}$ NMR spectrum of compound 15 (100 MHz, $\left.\mathrm{CD}_{3} \mathrm{OD}\right)$ BG-NB-365-71-AC3-full workup-repeat.3.fit
Bruker AVANCE 400 carbon

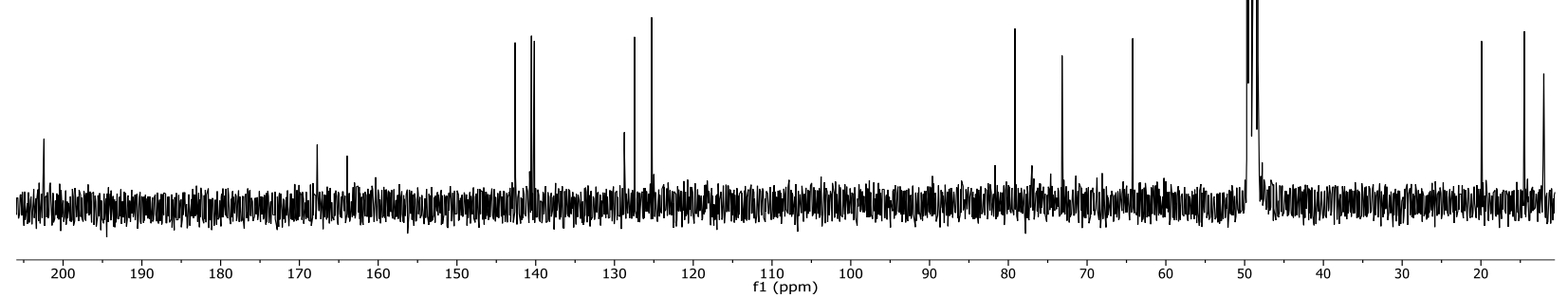


${ }^{1} \mathrm{H}$ NMR spectrum of compound 16 (400 MHz, CD 3 OD)

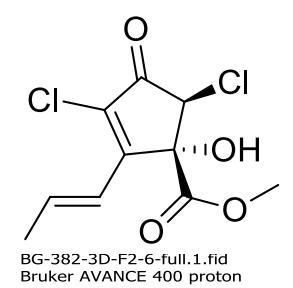

BG-382-3D-F2-6-full.1.1.id
Bruker AVANCE 400 proton

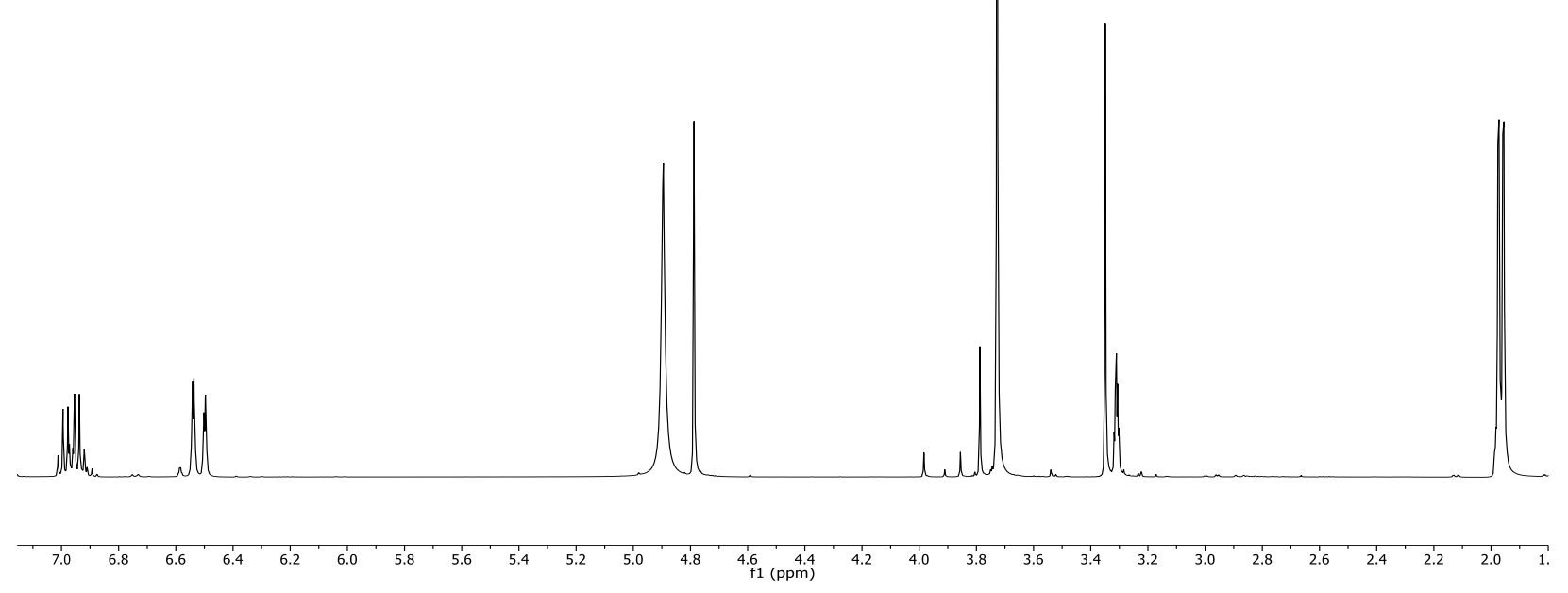

${ }^{13} \mathrm{C}$ NMR spectrum of compound $16\left(100 \mathrm{MHz}, \mathrm{CD}_{3} \mathrm{OD}\right)$

BG-382-3D-F2-6-full.3.fid

Bruker AVANCE 400 carbon
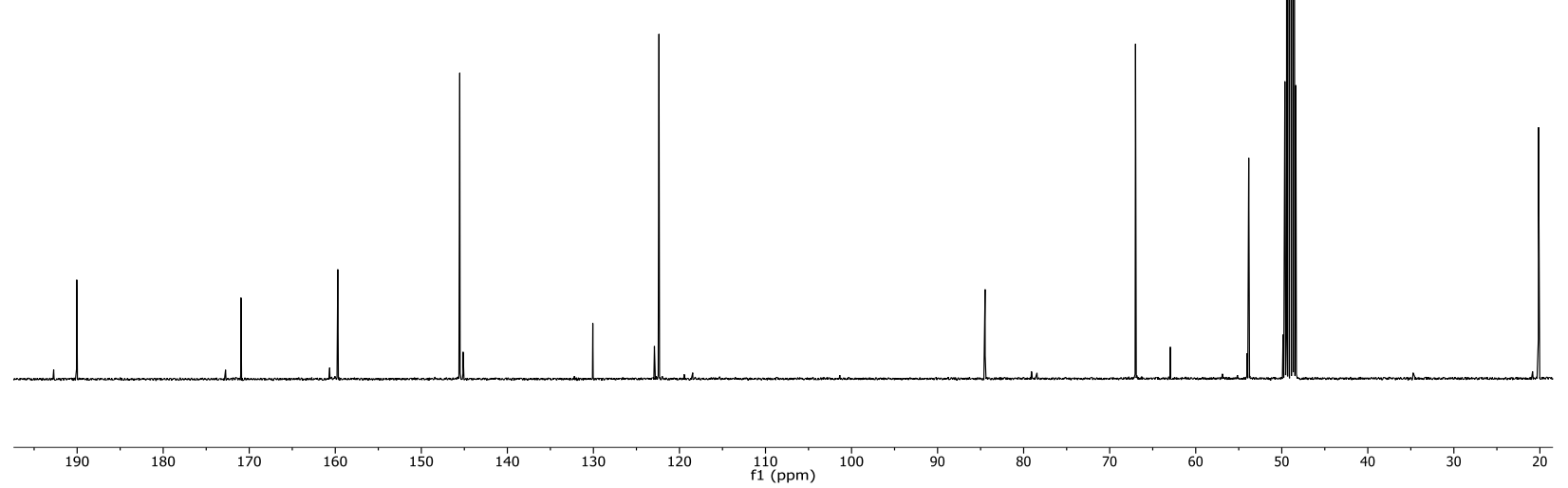
<smiles>C/C=C/C1=C(Cl)C(=O)[C@H](O)[C@]1(O)C(=O)OC</smiles>

${ }^{1} \mathrm{H}$ NMR spectrum of compound 17 (400 MHz, CD 3 OD)

BG-382-3D-F4-2-tull.1.fid
Bruker AVANCE 400 proton

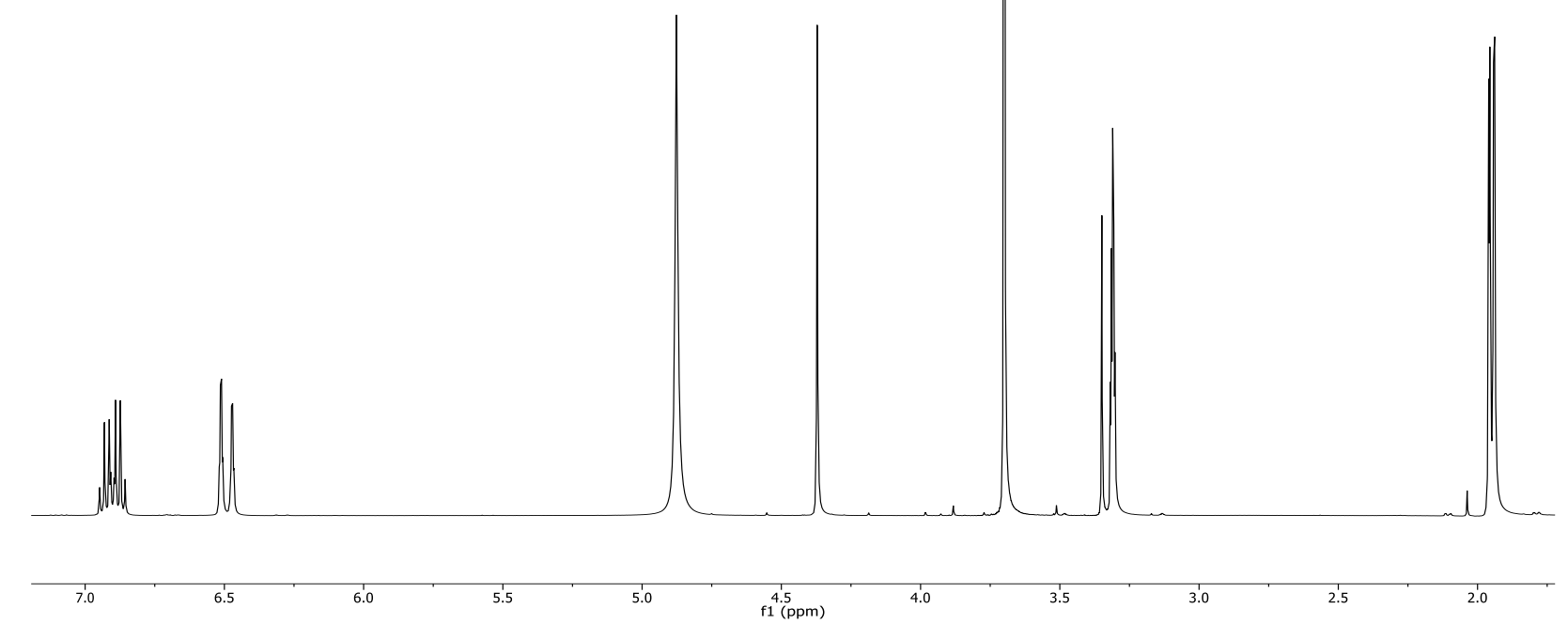

${ }^{13} \mathrm{C}$ NMR spectrum of compound $17\left(100 \mathrm{MHz}, \mathrm{CD}_{3} \mathrm{OD}\right)$

BG-382-3D-F4-2-full.3.fid
1D C13 Experiment

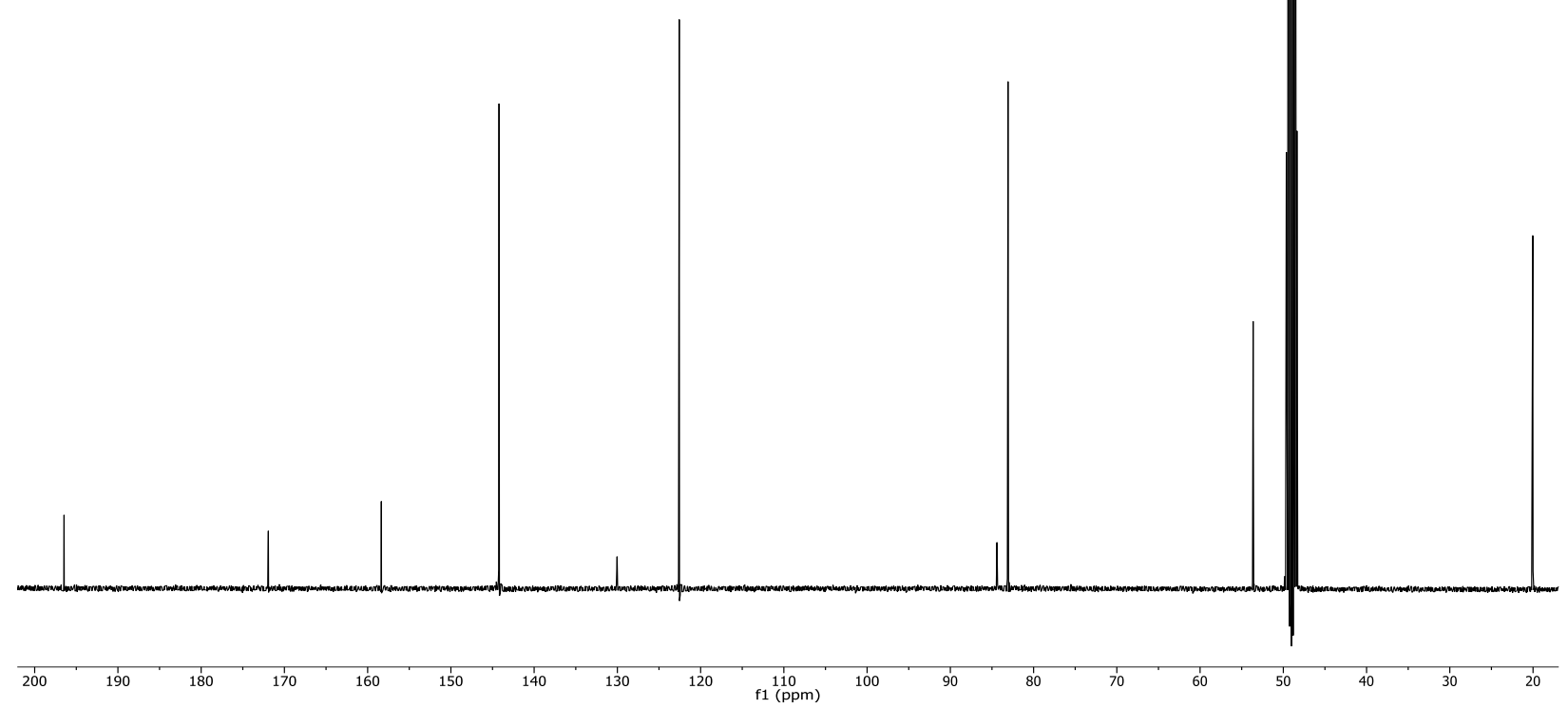


<smiles>C/C=C/C1=C(Cl)C(O)C(Cl)C1(O)C(=O)OC</smiles>

${ }^{1} \mathrm{H}$ NMR spectrum of compound 18 (400 MHz, CD $\left.3 \mathrm{OD}\right)$

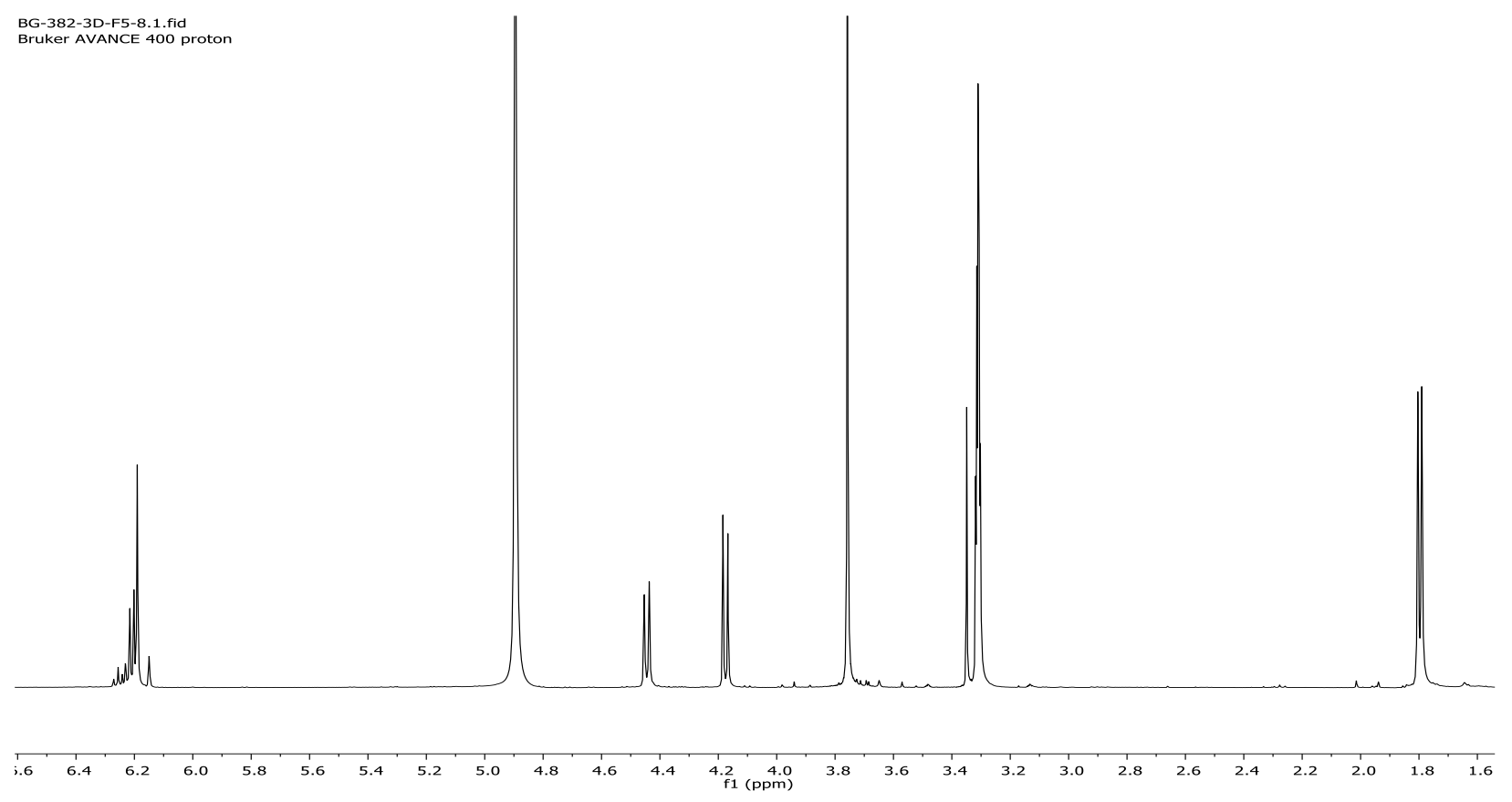

${ }^{13} \mathrm{C}$ NMR spectrum of compound 18 (100 MHz, $\left.\mathrm{CD}_{3} \mathrm{OD}\right)$

BG-382-3D-F5-8.3. fid

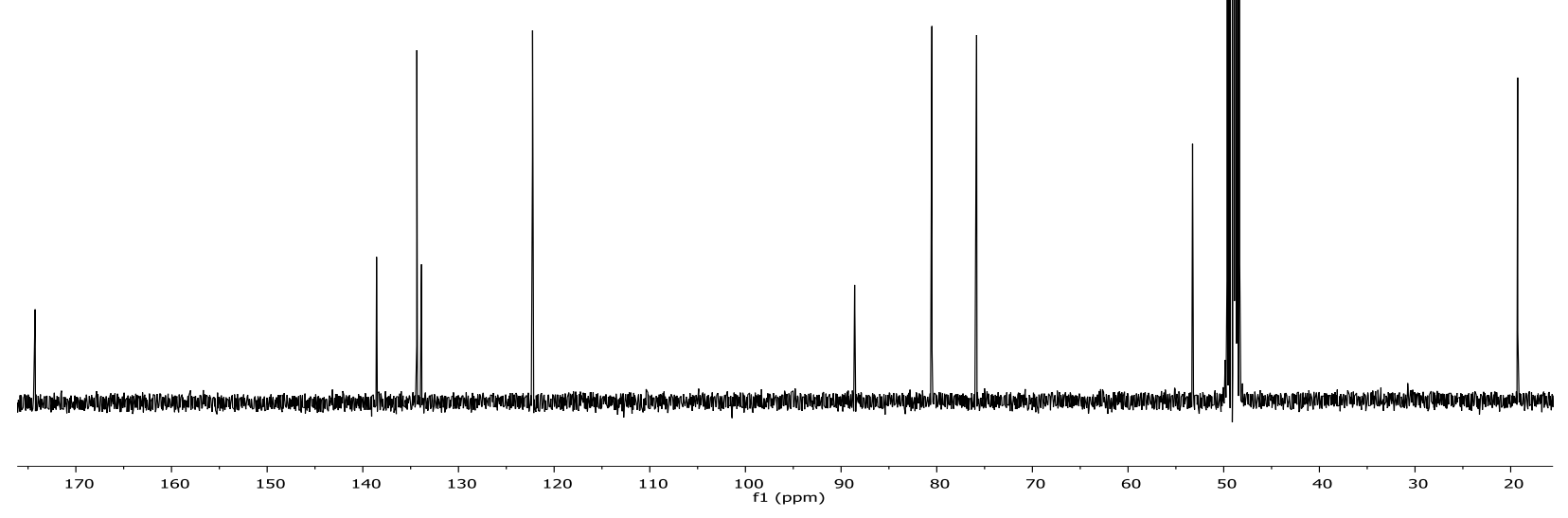


Appendix II - Strain, host, collection site and preliminary antifungal screening results

\begin{tabular}{|c|c|c|c|c|c|c|}
\hline \multirow{2}{*}{ Strain Code } & \multirow{2}{*}{ Species } & \multirow{2}{*}{ Host/Source } & \multirow{2}{*}{ Collection Site } & \multicolumn{2}{|c|}{ Bioassay Results* } & \multirow{2}{*}{$\begin{array}{c}\text { Extract } \\
\text { Mass } \\
\text { (mg) }\end{array}$} \\
\hline & & & & $\begin{array}{c}S . \\
\text { cerevisiae }\end{array}$ & $\begin{array}{c}\text { M. } \\
\text { violaceum }\end{array}$ & \\
\hline NB626-12A & Thysanophora sp. & Picea rubens endophyte & Fundy National Park, NB & 0 & 1 & 53.4 \\
\hline NB625-9H & $\begin{array}{l}\text { Rhizosphaera } \\
\text { kalkhoffi }\end{array}$ & Picea rubens endophyte & Fundy National Park, NB & 0 & 0 & 17.8 \\
\hline NB236-7B & cf. Rosasphaeria & Picea mariana endophyte & Grand Lake Meadow, NB & 0 & 2 & 49.6 \\
\hline W64103 & $\begin{array}{l}\text { Thysanophora } \mathrm{sp} . \\
\text { la }\end{array}$ & Isolated from cave wall & Anticosti Island, QC & 0 & 0 & 57.1 \\
\hline NB660 & Mollisia sp. & $\begin{array}{l}\text { on very old decorticated } \\
\text { decayed hardwood log }\end{array}$ & Aylmer, QC & 0 & 0 & 14.3 \\
\hline $\mathrm{RS} 10-5 \mathrm{~F}$ & $\begin{array}{l}\text { Phialocephala sp. } \\
\text { nov. }\end{array}$ & Picea rubens endophyte & Fundy National Park, NB & 0 & 2 & 44.5 \\
\hline NB626-11B & $\begin{array}{l}\text { Teratosphaeria } \\
\text { Bryochiton } \mathrm{sp} .\end{array}$ & Picea rubens endophyte & Fundy National Park, NB & 0 & 0 & 10.3 \\
\hline DAOM63909 & Thysanophora sp. 5 & & & 2 & 2 & 44.7 \\
\hline CBS612.84 & $\begin{array}{l}\text { Meloderma } \\
\text { desmazierei }\end{array}$ & Pinus ayacahuite needle & Mexico & 0 & 2 & 80.5 \\
\hline
\end{tabular}




\begin{tabular}{|c|c|c|}
\hline NB437-6B & Dermateaceae sp. & Picea rubens endophyte \\
\hline NB643 & Mollisia $\mathrm{sp}$. & Rotten hardwood log \\
\hline NB625-5J & Leotiomycetes sp. & Picea rubens endophyte \\
\hline $\mathrm{RS} 10-14 \mathrm{G}$ & Thysanophora sp. 3 & Picea rubens endophyte \\
\hline $\mathrm{RS} 10-12 \mathrm{~A}$ & Thysanophora sp. & Picea rubens endophyte \\
\hline $06-236 \mathrm{C}$ & $\begin{array}{l}\text { Phaeomoniella sp. } \\
\text { nov. } 1\end{array}$ & Picea rubens endophyte \\
\hline NB625-7H & Phialocephala sp. & Picea rubens endophyte \\
\hline NB639 & Mollisia $\mathrm{sp}$ & on rotten hardwood branch \\
\hline NB625-6C & Phialocephala sp. & Picea rubens endophyte \\
\hline NB365-71F & Rhytismataceae sp. & Picea rubens endophyte \\
\hline NB488-6B & $\begin{array}{l}\text { Lachnellula } \text { cf. } \\
\text { subtillissima }\end{array}$ & Picea rubens endophyte \\
\hline NB487-2H & $\begin{array}{c}\text { Tryblidiopsis sp. } \\
\text { nov. }\end{array}$ & Picea rubens endophyte \\
\hline
\end{tabular}

Little Lepreau, NB
Prescott-Russell, ON
Fundy National Park, NB
Fundy National Park, NB
Fundy National Park, NB
St. Martins, NB
Fundy National Park, NB
Fundy National Park, NB
Fundy National Park, NB
Fundy National Park, NB

\begin{tabular}{|c|c|}
\hline 0 & 17.4 \\
\hline 2 & 28.8 \\
\hline 0 & 11.2 \\
\hline 2 & 26.9 \\
\hline 2 & 54.2 \\
\hline 0 & 19.3 \\
\hline 0 & 19.0 \\
\hline 0 & 12.1 \\
\hline 2 & 18.6 \\
\hline 1 & 19.5 \\
\hline 1 & 56.4 \\
\hline 2 & 318.0 \\
\hline
\end{tabular}




\begin{tabular}{|c|c|c|}
\hline NB627-9CC & $\begin{array}{l}\text { Rhizosphaera } \mathrm{cf} \text {. } \\
\text { pini }\end{array}$ & Picea rubens endophyte \\
\hline NB371A & $\begin{array}{c}\text { Ombrophila } \\
\text { hemiamyloides }\end{array}$ & $\begin{array}{l}\text { Isolated from apothecia on } \\
\text { hardwood branch in stream }\end{array}$ \\
\hline NB285-4J & Rhytismatales sp. & Picea rubens endophyte \\
\hline NB625-9A & Phialocephala sp. & Picea rubens endophyte \\
\hline NB642 & Coccomyces strobi & $\begin{array}{c}\text { Dead corticated attached } \\
\text { branches on living Pinus } \\
\text { strobus }\end{array}$ \\
\hline RS10-5G & Thysanophora sp. & Picea rubens endophyte \\
\hline NB437-10G & Peziza varia & Picea rubens endophyte \\
\hline NB505-9I & $\begin{array}{c}\text { Unknown } \\
\text { Rhytismataceae } \\
\text { gen./sp. }\end{array}$ & Picea rubens endophyte \\
\hline NB625-10K & $\begin{array}{l}\text { Allantophomopsis } \\
\text { cf. lycopodina }\end{array}$ & Picea rubens endophyte \\
\hline NB437-8C & cf. Gremmeniella & Picea rubens endophyte \\
\hline
\end{tabular}

\begin{tabular}{|c|c|c|c|}
\hline Fundy National Park, NB & 2 & 2 & 129.0 \\
\hline Fundy National Park, NB & 1 & 0 & 12.4 \\
\hline Doaktown, NB & 1 & 2 & 16.2 \\
\hline Fundy National Park, NB & 1 & 0 & 33.2 \\
\hline Prescott-Russell, ON & 2 & 2 & 105.1 \\
\hline Fundy National Park, NB & 0 & 2 & 43.1 \\
\hline Little Lepreau, NB & 0 & 0 & 7.6 \\
\hline Fundy National Park, NB & 1 & 1 & 109.9 \\
\hline Fundy National Park, NB & 0 & 0 & 5.0 \\
\hline Little Lepreau, NB & 2 & 0 & 55.7 \\
\hline
\end{tabular}




\begin{tabular}{|c|c|c|}
\hline NB464-1G & $\begin{array}{c}\text { Tryblidiopsis sp. } \\
\text { nov. }\end{array}$ & Picea rubens endophyte \\
\hline NB464-12E & Leotiomycetes sp. & Picea rubens endophyte \\
\hline RS9-5D & Phacidiales sp. 5 & Picea rubens endophyte \\
\hline NB467 & $\begin{array}{l}\text { Phaeomollisia sp. } \\
\text { nov. }\end{array}$ & $\begin{array}{c}\text { Fallen Acer saccharum } \\
\text { branch }\end{array}$ \\
\hline RS10-10B & Phacidiales sp. 3 & Picea rubens endophyte \\
\hline NB423 & $\begin{array}{l}\text { Phialocephala } \\
\text { dimorphospora }\end{array}$ & $\begin{array}{l}\text { Isolated from conidiophores } \\
\text { on hardwood }\end{array}$ \\
\hline NB623 & Xylaria & Fallen Acer saccharum log \\
\hline RS10-8E & $\begin{array}{l}\text { Pseudoplectania } \\
\text { sp. }\end{array}$ & Picea rubens endophyte \\
\hline RS10-3B & $\begin{array}{l}\text { Lachnellula } \mathrm{cf} . \\
\text { calyciformis }\end{array}$ & Picea rubens endophyte \\
\hline CBS114583 & $\begin{array}{c}\text { Lophodermium } \\
\text { piceae } \\
\text { (European strain) }\end{array}$ & Picea abies \\
\hline
\end{tabular}

Little Lepreau, NB
Little Lepreau, NB
Fundy National Park, NB
Little Lepreau, NB
Fundy National Park, NB
Orleans, ON
Fundy National Park, NB
Fundy National Park, NB
Fundy National Park, NB

2

2

0

213.5

0

2

76.0

2

38.7

2

0

14.5

1

2

115.1

25.9

0

8.8

1

2

120.3

2

49.0 


\begin{tabular}{|c|c|c|c|c|c|c|}
\hline NB589 & Thysanophora sp. & $\begin{array}{l}\text { Isolated from conidiophores } \\
\text { on Picea rubens needle }\end{array}$ & Fundy National Park, NB & 0 & 0 & 136.7 \\
\hline RS9-6A & Phacidiales sp. 1 & Picea rubens endophyte & Fundy National Park, NB & 0 & 0 & 43.6 \\
\hline $\mathrm{RS} 10-5 \mathrm{H}$ & $\begin{array}{l}\text { Peyronellaea } \mathrm{cf} . \\
\text { pinodella }\end{array}$ & Picea rubens endophyte & Fundy National Park, NB & 0 & 0 & 9.7 \\
\hline RS10-2E & $\begin{array}{l}\text { Gen. nov. cf. } \\
\text { Phoma }\end{array}$ & Picea rubens endophyte & Fundy National Park, NB & 0 & 1 & 23.2 \\
\hline NB437-10B & cf. Gremmeniella & Picea rubens endophyte & Little Lepreau, NB & 0 & 0 & 17.4 \\
\hline RS10-3J & Phacidiales sp. 1 & Picea rubens endophyte & Fundy National Park, NB & 1 & 0 & 8.9 \\
\hline RS10-11C & $\begin{array}{l}\text { Unidentified } \\
\text { species }\end{array}$ & Picea rubens endophyte & Fundy National Park, NB & 0 & 1 & 33.4 \\
\hline NB437-2A & $\begin{array}{c}\text { Pseudoplectania } \mathrm{cf} . \\
\text { nigrella }\end{array}$ & Picea rubens endophyte & Little Lepreau, NB & 0 & 0 & 9.5 \\
\hline RS9-5Q & Phacidiales sp. 4 & Picea rubens endophyte & Fundy National Park, NB & 0 & 2 & 63.4 \\
\hline RS17-1L & Phacidiales sp. 1 & Picea rubens endophyte & Fundy National Park, NB & 0 & 1 & 33.0 \\
\hline
\end{tabular}




\begin{tabular}{|c|c|c|c|c|c|c|}
\hline NB487-3K & $\begin{array}{c}\text { Mycosphaerella cf. } \\
\text { berberidis }\end{array}$ & Picea rubens endophyte & Fundy National Park, NB & 0 & 1 & 20.1 \\
\hline RS9-7P & Sclerotiniaceae sp. & Picea rubens endophyte & Fundy National Park, NB & 0 & 2 & 76.7 \\
\hline NB437-6A & $\begin{array}{c}\text { Tryblidiopsis sp. } \\
\text { nov. }\end{array}$ & Picea rubens endophyte & Little Lepreau, NB & 0 & 2 & 173.1 \\
\hline $06-313 \mathrm{~B}$ & $\begin{array}{c}\text { Phaeomoniella sp. } \\
\text { nov. } 2\end{array}$ & Picea rubens endophyte & Parkindale, NB & 0 & 0 & 25.4 \\
\hline RS9-10K & Phacidiales sp. 2 & Picea rubens endophyte & Fundy National Park, NB & 0 & 0 & 9.4 \\
\hline RS17-9W & Thysanophora sp. & Picea rubens endophyte & Fundy National Park, NB & 1 & 0 & 38.0 \\
\hline DAOM 628553 & $\begin{array}{l}\text { Diaporthe } \\
\text { maritima }\end{array}$ & Picea rubens endophyte & Alma, NB & 0 & 2 & 89.5 \\
\hline NB236-1A & Rhytismatales sp. & Picea mariana endophyte & Gagetown, NB & 2 & 2 & 143.4 \\
\hline DAOM 250862 & Pezicula sporulosa & $\begin{array}{l}\text { Needle isolations from } 6 \mathrm{~cm} \\
\text { DBH red spruce in yellow } \\
\text { birch and red maple stand }\end{array}$ & Alma, NB & 0 & 2 & 93.1 \\
\hline DAOM 250863 & $\begin{array}{c}\text { Phaeocryptopus cf. } \\
\text { gaeumannii }\end{array}$ & Picea mariana endophyte & Doaktown, NB & 0 & 2 & 582.3 \\
\hline
\end{tabular}

